\title{
Understanding Academic Relevancy: Linking Practice to Classroom Through Adventure STEM Education
}

\author{
Alice Morgan \\ West Virginia University, anm0049@mix.wvu.edu
}

Follow this and additional works at: https://researchrepository.wvu.edu/etd

\section{Recommended Citation}

Morgan, Alice, "Understanding Academic Relevancy: Linking Practice to Classroom Through Adventure STEM Education" (2020). Graduate Theses, Dissertations, and Problem Reports. 7855.

https://researchrepository.wvu.edu/etd/7855

This Dissertation is protected by copyright and/or related rights. It has been brought to you by the The Research Repository @ WVU with permission from the rights-holder(s). You are free to use this Dissertation in any way that is permitted by the copyright and related rights legislation that applies to your use. For other uses you must obtain permission from the rights-holder(s) directly, unless additional rights are indicated by a Creative Commons license in the record and/ or on the work itself. This Dissertation has been accepted for inclusion in WVU Graduate Theses, Dissertations, and Problem Reports collection by an authorized administrator of The Research Repository @ WVU.

For more information, please contact researchrepository@mail.wvu.edu. 
Understanding Academic Relevancy:

Linking Practice to Classroom Through Adventure STEM Education

\author{
Alice Morgan \\ Dissertation submitted \\ to the Davis College of Agriculture, Natural Resources and Design \\ at West Virginia University \\ in partial fulfillment of the requirements for the degree of \\ Ph.D. of Natural Resource Science in \\ Recreation, Parks, \& Tourism \\ Dave Smaldone, Ph.D., Chair \\ Steve Selin, Ph.D. \\ Jinyang Deng, Ph.D. \\ Gay Stewart, Ph.D. \\ Marion Holmes, M.S. \\ Department of Recreation, Parks, \& Tourism
}

Morgantown, West Virginia

2020

Keywords: informal education, STEM education, adventure education Copyright 2020 Alice Morgan 


\begin{abstract}
Understanding Academic Relevancy:

Linking Practice to Classroom Through Adventure STEM Education
\end{abstract}

\begin{abstract}
Alice Morgan
The purpose of this research paper was to examine the relationship between vocational relevancy and adventure STEM education in the context of a four-day adventure STEM camp. Middle school students participated in a variety of adventure activities designed to teach STEM concepts. Using a concurrent triangulation mixed methods design, 246 students completed preand post-surveys that assessed changes in attitudes related to STEM interest, career interest, STEM career knowledge, STEM identity, STEM self-efficacy, and STEM value. Fourteen students and eight teachers participated in semi-structured interviews to further examine the role of vocational relevancy in curricula. Overall, results indicate some support for increased positive STEM attitudes as a result of attending camp, with positive results across multiple data points for STEM self-efficacy (surveys, student interview, teacher interview). STEM interest received support in teacher interviews, STEM career interest in surveys and student interviews, and STEM career knowledge in surveys. STEM values showed conflicting results. Emergent interview data also indicated the possibility of an increase in students' social and interpersonal skills. Though further research in this area is needed, findings support a link between vocational relevancy and adventure STEM education. Future potential research avenues are also discussed.
\end{abstract}




\section{Dedication}

Mi deciĉas ĉi tiun laboron al mia edzo, Kevin.

Vi estas mia gvida stelo kaj la lumo de mia vivo. 


\section{Acknowledgements}

I would like to acknowledge everyone who helped make my postdoctoral journey possible. Thank you to my family for the love and support along the way. In particular, thank you to my Mom who helped me find my wings and has never faltered in the belief that I can do anything. Your belief and encouragement made me who I am today.

To Dr. Dave Smaldone, thank you for the years of mentorship, encouragement, and chocolate. Thank you to the members of my committee, Dr. Steve Selin, Dr. Jinyang Deng, Dr. Gay Stewart, and Marion Holmes. I appreciate your guidance, kindness, and thoughtful feedback throughout this process.

Thank you to Greg Corio, Ali Jeney, Alison Conroy, Andrew Hoover, and to all the instructors of SAS for their help and laughter. Special thanks to the teachers of SAS, who do great things for the students of West Virginia.

Most of all, thank you to Kevin Brockett for your love, support, and willingness to proofread my dissertation. They don't make them any better than you. 


\section{Table of Contents}

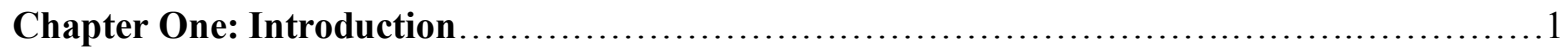

Statement of the Problem................................................................

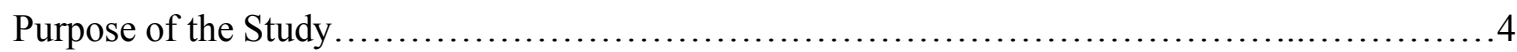

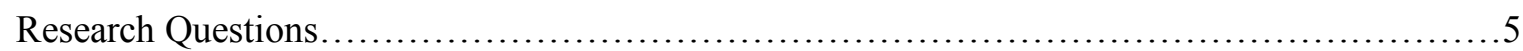

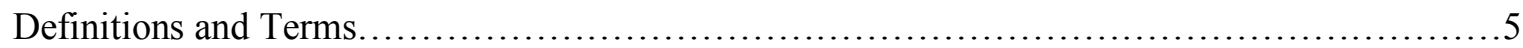

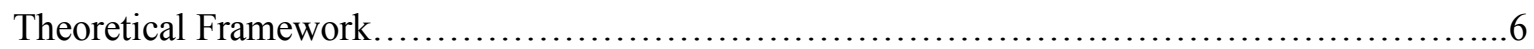

Gaps in the Literature................................................................

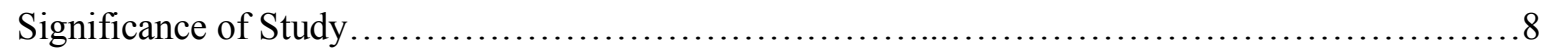

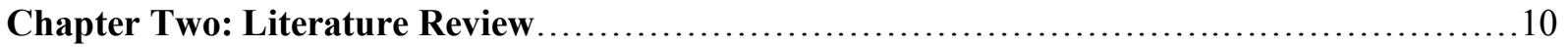

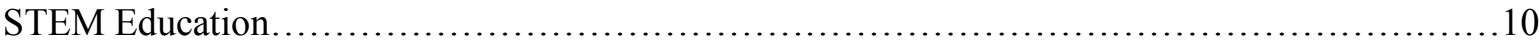

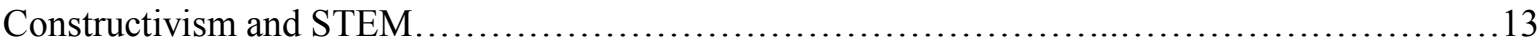

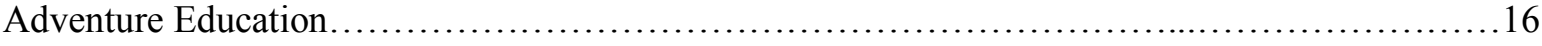

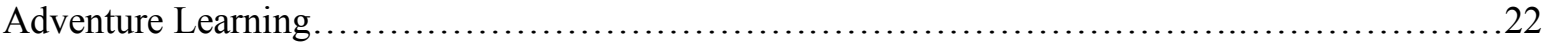

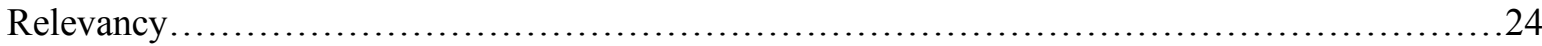

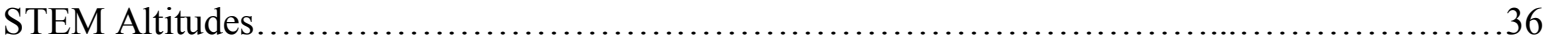

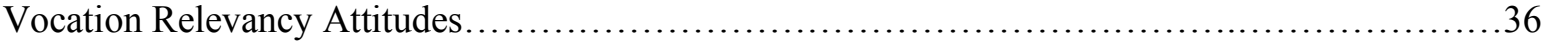

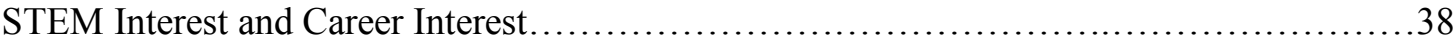

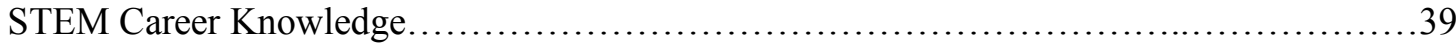

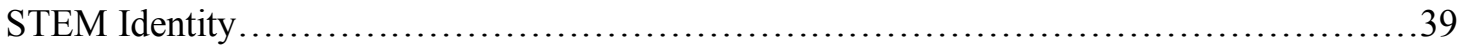

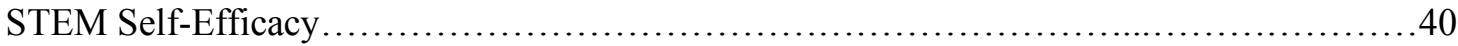

STEM Value....................................................................... 41

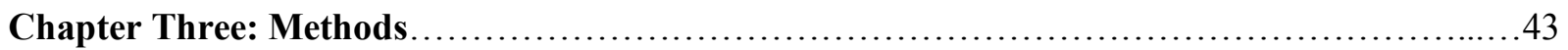

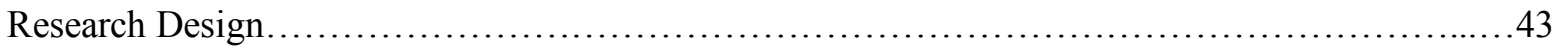

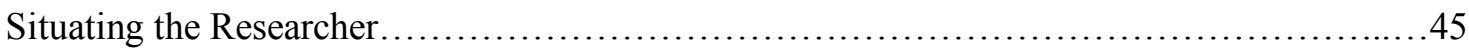




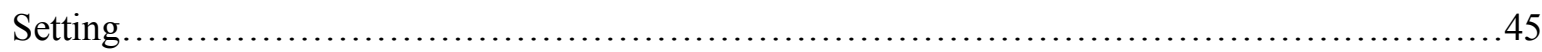

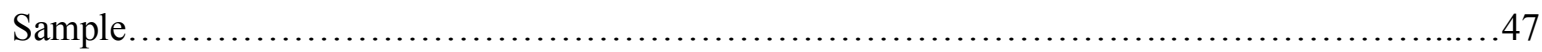

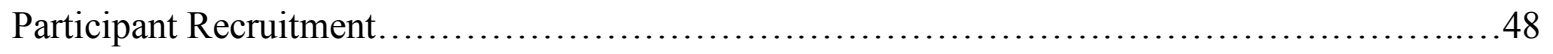

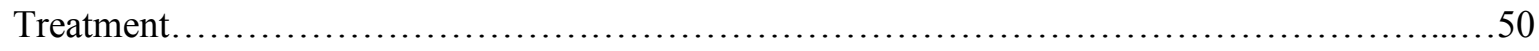

Measures............................................................................. 52

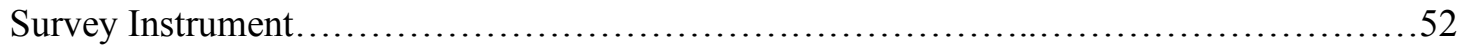

Interview Protocol............................................................. 54

Data Collection................................................................... 57

Data Analysis...................................................................60

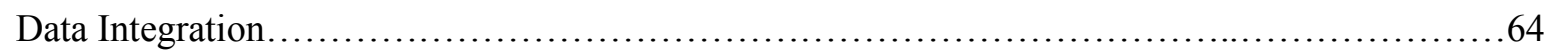

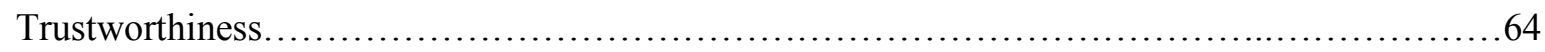

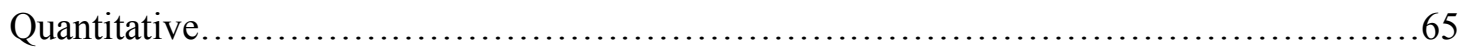

Qualitative................................................................66

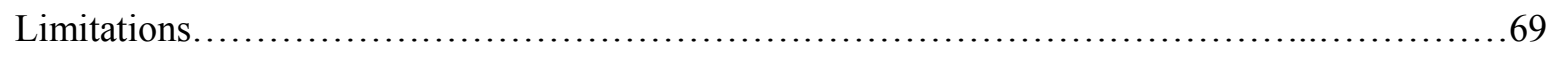

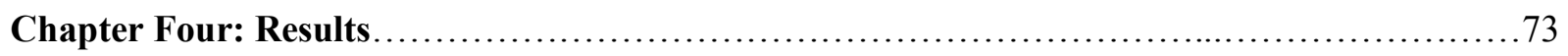

Quantitative Results........................................................... 73

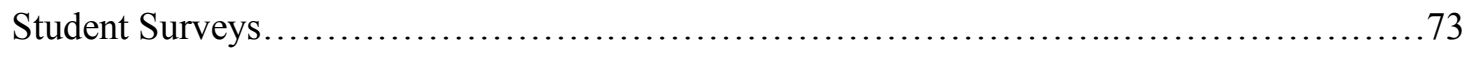

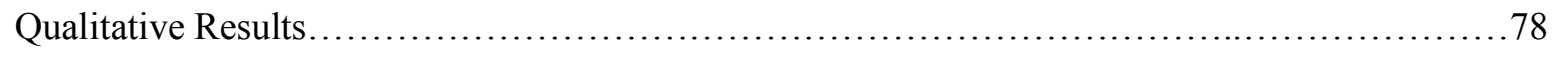

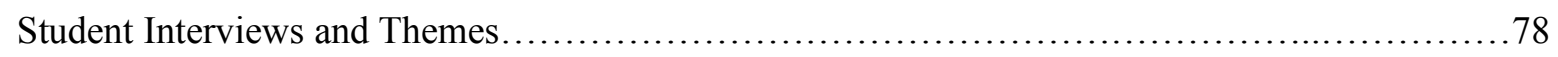

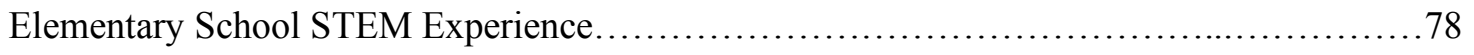

Preference for Learning at Science Adventure School.................................79

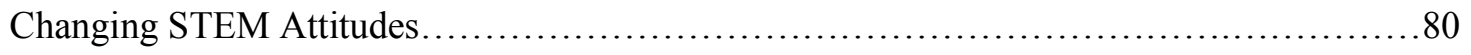

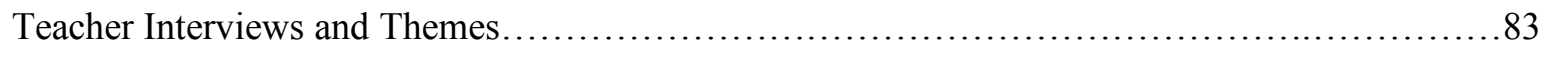

Science Adventure School Learning Environment..................................86

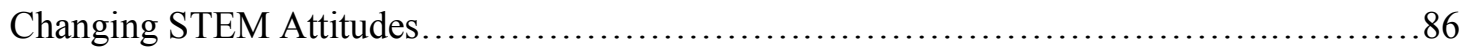

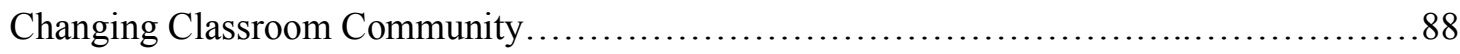




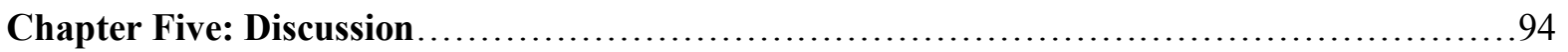

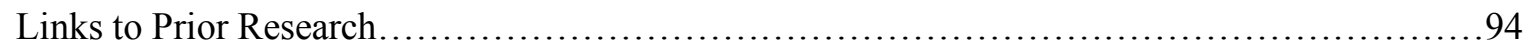

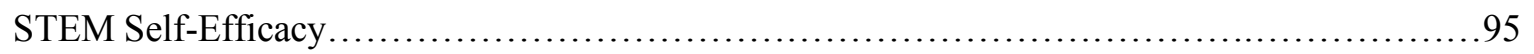

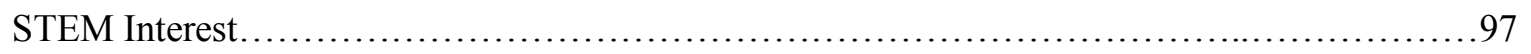

STEM Career Interest..........................................................99

STEM Career Knowledge........................................................... 100

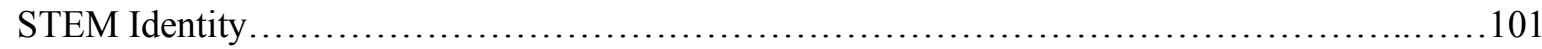

STEM Value................................................................. 103

Additional Outcomes............................................................... 104

Implications for Relevancy..................................................... 106

Recommendations for Future Research........................................... 108

Implications for Practice....................................................... 109

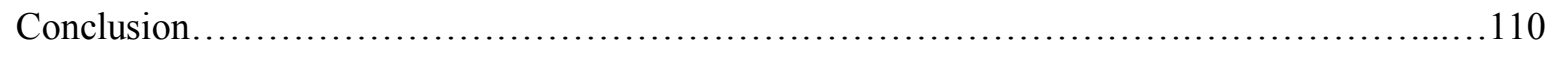

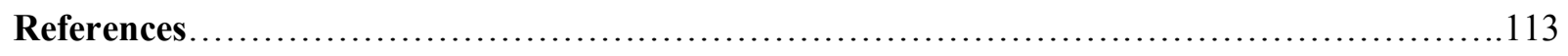

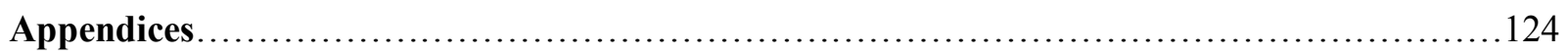

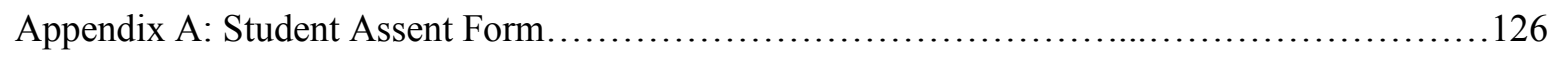

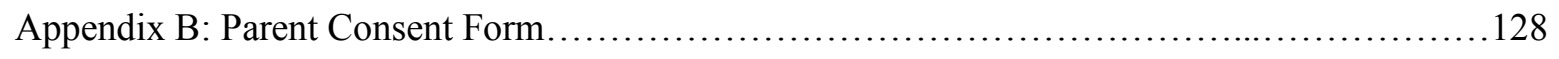

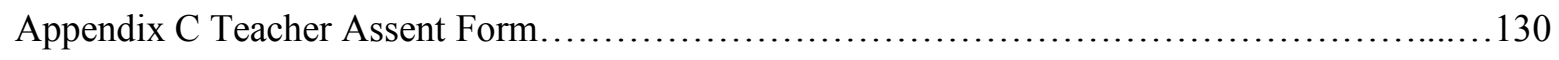

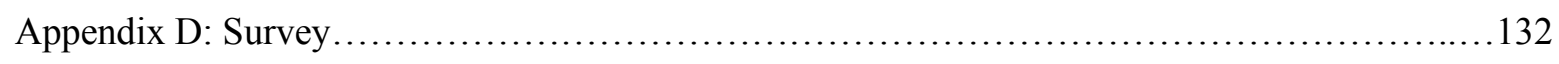

Appendix E: Student Interview Protocol............................................ 138

Appendix F: Teacher Interview Protocol:........................................ 139

Appendix G: Additional Student Themes and Codes.................................. 140

Appendix H: Additional Teacher Themes and Codes................................... 142 


\section{Chapter One: Introduction}

\section{Statement of the Problem}

Students in the United States are falling behind the rest of the world in terms of interest in STEM (science, technology, engineering, and mathematics) related fields and in their ability to study and work in these fields, which may lead to an inability to fill vacancies in a growing job market (ACT, 2017). A recent report from the U.S. Department of Commerce shows that the volume of STEM occupations has grown much faster than for non-STEM occupations during the last decade and are projected to maintain their growth pattern from 2014 to 2024 (Noonan, 2017). At the same time, students in the United States have been performing at lower levels in STEM subjects (Daugherty, 2013), and their interest levels in STEM remain stagnant (ACT, 2017). Educators, policy makers, and business leaders are concerned that there will not be enough STEM graduates to fill vacancies in a growing job market (Hanushek, Peterson, \& Woessmann, 2012). Both the growth of STEM jobs and the decline in student achievement levels in STEM subjects indicate a need to focus on STEM curriculum to meet the needs of the U.S. labor market and of the students who may one day seek to fill those job roles.

West Virginia is not exempt from the nationwide decline of STEM interest or an expected increase in STEM-based jobs. In a state like West Virginia, which struggles to retain its human capital (Christiadi, Deskins, \& Lego, 2014), STEM graduates can be particularly important. If more students who pursue STEM-based degrees, the state will more likely be able to retain a portion of them. As West Virginia's current workforce begins to retire, it will be crucial to the state's long-term economic stability for there to be skilled workers to replace them.

Despite a lack of students pursuing careers in the STEM, STEM curriculum is not lacking in the classroom. Policy makers and business leaders have been pushing for more STEM based 
educational opportunities in schools since the 1990's (Breiner et al., 2012), and these have steadily risen in response to their efforts. So, if there are plenty of STEM opportunities available to them, why do students remain uninterested in these classes?

Student interest in STEM education may be at the heart of the nation's STEM worker deficit (ACT, 2017). Students who are uninterested in STEM curriculum are unlikely to engage in STEM-based study or make a career in a STEM field. They dislike writing long reports, memorizing complicated scientific language, and the repetitive study required for standardized testing (Murphy, 2003). Many students report feeling bored in their science classes, and not only are they bored, but this attitude intensifies as they age (Murphy, 2003). Older students are more likely to hold negative attitudes toward science than younger students (Murphy, 2003). By the time they have begun to make career decisions, many students may have already dismissed science as a career pathway.

The concept of relevance may prove useful in understanding why students are experiencing lower levels of STEM interest. Relevance goes beyond interest and addresses the individual, societal and vocational needs of the students on an intrinsic and extrinsic level (Stuckey et al., 2013a). Students who find that their course material has an obvious impact upon their lives may be more likely to see science curriculum as important or useful. Positive attitudes can influence behavior (Fishbein, 1966), so a positive attitude toward science may lead to greater engagement with the subject. Engagement is "broadly a positive and proactive term that captures students' quality of participation, investment, commitment, and identification with school and school-related activities to enhance students' performance (Alrashidi, Phan, \& Ngu, 2016, p. 42)". Engagement has also been shown to predict student performance in school (Alrashidi, Phan, \& Ngu, 2016; Dogan, 2015; Fredericks, Blumenfeld, \& Paris, 2004). Thus, it follows that 
academic relevance has the potential to influence attitudes about the subject being taught, which can influence academic engagement, which may, in turn, lead to better performance in that subject.

Adventure education may be uniquely suited to increase the relevance of STEM education, because it is grounded in hands-on, practical experience (Miner \& Boldt, 2002; Ringholz, 2000), which is something children report as being their favorite part of science lessons (Murphy, 2003). Because most experiences in adventure education take place outside, they are often immediately novel and appealing to students (Walsh \& Golins, 1976). When combined with STEM education, adventure education can provide a more relevant vehicle for STEM learning than many classroom experiences. For example, many students have experienced riding a bike. In an adventure STEM lesson focused on bikes, students learn about the physics that relates to riding a bike and how their muscles influence its ability to start and stop. They then have the opportunity to manipulate the bike's movement as they ride. This lesson takes something that they are already accustomed to seeing, teaches them how it works with STEM principles, and allows them to experiment. These meaningful and personal connections are at the heart of relevance (Ham, 2016).

Given that the United States is struggling to produce and retain college graduates, particularly in STEM fields (ACT, 2017) it is important to explore options for increasing positive attitudes toward STEM subjects while students are still young and before they lose enthusiasm for STEM in their classrooms. Understanding how students feel about STEM classes and the effect of adventure STEM curriculum may help policymakers and educators better meet the needs of the state's students. 
As of yet, academic relevance is a relatively understudied construct and much about it and its relationship to how students experience school is unknown. This dissertation adds to the body of literature in both STEM relevancy and adventure STEM education by examining the effect that the inclusion of adventure curriculum can have on curriculum relevancy and STEM attitudes of students attending the West Virginia Science Adventure School (SAS) using a mixed methods design. By combining both quantitative and qualitative approaches, this study examines the multidimensional facets of the research questions. A quantitative approach assesses the effectiveness of an adventure STEM curriculum design on STEM attitudes, while a qualitative approach helps to further examine and help explain the quantitative results by exploring students' views about their curriculum in greater depth.

\section{Purpose of the Study}

The purpose of this mixed methods concurrent triangulation study was to assess the vocational relevancy of adventure STEM for sixth grade students in SAS, and to research any changes in STEM attitudes, including science identity (Herrera \& Hurtado, 2011; Carlone \& Johnson, 2007), science interest (Gilmartin et al., 2007; Eccles, 2007), STEM value (Ainley \& Ainley, 2011; Sjøberg \& Schreiner, 2005) science career interest (Sadler et al., 2011), and science self-efficacy (Eccles, 2007; Rittmayer \& Beier, 2009) as a result of participating in SAS. In the quantitative phase of the study, students' feelings toward curriculum relevancy and STEM attitudes were assessed with a pre- and post- adventure STEM experience survey. The qualitative portion of the study consisted of semi-structured in-person interviews with 14 students and 8 teachers shortly after their SAS experience to gain additional insights into the results of the 
statistical analysis and identify how students and teachers see the relevancy of adventure STEM curriculum.

\section{Research Questions}

R1) How does adventure STEM curriculum affect the STEM interest, STEM career interest, STEM career knowledge, STEM self-efficacy, STEM value and STEM identity of students participating in SAS?

R2) How do students and teachers participating in SAS regard the relevancy of adventure STEM curriculum as contrasted with school curriculum?

\section{Definitions and Terms}

Adventure education - an educational activity that takes place outside, usually with outdoor activities as the vehicle for learning and containing some amount of real or perceived risk (Priest \& Gass, 2017)

Academic engagement - attempting to reach the cognitive, behavioral, and emotional engagement needs of the student to improve participation (Fredricks et al., 2004)

Academic relevancy - how students experience their curriculum as personal and meaningful to their lives and connected to their futures (Stuckey et al., 2013a) (Ham, 2016)

Adventure STEM education - an emerging educational discipline that focuses on teaching STEM concepts through the vehicle of outdoor activities

STEM - the fields of science, technology, engineering, and mathematics (Gonzalez \& Kuenzi, 2012)

STEM career knowledge - a student's familiarity with science, technology, engineering, and mathematics fields (Blotnicky et al., 2018)

STEM education - replacing traditional lecture-based teaching with project-based approaches (Breiner, Harness, Johnson \& Koehler, 2012) focused on the fields of science, technology, engineering, and mathematics (Gonzalez \& Kuenzi, 2012) 
STEM self-efficacy - a student's belief in their capacity to succeed at tasks (Bandura, 1977) in STEM

STEM identity - students' ability to see themselves as science persons or STEM professionals (Herrera, 2005)

STEM interest - stable preferences that are focused on objects, activities, or experiences (Hidi, 1990) related to STEM

STEM value - the importance that students place on the knowing and being able to do STEM because of its usefulness in their personal lives and in the greater context of society (VincentRuz \& Schunn, 2018)

Vocational relevancy -aspects of life relating to the student's chosen career (Stuckey et al., 2013a)

\section{Theoretical Frameworks}

This study utilized two theoretical frameworks for relevancy as its foundation: the Model of Three Dimensions of Relevancy (Stuckey et al., 2013), and Ham's interpretive model of relevancy (2016). The Model of Three Dimensions of Relevancy focuses on how the student relates to the material individually, societally, vocationally, intrinsically, and extrinsically. According to Stuckey et al. (2013a), if students view their curriculum as beneficial to their current or future life, then the learner will see it as relevant and thus be more likely to engage in their learning environment. Conversely, if the student views their lesson as irrelevant to their life, they will likely become bored and disengage with the material.

Relevancy is also discussed in the interpretation discipline in regards to informal education. Ham (2016) writes that relevancy is a term that describes the personal and meaningful connections that communicators attempt to forge between information given and the audience (or student) who receives it. In order for the audience to be moved to both think and feel about the information (i.e., for the information to have relevancy), communicators should strive to have both a cognitive and affective impact on their audience. Information is meaningful when students 
have a frame of reference for material, which they can use to connect and build on for further learning. Personal information means that students care about the material they are learning (Ham, 2016): lessons matter beyond the classroom and students see where it can intersect with their values or beliefs.

These two models intertwine in adventure STEM education to form a theoretical base for this study. Ham's (2016) model of relevancy emphasizes that students must have a relationship to their learning material to care about it, while Stuckey et al.'s model emphasizes the areas of a student's life that educators can most easily address. By exposing students to relevant curriculum through outdoor STEM activities, educators may lead them to see STEM curriculum as a more relevant part of their lives. In the short term, this may be expressed through enjoyment and interest in a novel learning environment, positive feelings about themselves and their abilities, and a more positive view of STEM as a field and a potential career path. In the long term, they may come to see STEM as something that will provide them with vocational opportunities in the future.

\section{Gaps in the Literature}

Potential issues in this study arise from the lack of available literature on adventure STEM education. Both adventure education and STEM education are relatively new disciplines that have emerged in the latter half of the 20th century, and the combined discipline is in its infancy. Some work has been done in the field of adventure learning, which focused on introducing technology to formal classroom settings through the lens of adventure, but there is little on adventure-based STEM curricula. At the time of this dissertation, there has been some work with Indigenous American students (Miller, Doering, Roehrig, \& Shimek, 2012; Zwick \& 
Miller, 1996), a qualitative study looking at adventure STEM engagement (Son et al., 2017;

Mackenzie, Son, \& Eitel, 2018) and science-based geocaching (Larsen et al., 2014), but little else focused on combining adventure education and STEM education activities.

Additionally, academic relevance has not received much attention from researchers, and there are still large gaps in conceptualizations of this construct. The frameworks associated with science-based academic relevancy are still largely theoretical, with researchers working to define and organize concepts of relevancy (Eilks et al., 2014; Klafki, 2000; Ratcliffe \& Grace, 2003; Stuckey et al., 2013a; Swartz, Ben-Zbi, \& Hofstein, 2006; Young \& Glanfield, 1998) Some research has attempted to put frameworks into practice, but these studies are relatively few and currently limited to Hofsten and Kesner's (2016) work in chemistry education and textual analyses for relevant material in science documents (Khal \& Harms, 1981; Newton \& Newton, 1991).

\section{Significance of Study}

This study contributes to the limited amount of research related to adventure STEM and relevancy. Very few studies have been conducted in this area of research and none have focused on the relationship between relevancy and STEM curriculum.

Research of this nature is also significant to West Virginia educators and policy makers seeking to retain more STEM graduates. Adventure STEM education may prove an effective learning method for inspiring an interest in STEM both in school and as a potential career. It is important to examine STEM constructs like STEM interest to illuminate which areas are most important to support in education programs, and to illustrate the importance of supporting experiential programs like the SAS. Furthermore, by gaining a better understanding of relevancy 
associated with an adventure STEM curriculum, educators may be better able to utilize this approach in their own curricula to benefit their students by incorporating more experientially based activities into their classes and gaining the support of their administrations to pursue adventure STEM field trips. 


\section{Chapter Two: Literature Review}

The purpose of this literature review is to introduce the foundations of adventure education and STEM education and discuss the constructs that link them together. This review will begin by examining the STEM movement in the United States and the importance of including STEM in schools, before moving on to the historical roots of adventure education and some of the adventure philosophies most connected to adventure STEM education. Additionally, it will also discuss the concept of relevancy and its relation to the constructs of STEM interest, STEM career interest, STEM career knowledge, STEM identity, STEM self-efficacy, and STEM value.

\section{STEM Education}

In recent years, STEM educational approaches have become a popular trend in the United States to bolster the country's workforce with college graduates who can compete internationally and bring innovation to businesses and companies. The definition of STEM education incorporates both the subjects that instructors are expected to teach and the methods that they use to teach STEM curricula. STEM education refers to "teaching and learning in the fields of science, technology, engineering, and mathematics" (Gonzalez \& Kuenzi, 2012, p. 1). According to Breiner, Harness, Johnson \& Koehler (2012, p. 3), STEM education also involves "the replacement of traditional lecture-based teaching strategies with more inquiry and project-based approaches." For the purpose of this paper, the two definitions will be combined to include all four subject areas of STEM and experiential-based teaching methodologies. While there is some debate as to the overall combination of the four areas (Daugherty, 2013), a unified definition of 
STEM can include each area applied either alone or in conjunction with another area, regardless of how well they are integrated.

The STEM movement is a relatively recent development that began in the 1980s (Breiner et al., 2012). During this time, reports from organizations like the National Commission on Excellence in Education, the National Science Foundation, and the U.S. Department of Education stressed the importance of science, mathematics and technology education in the nation's schools (Breiner et al., 2012). Government policy was put into place to guide new educational efforts and soon the National Science Foundation was using the acronym SMET to refer to their work (Sanders, 2009). The acronym changed to STEM in 2001 and was soon viewed as the panacea for the poor performance of students in science and mathematics (Breiner et al., 2012). In 2007, the Committee on Prospering in the Global Economy of the $21^{\text {st }}$ Century directly referenced the need to focus on students' STEM abilities and made recommendations to ensure prosperity for the United States, including growing the talent pool with K-12 science and mathematics education and increasing the ability of the Unites States to recruit and train the brightest scientists and engineers in the world (National Research Council, 2007). Though it is a relatively new concept, increasing students' STEM exposure has quickly become a leading issue in the United States.

The benefits of pursuing a post-secondary STEM degree are numerous. STEM graduates can expect higher wages across their lifetimes and may be less likely to experience unemployment. STEM workers earned 29\% more than non-STEM workers in 2015, and they continue to make more than non-STEM graduates even when they choose a non-STEM occupation (Noonan, 2017). Additionally, STEM workers are half as likely to be unemployed as non-STEM workers (Noonan, 2017). STEM curricula can also increase learning and enjoyment 
of the subject, as lessons and projects are often student-designed and student-driven, which can in turn lead to higher GPAs and retention rates (Halpern et al., 2007). This assertion is corroborated in a study by Gilmer (2007), who found that exposing students to a pre-college STEM summer program led to higher GPAs in the first year of college and higher retention rates overall.

Since choosing a STEM degree has many benefits, it may seem counterintuitive for so many students to choose other degrees. Researchers have begun to look at why students seek other professional paths. Factors that can limit students' involvement in STEM are often sociocultural. According to a report conducted by the ACT (2017), minority, low-income, rural, first-generation, and female students are most likely to lag behind in STEM, while Caucasian males are more likely to have opportunities that encourage persistence. Those students from minority groups who do choose to pursue a STEM degree in college are more likely to drop out of their majors before graduation (Anderson \& Kim, 2006; Herrera \& Hurtado, 2011).

Minority, low-income and rural students may have more difficulty in STEM due to lack of access to quality pre-collegiate curriculum (Wang, 2013). Schools in low-income or rural areas may be less likely to be able to provide comprehensive STEM classes, provide professional development for teachers, and reward innovative programming (Hossain \& Robinson, 2012). Furthermore, minority, low-income and rural students who choose to pursue a STEM major may quickly find themselves too far behind their peers to persist unless they receive sufficient preparation in high school (Anderson \& Kim, 2006). Additionally, first-generation students may not receive the proper support from parental figures to feel secure in pursuing STEM (Hossain \& Robinson, 2012). While there is some evidence that girls do have an interest in pursuing science and see it as valuable, many drop out the of STEM pipeline because of a perceived 
incompatibility with traditional feminine roles, as some young women do not feel that they can have children and a job in a STEM field (Diekman, Brown, Johnston, \& Clarke, 2010). Lack of access is an important issue in STEM and while it is outside the scope of this study, there is a clear need to design studies related to making STEM equitable for all.

Sociocultural factors are not the only barriers to students entering STEM. Research shows that students' chief complaint about science class is that it is boring (Hossain \& Robinson, 2012; Turner et al., 2010). They dislike memorizing facts and equations, and writing long technical reports (Osborne, Simon, \& Collins, 2003; Owens et al., 2008). They also perceive science subjects as too difficult or unwelcoming (Turner et al., 2010). By the time many students reach middle school, they have already decided against pursuing STEM classes that are not required by their schools (Jenkins \& Nelson, 2005; Osborne, Simon, \& Collins, 2003). Students who perceive school as boring or irrelevant are less motivated to learn (McInerney \& McInerney, 2000). Interestingly, there is a distinction between interest in STEM as an idea and interest in STEM as it is taught in schools. Students see value in STEM as a concept and feel that STEM is good for society, but they view the STEM taught in their classes as uninteresting and irrelevant (Sjoberg \& Schreiner, 2005). Thus, the problem of students' disinterest in pursuing STEM careers may not be in the subject itself, but in how it is taught.

\section{Constructivism and STEM}

Constructivism is a key educational perspective that may illuminate the struggle to differentiate the concept of science and how it is learned in school. Frequently associated with the philosopher Jean Piaget, constructivism focuses on how a person learns based on the interactions between thoughts and experience (von Glaserfeld, 2005). From a constructivist 
perspective, people learn by building on their own understanding and knowledge of the world around them, through the experiences that they have, and reflection on their experiences (Fosnot $\&$ Perry, 2005). Thus, many constructivist lessons are active and involve the student pursuing questions and information, rather than being given an answer to memorize. Instructors serve more as facilitators of understanding and encourage collaboration among their students (Fosnot \& Perry, 2005). Additionally, learning is situated within the context of where the acquired knowledge will be applied. This means that students are asked to apply the material in as authentic a manner as possible, which can make the information they receive more enjoyable and more practical (Julyan \& Duckworth, 2005). For learning to be authentic, it must happen on its own and be meaningfully connected to the student's life, and it is often the result of life experience rather than directed teaching (Cajete, 1999). Authenticity is similar to relevance, in that it connects learning to life. However, authenticity is more individualized, whereas relevance includes societal and vocational aspects that result from interactions with others (Khal \& Harms, 1981).

Constructivism approaches can be found in formal educational settings, such as a traditional classroom, or in non-formal educational settings, such as museums, field trips, or youth camps. In both types of settings, teachers may have students conduct self-driven experiments or investigate topics of interest through a series of interrelated assignments (Forman, 2005). Problem-based learning is a popular constructivist teaching technique, which frames learning as a problem or scenario that must be investigated by the students (Walker et al., 2015). While both formal and non-formal classrooms can make use of constructivist techniques, they can be a particularly good fit for non-formal settings. A formal constructivist classroom may require a greater degree of time and effort on the part of the teacher to implement. In all but 
a few modern classrooms, schools may not have the resources to afford teachers the needed professional development (Hossain \& Robinson, 2012), making it difficult to plan and implement constructivist techniques.

In contrast, non-formal educators are often trained, equipped and expected to use constructivist techniques (Hooper-Greenhill, 1999). Museums encourage visitors to explore their collections through carefully planned interactive exhibits and programs, while many educational camps allow campers to pursue their own projects under the guidance of a trained counselor in an environment and to apply knowledge in an authentic setting. Many teachers would find it difficult to immerse their students in these environments long-term, but field trips can provide alternative learning environments.

Constructivism is not without its weaknesses. One important criticism to note is that some constructivist techniques do not support novice learners who require more guidance to develop underlying knowledge (Clark, Kirschner, \& Sweller, 2012). For instance, the practice of "pure discovery" where students are given free range to learn about a topic with no guidance from teachers would only produce learning in students with some background knowledge of the topic (Mayer, 2004). In this example, students cannot make a connection to the subject being taught (Ham, 2016). Teachers who neglect to provide foundational information to their students before allowing their students to attempt to apply knowledge risk incomplete understanding on the part of the students (Clark, Kirschner, \& Sweller, 2012). However, while constructivist methods need to be applied judiciously, they can still be useful in enhancing leaning. With careful application, they can not only make students' learning more enjoyable, but more relevant as well, presenting a natural partnership with adventure STEM education. 


\section{Adventure Education}

Adventure education is squarely rooted in the experiential education movement, which in turn is rooted in the beginnings of Western philosophy and education. Experiential education began in the philosophies of Socrates, Plato, and Aristotle (Stonehouse, Allison, \& Carr, 2011). Later, John Comenius pulled from these philosophers' theories when he began to formalize his own ideas of sensory education, where students were encouraged to explore learning material through their senses (Pennycook, 1989). The $18^{\text {th }}$ century philosopher David Hume argued that all of human knowledge and reason is rooted in experience (Cranston \& Jessop, 2018). These two ideas became the central theories used by John Dewey used to formalize experiential education and develop it into a recognized discipline. In his book, Experience and Nature, Dewey espoused learning through hands-on, personalized educational experiences and emphasized the development of critical thinking, problem solving, and social skills in his students' education (Dewey, 1958).

Adventure education, simply defined as an educational experience that takes place in conjunction with outdoor activities (Priest \& Gass, 2017) built on each of these perspectives and became formalized through the work of the German educator, Kurt Hahn. While Hahn was not the only early outdoor adventure educator, he remains one of the most recognizable today. Hahn's work began as founder and principal of the Salem School in Germany. He believed that the chief failings of youth at the time were their physical weakness, inexperience with practical skills, and lack of civic engagement (Veevers \& Allison, 2011). Working from these ideas, he created a school that encouraged strenuous physical exercise, acquisition of traditional skills like carpentry and boatbuilding, and lessons that not only educated students, but pushed them to think critically (Miner \& Boldt, 2002). 
Hahn's time at Salem School came to an end with the rise to power of the Nazi party in Germany, as he was vocally and vehemently opposed to their ideology. He escaped Germany for England where he established another school with similar principles called Gordonstoun School (Miner \& Boldt, 2002). Like Salem, Gordonstoun sought to develop well-rounded youth, which included their participation in outdoor activities (Veevers \& Allison, 2011). With World War II looming, Hahn partnered with Lawrence Holt, a businessman with interests in shipping to found the Outward Bound Sea School (Veevers \& Allison, 2011). This new school's curriculum included seamanship, physical conditioning and rescue training, with the aim of training its students for work on seafaring vessels. Students were often put into challenging physical and mental situations to strengthen their minds and bodies with the goal of helping them to survive at sea (Veevers \& Allison, 2011). The idea of using challenging experiences to inspire personal growth would become central to the transition of the Outward Bound Sea School to Outward Bound.

Outward Bound made the leap to the United States in 1961 when Joshua Miner adopted Hahn's principles to found the Colorado Outward Bound School (Miner \& Boldt, 2002). As time passed, Outward Bound spread and grew across the country influencing other notable figures in the outdoor adventure education movement. Paul Petzl, an Outward Bound instructor, founded the National Outdoor Leadership School (NOLS) in 1965 to train Outward Bound instructors, before moving his school to an expedition-based model that allowed lay people to develop leadership and outdoor skills (Ringholz, 2000). As the outdoor movement within the United States began to expand, it allowed for new innovations in the industry.

Founded by another Outward Bound instructor, Project Adventure began to move outdoor adventure education away from a strictly wilderness model. While early adventure 
programs were primarily concentrated in isolated wilderness settings, the fledgling field also grew to encompass less remote surroundings. In instances where financial or staffing resources were short, it was not feasible to take participants into the wilderness, so many practitioners turned to adventure-based challenge courses as an alternative. Project Adventure, an early adventure challenge program founded in 1971, used aerial ropes courses in conjunction with ground-based activities and challenges to emphasize personal growth (Cavert, n.d.). As challenge course programming expanded, adventure education no longer limited itself to remote areas. Even Outward Bound, known for its wilderness-based trips, began to establish urban adventures centers with an increased emphasis on urban expeditions (Outward Bound, 2019). Eventually, the field of adventure education further solidified into a formal discipline through the work of organizations such as the Association for Challenge Course Technology, the Wilderness Education Association, the Association of Experiential Education, and the Association of Outdoor Recreation and Education.

Its long history with outdoor education and experiential education can make adventure education difficult to define because it is strongly entwined with both. The three methodologies borrow theories and perspectives from each other and differ in subtle ways. Adventure education is also related to environmental education, and, to a lesser degree, to environmental interpretation (Priest \& Gass, 2017). Outdoor education and adventure education are almost - but not entirely synonymous. Outdoor education refers to learning and teaching that takes place outside, usually but not always through outdoor activities such as backpacking (Hanna, 1991). Adventure education also takes place outside, but almost always occurs through outdoor activities (Priest \& Gass, 2017). Similarly, experiential education, which is a process where the student learns from direct experiences (Bisson, 1996), can take place out of doors and involve outdoor activities, but 
can also take place indoors with non-outdoor activities. Environmental education also often takes place outside but is primarily concerned with teaching participants about the natural systems of the environment and encouraging stewardship of natural resources (Miles \& Priest, 1990).

Ewert and Hollenhorst (1989) characterize adventure education as "a variety of selfinitiated activities utilizing an interaction with the natural environment that contain elements of real or apparent danger, in which the outcome, while uncertain, can be influenced by the participant and the circumstance (p. 209)." Wurding (1994) adds that the purpose of adventure education includes helping "people learn more about themselves and the world they live in," while Miles and Priest (1990) specify that it can "expand the self to learn and grow and progress toward the realization of human potential (p. 1).” Each researcher characterizes adventure education in slightly different ways, but agree that it exposes students to the potential of risk (Ewert \& Hollenhorst, 1989), in a wilderness or wilderness like environment (Bisson, 1996), to help them grow as people (Wurding, 1994) and learn new physical skills (Priest \& Gass, 2017). For the purpose of this paper, adventure education refers to educational activities that takes place in the outdoors, usually with outdoor activities as the method for learning and with some associated amount of real or perceived risk (Priest \& Gass, 2017).

Adventure education outcomes vary depending on the scope of the program. A metaanalysis done by Hattie, Marsh, Neill and Richards (1997) on the outcomes of adventure experiences found that most programs claim to promote an increase in students' capacity for leadership, self-concept, academic performance, personal development, interpersonal skills, and "adventuresomeness". This study found a small to moderate impact in these areas, which increased proportionally with program duration and inversely to participant age. Later, Powell et al. (2018) examined outcomes associated with participation in wildland recreation activities. 
They examined 235 articles published between 2000 and 2016 and identified outcomes relating to personal development, pro-social behaviors, mental restoration, and environmental stewardship. While both Hattie et al. (1997) and Powell et al. (2018) highlight weaknesses and gaps within the literature, their findings do suggest that adventure education can have a positive effect on participants.

The dominant theories found in adventure education are rooted in the field of psychology and come from work in experiential education. Kolb's Experiential Learning Cycle is one of the most heavily utilized models in adventure education. With a foundation in the earlier work of John Dewey and Kurt Lewin, Kolb's model describes a cyclical process of participating in an experience, reflecting on the experience, forming or modifying ideas based on reflections, and putting those ideas into practice during the next relevant experience (Kolb \& Kolb, 2009). Kolb's model is not without criticism. Some argue that the learning cycle does not take a participant's social, cultural, or economic background into account (Seaman, 2007; Beard \& Wilson, 2006), while others feel that it is too simple a model for complex human thought (Miettinen, 2000; Seaman, 2008). Still others point out that the transference of learning from one context to another has never been adequately demonstrated by research (Brown, 2009). Though Kolb's theory does have some weaknesses, it is useful in that it provides a practical, simple tool for adventure education practitioners attempting to aid participants in forming meaning from their experiences. 


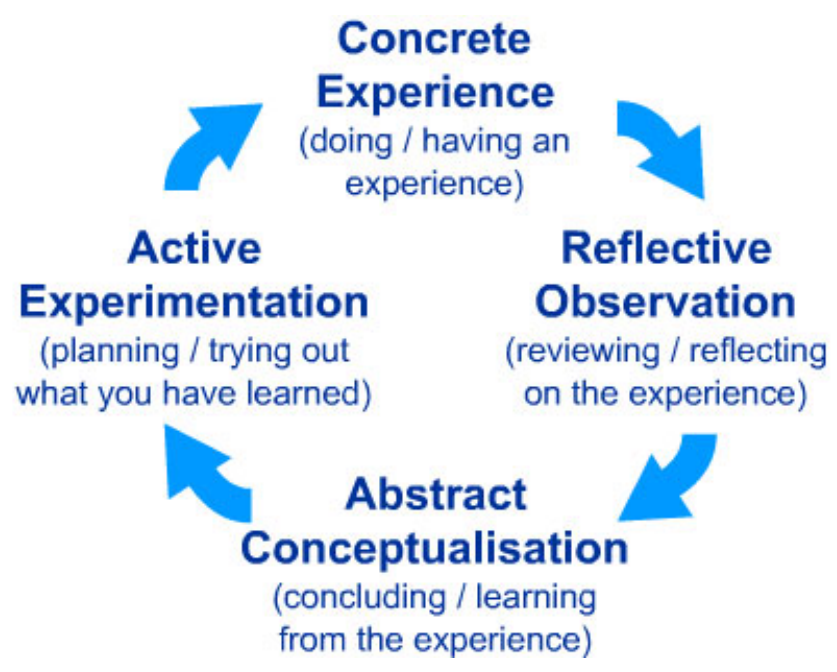

Figure One: Kolb's Experiential Learning Cycle

Other theories are also frequently found in adventure education, albeit not quite as often as the Experiential Learning Theory. When Kurt Hahn began his work, he was basing his ideas for experiential therapy on his observations of sailors and later of schoolboys under his care (Miner \& Bolt, 2002). In 1986, Albert Bandura stated his theory of self-efficacy, which describes an individual's belief in their ability to accomplish a given task. Though Bandura's theory has been used in much broader research contexts, outdoor educators have found it useful in describing outcomes of their work. Csikszentmihalyi's Flow Theory (1997), describes a process of reaching a state of mind where the participant is fully immersed in an experience which will allow them the optimal amount of learning and satisfaction. Finally, Walsh and Golins (1976) put forth a theory of adventure education that describes how students process their experiences in a novel environment. When a student is in a new environment with new people, they are free from the social constraints of their home environment. This freedom allows the student to explore their identity and can ultimately lead to changes in behavior when the participant returns home. 
These theories are all experientially based and focused on the needs of the learner. They come from a constructivist perspective that is often lacking in traditional classrooms. By pairing adventure education with STEM education, it becomes possible to tap into the strengths of both disciplines for greater academic learning. STEM education provides a more rigorous academically-focused curriculum, while adventure education frames the STEM curriculum by presenting interesting settings and activities along with an emphasis on personal growth and development, and by contributing constructivist teaching methods to better engage students to frame STEM curriculum.

\section{Adventure Learning}

Adventure STEM education is an emerging discipline. While there have been several studies on adventure STEM programs (Larsen et al., 2014; Mackenzie, Son, \& Eitel, 2018; Miller, Doering, Roehrig, \& Shimek, 2012; 1996; Son et al., 2017; Zwick \& Miller, 1996), little has been studied beyond these projects. The work of Miller et al. (2012) focused on the cultural context of learning through combining STEM principles with the traditional American Indian game of snow snakes to increase meaning for indigenous youth. Earlier, Zwick and Miller (1996) also looked at the science experience of American Indian students. They compared the test scores of students who participated in science-based outdoor educational activities with students who received traditional classroom-based lessons and found that the students given the outdoor lessons scored significantly higher. Son et al.’s (2017) and Mackenzie et al.'s (2018) papers both came from the same study. In this study, the researchers conducted focus group interviews with 22 high school students who participated in a five-day outdoor snow science program, and their findings suggest that the experience provided greater engagement opportunities in both physical 
activities and science education. Finally, Larson et al.'s (2014) work explored the idea that geocaching, a GPS-based outdoor activity, could be used to teach STEM concepts through a series of caches set in natural public spaces.

However, adventure learning is another new concept of note that combines some of the same principles and theories to create a closely related field to adventure STEM education. Like adventure STEM, adventure learning is built around outdoor activities and experiential learning (Doering, 2006), but in contrast, the students do not necessarily participate in the adventure. Instead, students follow along with an adventure taking place outside of their classroom through an online medium while participating in an inquiry-driven curriculum based on the progress of the adventure expedition and the real-world issues they encounter (Doering \& Veletsianos, 2008; Veletsianos \& Kleanhous, 2009).

One such project, Arctic Transect 2004, was an early example of adventure learning project that allowed students to follow along with a 3,000-mile dog sled expedition across the Canadian Arctic (Doering, 2006). Along the way, they took part in a hybrid curriculum that included an online component and an in-person classroom lesson. The curriculum was designed to have students interacting with each other, their teachers, and experts in the field, and followed a framework consisting of seven principles: 1) research-based curriculum grounding in problem solving, 2) collaboration and interactions between learners, experts, peers, and content, 3) internet-based content delivery, 4) time-based curriculum, 5) learning opportunities concurrent with adventure learning curriculum, 6) classroom curriculum aligned with online curriculum, and 7) adventure-themed curriculum (Veletsianos \& Kleanhous, 2009).

Adventure learning has several benefits. It provides a cost-effective and time-effective way for teachers to access places in the field where they could not normally take their students. It 
is also inherently exciting. Many students will be naturally drawn to the novel experience of the team in the field and the opportunity to follow along with their journey in real time. Though adventure learning may be immediately appealing to many students, given its focus on exciting adventures in exotic locations, it may not be as relevant. Because most students will likely never come into contact with the Arctic and similar locations, they may not feel as strong a connection to material as they would to curriculum based in their own region. While researchers do point out that the adventure learning model could be implemented in local contexts through an extension of the curriculum, termed “AL@” (Hougham, Eitel, \& Miller, 2015), this places the onus of instruction back onto the teacher to construct and implement new curriculum. Adventure STEM education curricula may require more resources than adventure learning, but may prove to be just as engaging with greater possibility to make content relevant to learners.

\section{Relevancy}

At the heart of adventure STEM education lies the concept of relevancy. The idea of relevance in education first emerged in the education reform movements of the late-nineteenth and twentieth centuries. Prior to this time, formal schooling opportunities were limited. In 1837, Horace Mann established a system to support public schools, funded by the United States government and open to students who previously lacked access to formal education (Cremin, 2018). John Dewey introduced the idea that human development should be a driver behind education (Dewey, 1958). Others continued to add progressive ideas. John Goodlad created the idea of non-graded schools (Goodlad, 1964), while Alexander Sutherland Neill (Neill, 1960) founded Summerhill School which granted students the freedom to choose their own education, and Maria Montessori emphasized that each should student be taught in a way that met 
individual educational needs (Montessori, 2013). With these reforms came the idea that subject matter should be relevant to the student.

While educators have worked to make content more relevant to students than in the past, many young learners still fail to see relevancy in their schoolwork. This is particularly true for science education. Starting around the age of nine, positive student attitudes toward science show a steady decline (Osborne, Simon, \& Collins, 2003). However, there is something of a split between the broad idea of science in society and science in schools. Many students have a positive view of science as it relates to solving world problems or being used to create policy but find the science lessons taught in their own classrooms to be boring or too difficult (Osborne et al., 2003). They do not find the material in class applicable to their personal lives or communities (Hofstein, Eilks, \& Bybee, 2010). Thus, making science education more relevant is crucial to increasing the personal interests of STEM students. When students recognize that studying science can help them grow, benefit their home communities, and be a viable career option, everyone benefits.

As with many terms used in an academic setting, "relevancy" used in regard to educational settings (particularly STEM) is not easily definable. Some researchers see relevancy as a synonym for interest (Childs, 2006; Sjoberg \& Schreiner, 2005). In this perspective, students consider certain topics as the most relevant if the students have the most interest in those topics. However, as noted by Stuckey et al. (2013a), educational content can have a great impact on a student's future even if the individual does not find the subject interesting. Another way to see relevance is as a way for students to construct meaning through interactions with their teacher and the subject matter (Schwab, 1973). As they learn, they gain the ability to see how the academic material is contextual to their lives. Similarly, Keller (1983) writes that relevance is 
connected to the student's personal needs, and that to see subject material as relevant, a student must see it as fulfilling a need (Stuckey et al., 2013a). Others add that relevance must also be personally meaningful (Ham, 2016, Means et al., 1997). Finally, a subject's relevance can also be defined by how useful the subject will be to solving world problems (Stuckey et al., 2013a). Though each definition has merit, in the context of this paper, academic relevancy will focus on students' experiences of their curriculum as personal and meaningful to their lives (Ham, 2016) and fulfilling their personal, societal, and vocational needs (Stuckey et al, 2013a).

One of the most widely cited relevancy studies is the ROSE, or Relevance of Science Education, survey. The ROSE survey was created as a result of a declining rate in students' choice of science and technology careers (Sjoberg \& Schreiner, 2005). The ROSE survey is an international effort involving over 40 countries (Sjoberg \& Schreiner, 2005), with the intent of discovering students' experiences, interests, priorities, images, perceptions and attitudes related to science and technology (Jenkins \& Pell, 2006). Researchers identified lack of relevance in science and technology curriculum as one of the chief factors in students' low interest in these fields (Sjoberg \& Schreiner, 2005). As of 2010, the data from the ROSE survey indicate that students in most countries agree that science and technology can make life better for society, though those in more developed countries are more skeptical than their male counterparts in less developed countries (Sjoberg \& Schreiner, 2005). Students also believe that technology will make work more interesting, although most students are not enthusiastic about science in general or as a future career path, especially girls (Sjoberg \& Schreiner, 2005). Ultimately, the survey summary recommends the need to "humanize" school and increase the context of the subject for the learner. The ROSE survey is useful for understanding how students feel about science and technology. However, as it largely uses the concept of relevance as a synonym for interest, the 
survey is somewhat limited in its ability to provide a deeper understanding of relevance in the classroom.

Though relevance is not widely studied in any field, there are several studies focused on relevance in the classroom. After sampling 220 students, a study by Greene et al. (2004) found that students showed more motivation when they viewed current classwork as the key to future success. Their work drew on Miller and Brickman's (2004) theory that "perceived instrumentality", another name for the concept of relevancy, influences engagement through a student's desire to achieve goals that are personally important to that person. In an in-depth study of three high school students, they found that the degree to which students saw schoolwork as instrumental to reaching their future goals was related to their perceptions of the intrinsic and extrinsic value of their classwork (Brickman \& Miller, 2001). Finally, Crumpton and Gregory (2010) found that low-achieving minority students who found coursework more relevant to their lives and future goals took more initiative to learn in class and showed more academic engagement in class.

Although researchers disagree on the nature of relevancy, many agree that it has its roots in the concept of meaningfulness. While not framed with the formal term of relevance, Dewey (1973) also made the link between meaningfulness and relevancy when he emphasized the connection that should be made between students' learning at school and their everyday lives. Specifically, Dewey believed that good educational experiences involve both continuity and interaction between the learner and the material they are learning (Dewey, 1938). Continuity is the belief that experiences will shape the learner's future either positively or negatively, while interaction encompasses the idea that a person's present experience results from the interaction between that person's past experiences and their present situation (Dewey, 1938). For example, 
how a student experiences a science class will not only depend not only upon how the teacher conducts the class, but also upon how past teachers in similar classes conducted those classes. From Dewey's theory, it follows that teachers who are able to make their classes more meaningful in the present make future classes more meaningful.

Much later, Jerome Bruner (1996) added the idea that a cultural context could also provide meaningfulness to students' experiences as children use the "toolkit" of their culture to make sense of the world. His book highlighted the need for educators to take cultural content into account when planning lessons. Gilbert (2006) looked at relevance in relation to contextbased learning and stated that students show lack of interest in science because of lessons situated in ill-chosen contexts. This leads to a lack of relevance because students come to view the subject as instrumental, rather than as something that can be worthwhile to learn for its own sake. It is the application of context, and therefore relevance, that gives students an understanding of why they should learn (Gilbert, 2006).

Most recently, Westbroek, Klasseen, Bulte and Pilot (2010) put forth the idea that to make science curriculum more meaningful, students must be motivated to reach a certain goal, and they must have the conceptual and procedural knowledge to attain that goal. This makes learning more contextualized, meaning that the concepts being taught are linked to real world applications, so students have a greater understanding of why they are learning (Westboek et al., 2010). To test their theory, the researchers observed students completing a water sampling lesson designed to provide motivation and the skills needed to reach the lesson goal. They conducted interviews, recoded lessons and class discussions, and evaluated written answers. Ultimately, they found that when students know how activities will contribute to the goal they want to achieve, the activities have more context. 
The link between meaningfulness and relevancy is particularly evident in the realm of environmental interpretation. The main of goal of interpretation is to facilitate connections between people and resources in informal circumstances (Ham, 2016). Informal education occurs outside of a formalized classroom setting, while formal education occurs within a classroom (Ballantyne \& Uzzell, 1994). Because of interpretation's emphasis on connections, it is an important factor to consider in the broader conversation on relevancy. The Theory of Planned Behavior (TPB) is one of the key frameworks in the literature on interpretation. Proposed by Icek Ajzen (1991), TPB states that attitudes toward behavior, subjective norms, and perceived behavioral control shape an individual's behaviors and intentions (Ajzen, 1991). In this theory, behavioral beliefs, which center on whether or not a behavior is acceptable to others, combine with normative beliefs, which are the beliefs of what other people find acceptable. These two beliefs also operate in conjunction with control beliefs, which dictate how successful a person perceives they will be at accomplishing an action (Ajzen, 1991). When combined, the theory notes that these three beliefs shape a person's intention to action, which, in turn, influences their behavior (Ajzen, 1991). Beliefs that are more salient are more likely to effect behavior change (Ajzen, 1991). Somewhat like relevancy, salient beliefs are those that first come to mind when a person begins to make a decision making them some of the most important in decision-making (Ajzen \& Fishbein, 2000). Thus, in the case of students, salient beliefs can influence what a learner may perceive as important and whether or not they will continue to engage with a lesson.

Ham's (2016) relevancy framework focuses provides a highly useful perspective on relevancy for adventure STEM education because of its aptness for use in the non-formal learning environments and its ability to frame other relevancy models. In this model, relevant information has two separate qualities: it is meaningful, and it is personal (Ham, 2016). 
According to Ham (2016), meaningful information facilitates connections between new ideas and the concepts people already know. It is also contextual; people will only understand and engage with information within the context of something they already known. Information that does not connect will be disregarded by the learner. Personal information connects a learner not just with information that is already familiar, but also with information that the learner cares about (Ham, 2016). It provides new insight into a topic that is important to the student and can touch on their values, beliefs, attitudes, and convictions (Ham, 2016). Like information that lacks meaning, information that is not personal will be disregarded by learners.

It can be easy for teachers and educators in a formal setting to create a curriculum that lacks meaning and personal connections, particularly in science education. Within formal classrooms, many teachers rely on traditional teaching methods such as rote memorization, lecture, or having students work through experiments according to exacting instructions. These lessons may feel sterile, because they often lack context and connection to the students' lives, causing students to disengage with the classroom curriculum.

While Ham's framework of relevancy discusses the domains of meaningfulness and personal connection in the context of environmental interpretation, relevancy in more formal STEM classroom settings has been operationalized differently. Shwartz, Ben-Zbi, and Hofstein (2006) studied scientists' perceptions of chemistry literacy, science literacy, and high school science education. They conducted in-depth, semi-structured interviews with chemists and science education researchers, facilitated workshops with chemistry teachers, and surveyed both chemists and the chemistry teachers from teacher workshops. They were able to identify four areas of relevance in chemistry education including promoting individual skill development, developing coping skills in individual life, building skills related to using science, and relating 
curriculum to a broader society. According to Stuckey et al. (2013a), this means that a student's interests, needs, and self-worth can provide relevance for the individual to engage with classwork.

In a discussion on science education in the United Kingdom, Young and Glanfield (1998, p. 16) point out that many students do not see the purpose of science in school because, "studying science no longer leads to a clear range of future careers and the sciences are not sufficiently concerned with human and social issues." They go on to point out the importance of "whole curriculum" which links different areas of scientific study, is contextualized socially, politically, and culturally, and creates opportunities for students to learn about the application of scientific skills and knowledge. Newton and Newton (1991) write that effective science teaching is relevant if it is long-term and meets the needs of a student's adult life. Their research analyzed the pictures and texts of elementary and middle school science documents, and they found that the material contained little to no indication of how science related to the lives of people. This led the researchers to recommend that teachers modify curriculum to make it more relevant. In their book, Science Education for Citizenship, Ratcliffe and Grace (2003) suggest that the role of science education should prepare students for a skills-based future and their eventual roles as responsible citizens. Similarly, Klafki's (2000) book explores the descent of science education from the Eastern European concept of "Allgemeinbuildung," which describes the role of schools in education and tasks schools with creating curricula that gives students a strong general education that prepares them for roles in greater society. In this work, Klafki lays out a method of teaching that includes relating instruction to a structure of knowledge, relating it to everyday life, and relating it to other subjects. 
Researchers have been attempting to organize these dimensions of relevancy into a cohesive unit for some time. In the field of biology education, Khal and Harms (1981) perceived relevance as four-dimensional: relevance for personal needs, societal needs, career education and awareness, and academic preparation. They arrived at their model through an analysis of biological science and educational literature and tested it through a series of focus groups. While they found it to be a useful model, these domains were most applicable to junior and senior grades, making it less helpful in studies focusing on younger students.

In their chapter of Topics and Trends in Current Science Education, Eilks et al. (2014) conceptualized relevance as directly impacting the life of students in the moment and in the future. Their relevancy model integrated earlier conceptualizations of relevance into the three dimensions of individual, society, and vocational, and also included the temporal aspect of present and future relevancy. It was based on an earlier fifteen-year project by Hofstein and Kesner (2006) which sought to make chemistry education more relevant in Israeli schools. Their work included multiple studies including the development and evaluation of new curricula. For their work, the researchers conducted case studies which focused on the role of bromine in the context of the Dead Sea, teacher training, planned site visits to industrial chemical facilities, and the development of an online website for teacher training and students use (Hofsten \& Kesner, 2016). When studying the teacher trainings, they found that teachers who were taught studentcentered teaching methods were more likely to use these techniques in their classrooms. They also found that when given choice, teachers were more likely to opt to take students on fields trips to industrial sites than not (Hofsten \& Kesner, 2016). Finally when assessing their curriculum as a whole through learning inventories, questionnaires, and interviews, the researchers found that students who participated in their curriculum developed a stronger 
appreciation for chemistry as a way to prepare them for future careers and societal roles, and found the material more interesting, enjoyable and related to their everyday lives (Hofsten \& Kesner, 2016).

Van Aalvoort's (2004) work described relevance as having personal, professional and personal/societal aspects. He defined the stand-alone personal dimension as concepts which immediately related to the student's life, whereas personal in the context of the personal/societal dimension related to social issues. Operating under this theory, the researcher's work consisted of designing a new course for grade nine chemistry students in the Netherlands. In this instance, the overall topic of the class was 'water.' The unit opened with a section that highlighted the physiological need that humans, animals, and plants have for water, immediately establishing relevance. It then progressed through the steps taken to purify water with emphasis on chemical processes. Throughout the unit, students were given opportunities to work through chemistrybased activities. Van Aalvoort's (2004) curriculum also sought to embed opportunities for the student to practice and discuss citizenship. Overall, this work provides an in-depth look at how relevancy domains can be integrated into the classroom through science-based activities.

These three domains of relevance have been further unified in The Three Dimensions of Relevancy Model (Stuckey et al., 2013). This model operates under the assumption that science learning is most relevant when it will have positive consequences in the life of the student, either in the present or in the future. These positive effects are spread over three dimensions: individual, societal, and vocational. The individual facet focuses on factors immediately relevant to the students, such as getting good grades in school or gaining the social skills that will help them work with others and maintain relationships. The societal dimension is related to how the students interact with the people and community surrounding them. For example, science 
learning could help a student gain a greater sense of agency in their immediate community, such as awareness of community needs. Later, science learning can inform one's behavior as a responsible member of society as it may provide the individual the knowledge and abilities to act on community needs. Finally, the vocational dimension focuses on aspects of life relating to the learner's career. In the immediate term, this could include factors such as learning about career paths or passing exams to advance through grade levels, and in the long term could include getting a satisfactory job. Stuckey et al. (2013a) also posit that relevance in science education must touch on the intrinsic and extrinsic needs of the student. Intrinsic needs encompass a learner's interests and motivations, such as an interest in robotics or a desire to learn more about astronomy purely for enjoyment. Extrinsic needs are those that come from the societal expectations of other people, such as going to college or getting a job. Relevant curricula meet both of these needs.

Stuckey et al. (2013b) sought to validate this model through focus groups with science education experts that included student teachers with bachelor degrees in science fields, student teachers with a Masters of Education degree, trainee teachers, early career teachers, experienced teachers who had experience in curriculum development, and science education researchers. Each focus group began with a discussion on the definition of relevance as it related to science education. The groups were then presented with the Three Dimensions of Relevancy Model for discussion. Finally, the groups were asked to weight the dimensions of relevancy. The researchers then performed a content analysis on the transcribed interviews. They found that while groups had difficulty agreeing on a definition of relevancy, all agreed that it included the idea that a lesson should meet a student's need. All groups mentioned each of the three dimensions in Stuckey et al.'s relevancy model, though more emphasis was placed on the 
individual dimension. The groups also weighted the individual dimension more heavily for younger students and the vocational and societal dimensions more heavily for older students.

As a cautionary note, this model is highly contextual and depends upon on the student's culture and life experiences. For instance, the societal expectations for an American student will likely be substantially different from the expectations for their peers living in Japan or Africa. To fully teach to each dimension of relevance, instructors must have a greater knowledge of their students' individual, societal, and vocational desires and interests. However, while this model may lack some practicality in a classroom setting, it is useful for understanding the complexities behind relevance and provides teachers with a solid foundation for improving the relevancy of their lessons.
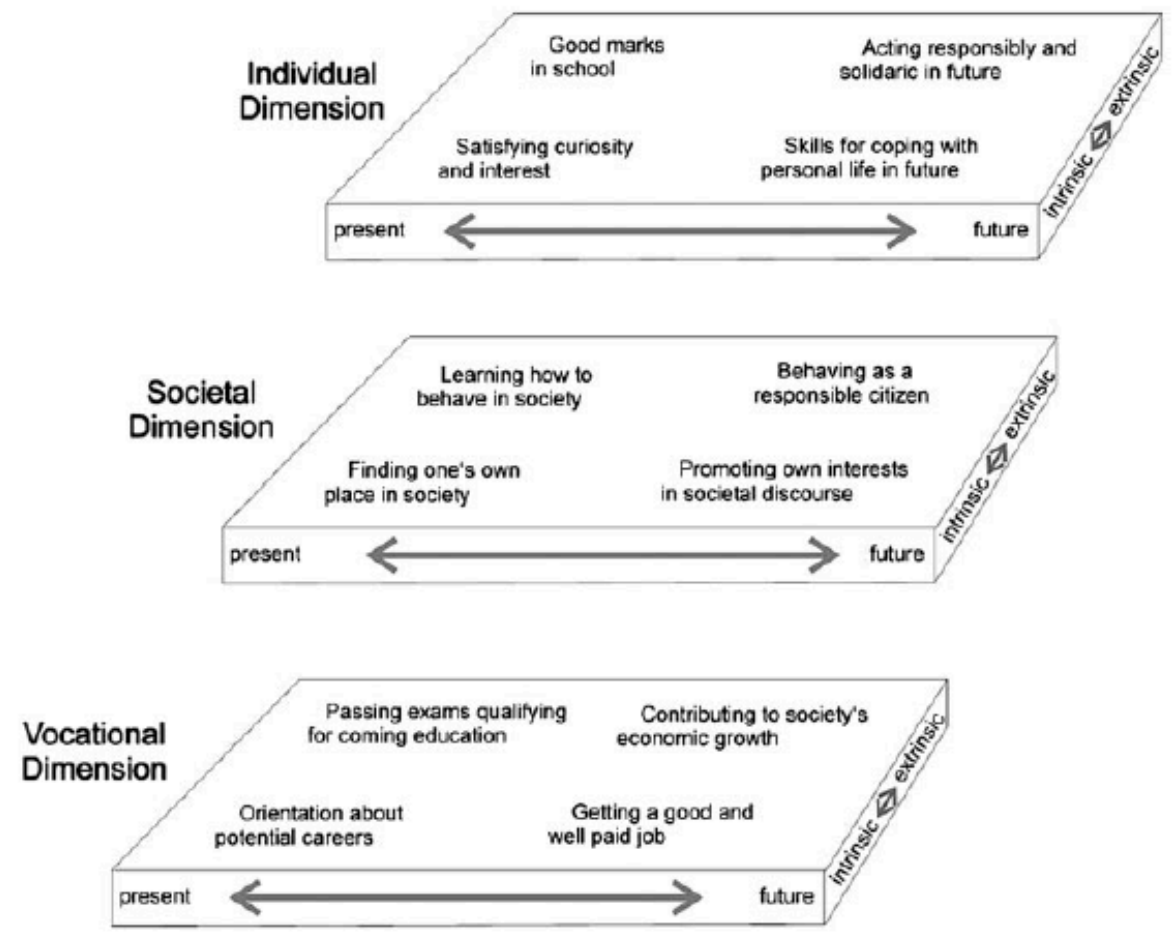

Figure 2: Stuckey et al.'s (2013b) Model of Relevancy with examples

In summary, while similar to the construct of interest, relevancy includes aspects of a student's present and future life beyond simple attraction to a subject. In many schools across the 
world, students do not find science to be relevant to their lives because they cannot see how it will benefit them. Research indicates that students must have a meaningful frame of reference for the material they will learn and that they must care about it personally. Furthermore, they must see that it connects to their lives both in the present and in the future across multiple dimensions.

\section{STEM Attitudes}

By making STEM curriculum more relevant to students, it may become possible to increase positive attitudes toward their STEM classes, which may increase persistence in STEM (Osborne, Simon, \& Collins, 2003). Attitudes are: 1) affective, relating to how people feel about things or other people, and 2) evaluative, meaning that they determine the degree to which people see something as good or bad (Gawronski, 2007). Attitudes are also important because they can play a role in changing behavior (Fishbein, 1966).

\section{Vocational Relevancy Attitudes}

Vocational relevancy focuses on aspects of life relating to the learner's career. At younger ages, this could include passing exams and progressing through grade levels, and later could include finding a satisfactory job or achieving high-level professional certifications (Stuckey et al., 2013a). For the purpose of this study, vocational attitudes refer to the both academic and vocational aspirations as middle school students are not yet employed but do spend their "workday" in school. 


\begin{tabular}{|c|c|c|}
\hline Researcher & Conceptualization of Relevancy & Domains \\
\hline Khal \& Harms, 1981 & $\begin{array}{l}\text { There are four domains of relevancy, including } \\
\text { personal needs, societal needs, career education } \\
\text { and awareness, and academic preparation. }\end{array}$ & $\begin{array}{l}\text { Personal, } \\
\text { Societal, } \\
\text { Vocational, \& } \\
\text { Academic }\end{array}$ \\
\hline Newton \& Newton,1991 & $\begin{array}{l}\text { Relevant education prepares children for the } \\
\text { long term and addresses the needs of their adult } \\
\text { lives. }\end{array}$ & $\begin{array}{l}\text { Societal \& } \\
\text { Vocational }\end{array}$ \\
\hline Young \& Glanfield, 1998 & $\begin{array}{l}\text { Relevant education links different areas of } \\
\text { scientific study, is contextualized socially, } \\
\text { politically, and culturally, and creates } \\
\text { opportunities for students to learn about the } \\
\text { application of scientific skills and knowledge. }\end{array}$ & $\begin{array}{l}\text { Societal \& } \\
\text { Academic }\end{array}$ \\
\hline Klafki, 2000 & $\begin{array}{l}\text { Relevant education prepares students for greater } \\
\text { role in society. }\end{array}$ & Societal \\
\hline Ratcliffe \& Grace, 2003 & $\begin{array}{l}\text { Science education prepares children for } \\
\text { vocational future and role as responsible citizens. }\end{array}$ & $\begin{array}{l}\text { Societal \& } \\
\text { Vocational }\end{array}$ \\
\hline Van Aalsvort, 2004 & $\begin{array}{l}\text { The four domains of relevancy include personal } \\
\text { relevance, professional relevance, social } \\
\text { relevance, and personal/societal relevance. }\end{array}$ & $\begin{array}{l}\text { Personal, } \\
\text { Vocational, } \\
\text { Societal (social } \\
\text { issues and } \\
\text { citizenship) } \\
\end{array}$ \\
\hline $\begin{array}{l}\text { Shwartz, Ben-Zbi, \& } \\
\text { Hofstein, } 2006\end{array}$ & $\begin{array}{l}\text { Relevant curriculum facilitates individual skill } \\
\text { development, develops coping skills in } \\
\text { individual life, builds skills related to using } \\
\text { science, and relates curriculum to a broader } \\
\text { society. }\end{array}$ & $\begin{array}{l}\text { Personal, } \\
\text { Academic, \& } \\
\text { Societal }\end{array}$ \\
\hline Stuckey et al., 2013 & $\begin{array}{l}\text { Relevant curriculum has positive consequences } \\
\text { on the life of the student and has three } \\
\text { dimensions: individual, societal, and vocational. } \\
\text { It impacts the present and future, and meets } \\
\text { intrinsic and extrinsic needs. }\end{array}$ & $\begin{array}{l}\text { Personal, } \\
\text { Societal, \& } \\
\text { Vocational }\end{array}$ \\
\hline Eilks et al., 2014 & $\begin{array}{l}\text { Relevant curriculum directly impacts the life of } \\
\text { the student today or in the future. It was three } \\
\text { dimensions: individual, societal, and vocational. }\end{array}$ & $\begin{array}{l}\text { Personal, } \\
\text { Societal, \& } \\
\text { Vocational }\end{array}$ \\
\hline Ham, 2016 & $\begin{array}{l}\text { Relevant curriculum is meaningful (i.e., } \\
\text { facilitates connections between new information } \\
\text { and what people already know) and personal } \\
\text { (i.e., connects to things that people care about). }\end{array}$ & Personal \\
\hline
\end{tabular}

Table One: Conceptualization of relevancy has changed through time with emphasis in different domains. 


\section{STEM Interest and Career Interest}

Interest is an overarching construct found in STEM attitudes, with identity and selfefficacy as additional constructs or subconstructs. STEM interest can refer to several dimensions. This study focuses on subject interest, which refers to a student's curiosity in learning about the STEM subject, and career interest, which refers to a student's desire to pursue a job in the STEM fields (Sadler et al., 2011). Though they are linked, it is important to distinguish the two, as a student who enjoys learning about STEM may not want to become a professional in the field, and vice versa. STEM interest, STEM identity, and self-efficacy may be key components of increasing students' interest. STEM interest can be defined to include "a combination of students' self-perceptions and interest in science and science-related work" (Gilmartin et al., 2007, p. 982). Any interest that a student has in a particular subject, STEM included, increases the likelihood that they will pursue and persist in a related career choice (Eccles, 2007). Interest, combined with career aspirations, informs the value that the person places on a career path in relation to the costs which they may have to incur to pursue and retain the career (Eccles, 2007).

Research indicates that many students show more interest in learning about STEM subjects than they do in taking STEM classes. Osborne, Simon and Collins (2003) posit that this may be because contemporary science curriculum focuses on scientific discoveries from the past rather than on how science addresses issues from the present. Science in the classroom often seems disconnected from modern culture and is presented as something that should be studied for its own sake (Ebenezer \& Zoller, 1993), rather than for its potential to effect change. The lack of perceived relevance, and therefore interest in taking STEM classes, is also likely contributing to why students do not choose to pursue STEM. Even though many students see the concept of STEM as interesting, they are still not interested in pursuing STEM careers (Abels, 2015; 
Jenkins \& Pell, 2006). Taken together, for students to want to work in STEM fields, they must see STEM courses as relevant as well as interesting to study.

\section{STEM Career Knowledge}

Career knowledge relates to information associated with potential careers, and STEM career knowledge specifically refers to a student's familiarity with science, technology, engineering, and mathematics fields (Blotnicky et al., 2018). This includes knowledge about what careers options exist within a discipline and the requirements to gain employment in a career role (Blotnicky et al., 2018). Student with STEM career knowledge are more likely to have increase interest in a future STEM job and more likely to pursue STEM degrees (Blotnicky et al., 2018; Zhang \& Barnett, 2015). Furthermore, supplying students with STEM knowledge can increase the likelihood that they will take more science and mathematics classes in high school (Harackiewicz et al., 2012).

\section{STEM Identity}

Identity is a complex construct, but it can be defined "as an individual's understanding of [themselves] as a separate entity" (Herrera, Hurtado, Garcia, \& Gasiewski, 2012, p. 4). According to Gee (2000), a person's “core" identity develops from enduring identity patterns over a long period of time. An identity can also be characterized by being personal (Wortham, 2004), actively created (Polman \& Miller, 2004) and encompassing all aspects of a person's life (Gee, 2000). Furthermore, identity is similar to self-concept, which refers to a student's perception of self in a domain or subject (Hughes et al., 2013). Identity is particularly important 
to students in STEM classes because it can relate to their perceptions of science (Herrera \& Hurtado, 2011).

One proposed solution to increasing interest in STEM classes is to improve students' STEM identity, which refers to their ability to envision themselves as capable of successfully participating in STEM (Herrera \& Hurtado 2011). Developing a positive STEM identify allows students to make connections between the subject and their personal identities (Carlone \& Johnson, 2007; Riedinger, 2011, 2015). Researchers generally agree that STEM identities are best developed through exposure to opportunities for observation and participation in authentic science-based experiences with scientists (Hughes et al., 2013; Barab \& Hay, 2001; Bell, Blair, Crawford, \& Lederman, 2003). Scientists are important to STEM identity formation in students because they provide social validation, recognition of science identity, and a positive introduction into a scientific setting from a credible source of scientific authority (Carlone \& Johnson, 2007).

\section{STEM Self-Efficacy}

STEM self-efficacy can also play a role in the formation of STEM identity. Although self-efficacy generally refers to a student's belief in their ability to be successful (Bandura, 1977), STEM self-efficacy specifically refers to a student's belief in their ability to be successful at STEM-related activities. Once a student has developed a high self-efficacy in a STEM academic area, they will be more likely to continue working toward a long-term goal related to that area, regardless of occasional failure or setback (Eccles, 2007; Rittmayer \& Beier, 2009). Therefore, students who develop a strong sense of STEM self-efficacy may be more likely to pursue STEM careers. 


\section{STEM Value}

STEM value is the importance that students place on knowing and being able to engage in STEM because of its usefulness in their personal lives and in the greater context of society (Vincent-Ruz \& Schunn, 2018). Research shows that students have differing perceptions of the value of STEM in these two domains. Students often recognize that STEM is valuable societally, but are not as likely to see science as useful to themselves (Sjøberg \& Schreiner, 2005). However, Ainley \& Ainley (2011) note that strongly valuing science is predictive of an interest in learning STEM. While their work does not distinguish between society and personal life, when taken with the findings of the ROSE survey (Jenkins \& Nelson, 2005; Sjøberg \& Schreiner, 2005), it is likely students who personally value science are more likely to purse STEM learning than those who see the value of STEM in society.

In summary, relevant STEM curricula can influence STEM attitudes, including: interest, identity, STEM self-efficacy, and STEM value. STEM interest is the combination of selfperceptions and curiosity towards STEM and STEM-related work. Identity and STEM selfefficacy are both self-perceptions, with identity focused on how students perceive themselves and self-efficacy focused on students' perception of their abilities to succeed at a given task. STEM value relates to the perceived usefulness of STEM to society and students' personal lives. Relevant curricula may lead to a positive increase in STEM constructs which may, in turn, lead to engagement and persistence in STEM classes and eventual STEM vocations.

\section{Conclusion}

Adventure STEM education is a new and still-developing field, and it has the potential to affect the lives of the students who take part in its programs by creating meaningful personal 
connections with curriculum. Adventure education seeks to educate multiple dimensions of the student by allowing them to learn and grow as individuals, while STEM education can inspire a greater interest in STEM curricula in schools and open new potential vocations. Together, the united disciplines have the potential to revitalize how students regard STEM classes in their schools by making science curricula more relevant. By increasing the relevance of STEM, adventure STEM education has the potential to make a strong positive change in West Virginia and beyond. 


\section{Chapter Three: Methods}

\section{Research Questions}

R1) How does adventure STEM curriculum affect the STEM interest, STEM career interest, STEM career knowledge, STEM self-efficacy, STEM value and STEM identity of students participating in SAS?

R2) How do students and teachers participating in SAS regard the relevancy of adventure STEM curriculum as contrasted with in-school curriculum?

\section{Research Design}

This is a mixed methods quasi-experimental study designed to both assess change in relevancy constructs within the context of SAS and gain a better understanding of how students perceive the relevancy of the adventure STEM curriculum. A mixed methods framework was chosen because of its pragmatic approach that seeks to combine the best of both quantitative and qualitative approaches into a flexible design (Maxcy, 2003). By using both approaches, it becomes possible to compensate for weaknesses in one methodology with strengths of the other (Johnson \& Onwuegbuzie, 2007).

Specifically, this study utilizes a concurrent triangulation design, which is used for crossvalidation within a single structure (Terrell, 2012). In this methodology, both qualitative and quantitative data are collected in the same phase of research, analyzed separately, and then integrated during the interpretation phase of the study (Terrell, 2012). Additional benefits of utilizing a triangulation-based study include increasing study validity and reducing method and researcher biases of the study (Greene et al., 1989).

Quantitative research is important for understanding the effect of the intervention on the treatment group (Bloomberg \& Volpe, 2008). In this case, the study seeks to explore the effects of SAS on students STEM attitudes. To quantitatively examine the relationship between 
adventure STEM curriculum and relevancy, a non-randomized quasi-experimental design with a both a treatment and control group was used. The treatment group consisted of the students who attended the SAS during the autumn of 2019, and the control group consisted of students from the same schools who did not attend the camp. The study was intentionally non-randomized, as the total treatment group of 393 sixth-grade students were include in the same sample. Priority was given to surveying all students to strengthen the foundation for making inferences based on the data by means of obtaining a larger sample size.

Qualitative research seeks to understand the social setting from the viewpoint of the participants (Bloomberg \& Volpe, 2008). It is similarly crucial to this research because it permits the opportunity to explore the thoughts of SAS participants with respect to STEM and how those perspectives have changed in relation to their time at SAS. For the qualitative portion of this study, a phenomenological approach is the most appropriate. As Van Manen (2016) describes, phenomenology is the reflection of the lived human experience. In particular, phenomenological research seeks to describe what all participants have in common as they experience a phenomenon (Creswell et al., 2003) and distill those experiences down to the universal essence of their interaction with the phenomenon (Van Manen, 2006). As this study seeks to understand how students and their teachers experience their curriculum both at the science camp and in the context of their schools, a phenomenological approach is a natural fit. In this case, the impact of the science camp curriculum is the "object of human experience" (Van Manen, 2016), which will be described and distilled. The phenomenological approach also follows a small number of subjects through their experience (Bloomberg \& Volpe, 2008), making it less intrusive to the treatment group of participants as a whole because fewer of them will be needed to achieve data saturation. 


\section{Situating the Researcher}

While it is always important for researchers to take their biases into account when embarking on a new project regardless of the research methodology, it is especially important in qualitative research, where the interpretation of the data is filtered through the lens of the researcher. While I never took part in an adventure- or STEM-based program as a child, I have always felt a keen affinity for the natural world, which arose from explorations in my backyard. As the area I grew up in has a similar socio-economic conditions to those of the sample population of this study, these types of opportunities were not available to me during childhood. In college, I maintained an interest in natural science, but never felt that I would find success in a scientific career path. While I love my life as an outdoor educator, I do sometimes wonder if I would have ended up in a different place given more opportunities. A more important source of bias is my involvement with this project is my role as the research graduate assistant for SAS. In addition to collecting data for my doctoral dissertation, I am also performing an internal evaluation of the program for the dual purpose of improving it for future years and as support for future funding proposals. I intend to be aware of my bias throughout all aspects of this research project, with the goal of gaining a better awareness of how adventure STEM curriculum affects youth outcomes.

\section{Setting}

The West Virginia SAS camp was hosted by the Summit Bechtel Reserve, a 14,000-acre stretch of property located in southern West Virginia. According to its website, the Summit is located in Fayette and Raleigh Counties near Beckley, West Virginia (Summit Bechtel Reserve, n.d.). It is one of the four major facilities that are managed by the Boy Scouts of America and it 
is home to the National Scout Jamboree. The Summit has three centers of activity: the Paul R. Christen National High Adventure Base, the James C. Justice National Scout Camp and the John D. Tickle Training and Leadership Center. These three centers can collectively host as many as 40,000 individuals overnight, and provide activities which include mountain biking, BMX biking, skateboarding, archery, rifle and shotgun shooting, zip-lining, canopy tours, swimming, scuba, challenge course, rock climbing, and rappelling. There are also interpretive trails, a wetlands boardwalk and a sustainability treehouse, which showcases the local ecosystem and sustainable technology.

Students attended the SAS from September through October of 2019 for four days of programming. Students and teachers attended camp for free through funding provided by private donors. They camped onsite in tents for three nights and received meals from the dining facility. Campsites were split evenly by gender with 3-4 students of the same gender assigned to one tent. Each group of 14 students was assigned two SAS instructors to accompany them throughout their time at the camp and serve as discussion facilitators and resources for support. One teacher from the students' schools was assigned to each group to assist instructors and provide continuity for teachers.

Students interacted with two kinds of staff on a daily basis: their assigned group facilitators and environmental and STEM education instructors. Both groups of staff took part in a week-long training prior to the beginning of SAS with emphasis on content delivery and group discussion facilitation. While there was some overlap in training, facilitator training focused most heavily focused on managing interpersonal relations, delivering group discussions, promoting individual and group growth, and creating an enjoyable camp experience. 
Environmental education and STEM education instructors' training revolved around delivering STEM or environmental education lessons related to their areas of focus.

\section{Sample}

The sample consisted primarily of public school sixth-grade grade students who came from rural counties located in south western West Virginia, along with one class of private school sixth-grade students from northern West Virginia. Specifically, sixth-grade students were targeted for this study as research shows that science interest markedly declines in middle school (Jenkins \& Nelson, 2005; Osborne, Simon, \& Collins, 2003). Eleven schools took part in the study. The racial and ethnic makeup of this experimental group was predominantly White or Caucasian at $74.4 \%$. Other groups included Black/African American at 4.1\%, Hispanic/Latino at $2 \%$, Asian at 1.2\%, Native Indian/Indigenous American Indian at .8\%, Two or More Races at $10.6 \%$, and Other at $3.3 \% .3 .7 \%$ of students chose not to disclose this demographic information. There was an almost even split between female and male students with $51.6 \%$ of students identifying as female, $47.6 \%$ of students identifying as male, and $.8 \%$ of students identifying as "other". Demographics for the control group were consistent with the treatment group. Population demographic estimates for West Virginia as a whole consist of White or Caucasian at 93.5\%, Black/African American at 3.6\%, Hispanic/Latino at 1.7\%, Asian at .8\%, Native Indian/Indigenous American Indian at .3\%, and Two or More Races at 1.8\% (United States Census Bureau, 2019). While the sample of this study is somewhat more diverse than the general population of the state, it is still relatively consistent with the state's demographics.

The treatment group sample size of the quantitative portion of this study consisted of 344 students from middle schools in Raleigh, Fayette, Nicholas, and Monongalia Counties. The 
control group consisted of 53 students from the same schools as the treatment group. Raleigh, Fayette, and Nicholas Counties are local to the study site area near Beckley, West Virginia, while Monongalia County is located in the northern part of the state.

The sample size of the qualitative portion of the study consisted of 14 students and 8 teachers. Student interviews were prioritized as their experiences were deemed most relevant to triangulate survey data, though the teachers' perspectives were also important to include. The number of interviewed participants was consistent with the recommendation that 5 to 25 individuals be interviewed in phenomenological studies (Polkinghorne, 1989). Students came from the same schools as the treatment population, and interviewed students also completed the survey. Generally, one student from each school was chosen to interview, though one school brought significantly more students than the others. Four students instead of one were interviewed from this school to ensure that enough interview data were collected and that the quantity of interviewed students was proportional to the number of students who attended the camp. Teachers came from the same school systems as the students. Racial demographic data were not collected from student or teacher interviews. Nine students identified as female and five students identified as male, while six teachers identified as female and two teachers identified as male.

\section{Participant Recruitment}

All sixth-grade students and teachers from the schools who attended SAS had an opportunity to participate in this study. To ensure ethical compliance, Institutional Review Board approval to conduct the study was secured before participants were recruited. During the recruitment process, parental and student consent forms were sent home with camp paperwork to 
ensure that guardians had ample time to consider their students' participation in the study. Consent forms explained the purpose of the study being performed and any potential impacts to the students. Parents were given contact information to permit additional questions regarding the study. School officials were also asked to secure participants for a control group and these students also had consent forms sent home for parental and student consent. Survey data collection only proceeded when both parents and students returned signed consent forms. Before participating in an interview, each student gave verbal recorded consent. Teachers who were interested in being interviewed were emailed consent forms to sign and return and also gave verbal recorded consent before their interview began.

For the quantitative portion of the study, convenience sampling was used. Convenience sampling is used when settings, groups, or individuals are conveniently available and are willing to participate in the study (Onwuegbuzie \& Collins, 2007). Due to limited numbers of available spaces for students, quotas were put in place, and teachers were given the ability to select attending students. All students who attended SAS and met the consent requirements were surveyed. While more randomized selection methods were considered, convenience sampling was ultimately chosen because all students could be accessed for study and surveying all students would result in a larger pool or data for analysis. By necessity, the control group students were also a convenience sample, which was generated via a direct request for teachers to secure a class of sixth-grade students who did not participate in the camp.

Student participants of the qualitative portion of the study were purposefully selected from each school. Purposeful sampling is used when the researcher needs to select individuals for the study that meet certain criteria (Onwuegbuzie \& Collins, 2007). Students were selected based on the recommendations of their teachers. Specifically, teachers were asked to choose 
students who were comfortable speaking and being recorded. Teachers were told that students did not need to like science or be strong academic performers, only that they be comfortable talking with a stranger and answering questions. This was done in an attempt to avoid interviewing only students with strong positive science attitudes. Students were chosen from each school to ensure a better understanding of population school systems. After a teacher provided a recommendation for a student to interview, the student was approached and asked if they would be interested in participating in the study. All students who were approached wanted to participate. In the event that a student did not wish to participate, another recommendation would have been sought from a teacher.

Teacher participants in the qualitative portion were a convenience sample. Due to the limited number of teachers from each school who attended, it was deemed best to approach all potential interview subjects with the goal of obtaining enough interview data. All teachers who attended SAS were sent an email asking for participation and given a brief overview of interview expectations. Teachers who were interested in participating were sent a follow-up email with more detailed instructions and a consent form.

\section{Treatment}

In comparison with one standard week of school, a week of camp consisted of four days of programming. Students' arrival time at camp depended on the distance traveled, but most schools generally arrived around midmorning on Tuesdays. Once they arrived, students immediately split up into groups, stowed their belongings in their tents, and then participated in a site orientation, introductory icebreakers, and a scavenger hunt session. Over the course of the four days, students participated in a variety of adventure STEM activities including Science 
Behind the Sport (SBTS) rock climbing, SBTS ziplining, and SBTS archery. They also took part in environmental education activities such as phenology and freshwater ecology, as well as positive youth development curricula that included end-of-activity and evening discussions.

Each day, students rotated through a variety of adventure STEM classes, which included content lessons with time spent doing the activity and applying the material in the moment. During their rock climbing class, they learned about the physics principles involved with climbing equipment and their body movements while climbing, as well as rock geology and its relation to climbing. Through zip-lining, they explored the forces exerted on them while ziplining and estimated their zip-lining speeds, and also learned more about forest ecology at each zip platform. In archery class, the students learned about the scientific principles behind a bow and the arrow's flight. Phenology lessons focused on identifying seasonal changes in the landscape. Finally, students also participated in a freshwater ecology activities, where they learned about the effects of pollution in water systems as they conducted a macroinvertebrate inventory in a stream that leads into the Summit's lake. Each evening the students had activity time where they chose an activity to try. Activities varied based on instructor interest but including things like fishing, tea drinking, slack lining, and a geology escape room. On Tuesday and Wednesday evening they also had focused discussions on fears related to transitioning to middle school and on positive self-talk. The night before leaving camp, the students participated in a celebratory campfire night. Prior to leaving on Friday, each class had an opportunity to complete the "Big Zip", a particularly tall and long zip line, and participated in a bead ceremony, which allowed them to recognize each other's strengths and accomplishments in the preceding days. 


\section{Measures}

\section{Survey Instrument}

Students were given a sixteen-item 5-point Likert-type survey instrument to assess vocational relevance, specifically STEM interest, STEM career interest, STEM self-efficacy, STEM identity, STEM value, and STEM career knowledge. The survey focused on the vocational domain of relevancy as this best aligns with a pragmatic view of program curriculum and outcomes. The SAS camp focuses its curriculum on adventure STEM instruction, making STEM-related attitudes more tightly linked to program outcomes. As the SAS camp's curriculum falls most heavily in the science domain of STEM, instruments using the term "science" were prioritized over items focusing on other STEM domains.

The survey began with demographic questions. This was both to allow the students to get used to the survey before proceeding to the more difficult questions, and to collect information that could provide context on the students' experience. To better pair pre- and post-surveys, students were asked to provide their schools, initials, teachers' name, and full birthdates. They were also asked to provide their genders, race, guardians' levels of education, and families' financial situation.

The survey instrument used in this research drew from two existing instruments. These instruments were chosen because they were designed for youth which made them more appropriate for sixth-grader survey comprehension. Additionally, both surveys came from studies situated in an informal STEM learning setting, making them more similar to the context of SAS. In order to maintain survey brevity for the students, full scales were not used, but 3 to 4 items for each construct were chosen. The first was from Vincent-Ruz \& Schunn's (2018) work focusing on the science competency beliefs in middle school children, which was chosen to 
evaluate the constructs of STEM self-efficacy, Science identity, and STEM value. Specifically STEM self-efficacy was evaluated by the items: "I think I am very good at coming up with questions about science.", "I think I am very good at doing experiments.", and "I can do the science activities I get in class." Science identity was evaluated by the items: "I am a science person.", "My family thinks of me as a science person.", and "My teachers/instructors thinks of me as a science person." Finally, STEM value was measured with: "Knowing science is important.", "Knowing science helps me understand how the world works.", and "Thinking like a scientist will help me do well." According to the aforementioned researchers (Vincent-Ruz \& Schunn, 2018), the survey was developed to meet the reading levels of a diverse group of middle school students from different genders and ethnicities. It was also designed to measure the general domain of science rather than school in general or specific science subjects, and with strong instrument psychometrics that were validated and tested by their authors. These factors made this survey ideal for work with SAS. Individual items were chosen based on their relevancy to SAS.

The second instrument used in this project, the Science Opinion Survey, used in this project comes from Gibson \& Chase's (2002) work with the attitudes of middle school students toward science. This instrument was used to evaluate the constructs of STEM interest and STEM career interest. STEM interest was measured with the statements: "Science lessons are fun.", "I would like to learn more about science.", and "Science is one of the most interesting school subjects." The Science Opinion Survey consists of 30 statements and was originally created for the National Assessment of Education Progress to assess subject areas across the United States (Gibson \& Chase, 2002), and it was written to accommodate middle school reading levels. Although it was not an item from Gibson \& Chase's (2002) research, students were also asked to 
name three potential STEM careers to evaluate whether their knowledge of STEM career options changed after spending time at the SAS.

The survey instrument was designed with the needs of children in mind. The survey was as short as possible, with items from middle school-based surveys that include age-appropriate language and sentence structure (Christensen, 2017). As Likert scales can sometimes be more difficult for youth, the survey ranking system used words instead of numbers (Mellor, 2013). Though surveys can be tedious for students, particularly young ones, all effort was made to ease the survey-taking experience of taking the survey.

\section{Interview Protocol}

Fourteen semi-structured, in-person interviews were conducted with students immediately following SAS. In-person interviews were chosen because they both capture a participant's state of mind and allow for the observation of gestures and tonal inflection, which can add additional shades of meaning to spoken words (Harrell \& Bradley, 2009). Semistructured interviews have been chosen for their adaptability as they give the option of pursuing additional avenues of inquiry based on the information that the participant relates (Harrell \& Bradley, 2009). This flexibility can lead to deeper and more nuanced answers from participants (Harrell \& Bradley, 2009). In keeping with a phenomenological approach, interview questions were open-ended and sought to ask the two broad questions central to this research approach: "What have you experienced in terms of the phenomenon?" and "What contexts or situations have typically influenced or affected your experiences of the phenomenon?” (Moustakas, 1994) in a manner that would be assessable in light of the context and age of the participants. 
The interview protocol for students drew from two previous studies. The first was Hughes, Nzekwe, and Molyneaux's (2013) study which looked at the formation of STEM identity in middle school students attending informal science programs, particularly in regard to gender. Though the study focused on science identity, many of its questions were well suited for being adapted to other constructs. The questions "What is your favorite subject in school?" and "What is your least favorite subject in school?" were used to assess science interest. "What was science like in elementary school/middle school?" was used to gain an idea of previous exposure to STEM material. The questions "What are your current science and math courses like?" and "What do you enjoy and what do you dislike about these classes?" were important to learn more about STEM interest. "What do you think most people would picture when they think of a scientists or engineer?" and "How do you think of a scientist of engineer?" were used to assess science identity. Finally, "What career would you like to have and why?" was used to assess STEM career identity.

The other study we adapted interview questions from looked at STEM-based outcomes (Sahin, Ayar \& Adiguzel, 2014) in 10 students from $5^{\text {th }}, 6^{\text {th }}, 7^{\text {th }}$, and $9^{\text {th }}$ grade with the goal of understanding student experience and learning in after-school STEM programs. As with the previous study, differing contexts required that questions be adapted to better fit the research goals of this study. However, the following question informed the final interview protocol, "To you, what are the similarities and differences between your regular class activities and the things you do in the STEM after-school activities?" and was adapted to ask students about the differences they saw between science class and SAS.

Existing interview protocols could not be located for some constructs of interests, so questions were created independently of existing literature, though they were informed by 
corresponding survey items when possible. For instance, the question "Do you think science is important to learn about? Why?" was used assess STEM value and related to the survey item "Knowing science is important". Other questions unrelated to existing interview protocols included "Have you ever studied science before?" and "How would you define science" which were used to gauge previous exposure to STEM activities in the classroom. "Do your parents or caregivers work?" and "What kinds of jobs do they do?" sought to elicit potential influences in STEM attitudes from the student's family. Finally, "What do you think you learned by participating in Science Adventure School?" gave students a chance to talk about potential changes in STEM self-efficacy, and "Can you tell me about what part of the Science Adventure School made the biggest impact on you?" was used to gain general insights into SAS and allow students to talk about anything else that they felt was important to their SAS experience.

Teachers' interviews were less focused on specific STEM constructs. This was because teachers had only been with students for a short time before attending SAS, or in some instances, were not one of the students' main teachers. It would not be realistic for teachers to be able to assess changes in specific constructs without having deeper baseline knowledge of their students. Instead, teachers were asked more general questions with the goal of connecting their insights to constructs during the data analysis process of coding.

Their interview protocol was also informed by Hughes, Nzekwe, and Molyneaux's (2013) study. Specifically, the questions "Did you notice any changes in the participants from start to finish? Can you give examples?", "Did you notice any changes in the participants' views of science? Can you give examples?", "What activities do you think had the largest effect on participants? Why?", and "Which activities were your favorites? Why?" were all questions that were borrowed from that earlier study to interview teachers. The question "Did you notice any 
changes in the participants' views of science?" was further adapted to ask about changes in students' attitudes about themselves and potential changes in their classroom communities, and to gain more information about potential social influences on STEM attitudes.

Some questions were not based in prior literature, but were asked to collect baseline data about the teachers and their interests in the SAS in order to improve programming. Because factors related to teachers and their choice to attend SAS could affect the attitudes of students who went to SAS, several questions were asked to gain a better picture of the participating teachers. These included "What subject do you each", "How long have you been teaching?", "What grades have you taught?", "Why did you decided to bring your class to Science Adventure School?", and "What kind of teaching techniques do you use in your classroom?"

In the cases of both student and teacher interviews, the questions were structured so that more easily answered questions such as demographic information were asked first (Doody \& Noonan, 2013). Questions that required more thought or could be thought of as more personal were deliberately placed towards the middle or end of the interview, so that participants had time to become familiar with the interview process and build rapport with the interviewer (Doody \& Noonan, 2013). In both cases, the interview ended with a question asking if the participant had anything else to add, in order to collect any additional thoughts by the participant and to provide a transition to the end of the interview. Interviews were structured this way to both increase comfort for the interviewee and gain better quality data (Doody \& Noonan, 2013).

\section{Data Collection}

To achieve its research objectives, this study utilized a mixed methods concurrent triangulation design, meaning both qualitative and quantitative data were be collected 
simultaneously (Terrell, 2012). The quantitative portion of the study was conducted over the course of two months (September 2019 through October 2019). All students were asked to voluntarily participate in this study. Those who chose to participate were given a survey while at their schools on the Monday before they attended camp. Survey administration method varied by school capabilities. All treatment surveys were administered digitally using Qualtrics software (Snow \& Mann, 2013) through desktop computers, laptops, or tablets. All control group surveys were administered via paper survey. As student reliability in completing surveys cannot always be assumed, using two separate survey media was done deliberately to guarantee that the two samples surveys could not inadvertently become mixed.

The same survey was re-administered post-camp. In most cases, this meant that students took the post-survey on the Monday after returning from camp, a week after taking the presurvey. One school was unable to accommodate this time frame due to state-mandated testing, so that school was rescheduled for the next week's collection period. The settings for data collection varied by each school's ability to accommodate the number of students in each group. Surveys were taken in cafeterias, school libraries, classrooms, or computer labs. Survey administration took between 30 minutes to an hour depending on school capabilities. Multiple schools were visited during each data collection day, so students took surveys based on school schedule availability. Though not necessarily at the same time, survey data collection always occurred during normal school operation hours.

In all but one instance, at least one teacher or other school staff member was available to monitor students during data collection. The researcher introduced the survey and gave students instructions for taking the survey. They were reminded that they did not have to take the survey, were allowed to skip questions, and could end the survey at any time without any consequences. 
With the exception of two data collection days, two staff from SAS were also present during data collection to provide assistance. SAS staff, teachers, and administrators were instructed that they could assist students with reading comprehension or other general questions but should not answer questions for students.

The qualitative component of this study had two phases. All interviews were recorded with a digital recorder in both phases. The student interviews took place concurrently with the post-survey administration. Upon arrival at the school, the researcher solicited suggestions from teachers to find a student who was well suited for an interview. The student was approached while they completed their survey. Upon granting consent, the student was instructed to report to the primary researcher when their survey was completed. Before beginning the interview, all students were reminded that they could skip questions or end the interview whenever they wanted. The recorder was then started and students were asked to give verbal consent to the interviews before moving through the interview protocol. In one instance, the digital recorder lost power. When this occurred, the interview continued and the researcher took notes on the remainder of the interview.

When possible, interviews were given in an empty classroom. To ensure student safety, doors were left open with a school staff member in close proximity. When setting constraints did not allow for a separate room for interviews, students were positioned as far away from others as possible. In all cases, students were out of earshot of others. While interviewing in a non-private setting was not ideal, the researcher strove to optimize the situation given the limited options imposed by practical school constraints.

Teacher interviews took place after student data collection was completed (late October 2019 through November 2019). Interviews took place via telephone with the researcher in a 
secure, private location which no chance of being overheard. Before the interview began, all participants were reminded that they could skip questions or end the interview whenever they wanted. The recorder was then started and teachers were asked to give verbal consent to the interview, before reviewing through the interview protocol. There was also one unexpected recorder failure during one of the teacher interviews, which was treated the same as when this occurred during the student interview. Interview notes can be found in Appendix H.

To ensure ethical collection of data, no participant names were collected as part of either the student or teacher surveys. However, the initials of the teachers were kept with the interview transcripts for the respective teachers to allow them to be contacted for member checking. "Member checking" refers to the process in which an interview subject is given access to the interview material to further verify the accuracy of the transcription (Shenton, 2004). Student survey participants were also asked to give their birthdays and initials to assist with pairing their responses for data analysis. Consent to proceed with data collection was collected during each phase of data collection and participants were frequently reminded of their right to terminate the study at any point. All information was de-identified during the data cleaning process and kept confidential. To ensure that participants did not feel pressured to participate in the study, no incentives were given. However, stickers were made available for the duration of the survey data collection for any student who wanted one to express gratitude for their participation. It was emphasized that students could take stickers even if they did not participate in the survey.

\section{Data Analysis}

Data collection and analysis occurred simultaneously, and findings were compared after individual analysis. Quantitative data consisted of information collected from students using the 
survey instrument. Before data could be analyzed it had to be prepared and cleaned. All presurvey data was manually entered into an Excel spreadsheet. Post-survey data was matched to pre-survey data by comparing birthdate, school, and main teacher name. Survey data that could not be matched or that was missing either a pre- or post-survey was eliminated from the data set. Survey data that could be matched but which contained more than three skipped questions in total or more than one skipped question in a single construct were eliminated In the event that a survey had less than three skipped questions, the average was taken for the other items associated with that construct and substituted in for the missing question (Huisman, 1999). For example, if a student had answered two of the three STEM self-efficacy items with a "2" and a " 4 ", the average would have been taken for the two answered items and a "3" would have been used to fill in the skipped item.

The data for STEM career knowledge was treated differently than the rest of the STEM construct data. For this item, students were asked to name three different STEM careers. These answers were scored by hand with "1" equating to no correct answers or a skipped question and "4" equating to the student naming three STEM careers. Answers were evaluated with any recognized STEM career accepted as a correct answer. Answers such as "zip line guide" were also accepted because students were exposed to these careers in conjunction with STEM at SAS. Answers that did not correspond either to a known career or to a non-traditional STEM career to which students would have been exposed at SAS were not accepted. Incorrect answers included entries such as "football player", "dancer" or "actor".

Once data was cleaned, Statistical Package for Social Science (SPSS) software was used to compare the mean pre- and post-survey difference of each construct by individual student through the use of a paired t-test analysis (Hsu \& Lachenbruch, 2005). A paired t-test analysis is 
a statistical procedure used to assess whether the mean difference between a set of observations is zero and is frequently used in test and re-test research designs (Hsu \& Lachenbruch, 2005). Because analysis was done at the individual level, data from private school students were not removed. A frequency analysis was used to compute demographic information. Cronbach's alpha, which estimates the internal consistency of responses in multi-item scales (Vaske et al., 2017), was calculated for each construct's survey item.

Qualitative data analysis included the information from students and teachers, though each sample was analyzed individually. After interviews were recorded, they were transcribed verbatim by the researcher. Transcribing by hand provided an opportunity to gain initial familiarity with the interview data. Any identifying information was removed during the transcription process. Transcriptions of teacher interviews were emailed to each respective teacher for member checking.

After the data was prepared, conventional content analysis was used to identity relevant pieces of data for further analysis (Hsieh \& Shannon, 2005; Bowen, 2009). This technique is an established method for looking at text-based data (Thorne, 1994) on a phenomenon where literature is limited (Hsieh \& Shannon, 2005). A priori codes were established before analysis began. A priori codes are used when specific outcomes are sought from the qualitative data (Saldaña, 2016), and are also necessary to integrate data after analysis in mixed methods studies with concurrent triangulation designs (Greene et al., 1989). In this study, a priori codes consisted of the STEM constructs assessed by the survey questionnaire. Codes were also allowed to emerge as a result of the coding process (Saldaña, 2016).

Student and teacher interviews were examined separately. Data analysis for each began by reading the data repeatedly to fully immerse the researcher in the data and form an initial 
impression of the relationship between interviews (Hsieh \& Shannon, 2005; Bowen, 2009). Transcripts were then read word-for-word to capture key thoughts and concepts. (Hsieh \& Shannon, 2005). These impressions were analyzed to generate codes associated with each key piece of text (Hsieh \& Shannon, 2005). Next, Dedoose software was used to code transcripts with both a priori and emergent codes (Taylor \& Treacy, 2013). Codes were categorized based on their relationships and linkages to other codes, and categories were clustered into meaningful themes (Hsieh \& Shannon, 2005). Subthemes were generated as they emerged and organized into a hierarchical structure with the corresponding exemplary text (Hsieh \& Shannon, 2005). Data analysis was considered complete upon emergence of a consistent picture of how students and teachers viewed the curriculum (Bowen, 2009). Themes were then compared for frequency of appearance across the corresponding pool of student or teacher interviews. In qualitative research, frequency of code or theme is not considered as important as breadth of experience (Saldaña, 2016). However, as the guiding research framework primarily seeks to triangulate methods, only the themes that were mentioned at least $50 \%$ of the time are further discussed in Chapter 5. Less frequently mentioned codes and themes can be found in Appendix I and J. Coding followed Saldaña's (2016) approach, with the researcher performing the bulk of the coding, and associated assistants providing collaborative coding throughout the process for the purpose of providing a "crowd sourcing reality check (p. 38)" to ensure that codes authentically represented the data. A quantitative intercoder agreement approach was considered, but ultimately rejected as some methodologists question the utility of the practice in an interpretive process and instead favor in-depth discussion with group consensus as being truer to the discipline. As the next step in the coding process, two researchers independent of the project were recruited to review the data. One was given the student interviews to review, while the 
other received the teacher interviews. They examined the data, making their own notes and generating their own codes and themes, before the group met to discuss findings (Saldaña, 2016). Discussion continued until all involved had reached a consensus on the codes and themes. (Saldaña, 2016).

\section{Data Integration}

Quantitative and qualitative data were analyzed separately following a concurrent triangulation strategy (Terrel, 2012). After findings for were each were finalized, the results were compared during the interpretation phase of the study to search for similarities and differences between the two datasets (Terrel, 2012). Specifically, the results of each survey construct were compared with the instances where the same construct emerged or did not emerge from interview data. These results are integrated and presented together in Chapter 5.

\section{Trustworthiness}

Both quantitative and qualitative methodology seek to demonstrate trustworthiness in results. However, each methodology uses different constructs to assess this quality. Quantitative methods focus on internal and external validity, reliability, and objectivity (Lincoln \& Guba, 1985), while qualitative methods assess credibility, transferability, dependability, and confirmability (Guba, 1981). The following section will explore quantitative and qualitative trustworthiness in relation to this study's methodology. 


\section{Quantitative}

A quantitative approach seeks to establish trustworthiness of findings through internal and external validity, reliability and objectivity (Lincoln \& Guba, 1985). Internal validity refers to how well a study establishes a relationship between a treatment and an outcome (Heffner, 2017), and can be improved through random selection and randomization, blinding, experimental manipulation, and careful adherence to study protocol to limit the possibility of affecting the outcome (Trochim, 2006). Due to study constraints, it was not possible to introduce random selection or randomization, although experimental manipulation was introduced through the use of a control group. Additionally, internal validity is further supported through the avoidance of the threats to internal validity outlined by Campbell and Stanley (1966). Efforts to ensure such threat avoidance included conducting the study over a short duration of time and administering data collection instruments as consistently as possible (Campbell and Stanley, 1966).

External validity refers to the degree to which a study can be applied to other settings (Trochim, 2006). One of the most important factors of external validity is choosing a sample that can represent the chosen population and ensuring that the sample size is large enough (Landreneau, 2009). It can be improved by using statistical analysis to control for experimental group characteristics, by replicating the study, by conducting a study in a natural setting, and by clearly defining the population (Trochim, 2006). This study's sample size supports some generalization to sixth-grade youth of similar socio-economic background, but it is not broadly generalizable as a result of the use of a convenience sample. Randomized sampling is best suited to support study generalizability (Thomas, 2009).

A study that is reliable is able to show similar outcomes if replicated (Trochim, 2006). There are three types of reliability: test-retest, interrater, and internal consistency (Trochim, 
2006). Test-retest and interrater reliability would require that this study be repeated, which has not happened at the time of this paper's writing. Internal consistency can be calculated using statistics, which has been done using Cronbach's alpha (Trochim, 2006). Alphas indicate a reasonable level of internal consistency in the survey and are discussed later (p. 74).

Finally, objectivity in a study refers to the ability of the researcher to remain objective with respect to the work (Payne \& Payne, 2004). While bias is inherently human, objectivity can be achieved through admission of biases and consideration of the same as potential impacts on a study. Implicit biases in this study have already been explored (p. 45). Maximum effort was expended to avoid the effects of bias by remaining at a distance from SAS programming and participants, other than in the context of data collection. The oversight of peers and academic mentors throughout the research process further mitigated potential effect of bias.

\section{Qualitative}

The trustworthiness of qualitative data is sometimes called into question because validity and reliability cannot be addressed in the same manner in quantitative work (Shenton, 2004). However, qualitative researchers have their own means of establishing the trustworthiness of their work with corresponding four corresponding constructs: credibility, transferability, dependability, and confirmability (Guba, 1981). Each construct will be examined in relation to the current study.

Credibility is one of the most important factors in establishing trustworthiness (Lincoln \& Guba, 1985) and refers to how well a study's findings match reality (Merriam, 1998). Several of the steps outlined in Shenton (2004) were taken to ensure credibility. First, this study uses established research methods and is grounded in prior social science research in the STEM, 
education, and outdoor education disciplines. The researcher was also acquainted with SAS through her capacity as the graduate assistant for the program, which led to a familiarity with the organization's structure and methods, and to knowledge about the participants in the program. While this study did not employ triangulation through other qualitative methods, it was achieved quantitatively by means of survey implementation and by seeking the viewpoints of both students and teachers (Shenton, 2004). Participants were well informed of their right to leave the study at any time, addressing Shenton's (2004) point that tactics should help ensure honesty. Peer scrutiny was used throughout the study through the assistance of the dissertation committee and independent peer graduate students (Shenton, 2004). Teachers were also given the opportunity to view their interview transcripts to provide member checking (Shenton, 2004). Though not all strategies for ensuring credibility could be addressed (i.e. random sampling), as many as aligned with the study's design and constraints were employed to ensure the most credible study possible.

Transferability refers to the degree that a study's results can be applied to other situations (Merriam, 1998). However, since findings in qualitative research involve a small number of subjects and are highly contextual to their situations, it is often not appropriate to consider transferability to a broader group. In instances where transferability may be applicable, it is important to have a full understanding of the elements of the study, including: the organizations taking part, any restrictions in the type of participant contributing to study, number of participants, data collection methods, number and length of data collection sessions, and the time period when data was collected (Shenton, 2004). Based on the interview data with students and teachers, the qualitative portion of this study is not transferable. This is primarily due to the convenience and purposive sampling used to select participants. Though an effort was made to 
prevent this, the majority of students interviewed had established interests in STEM subjects before attending SAS. While teacher interviews were likely less biased than students', not enough information on their backgrounds was collected to understand their potential biases (Merriam, 1998).

Dependability seeks to show that similar results would be obtained if the study were repeated under the same set of circumstances (Shenton, 2004). Like transferability, dependability can be difficult to achieve given that qualitative methods are contextual to time, place, and people. Researchers often rely on the study's credibility to bolster its dependability (Lincoln \& Gupta, 1985), which can also be satisfied by keeping detailed records of the research design and implementation, data gathering details, and reflective appraisal of the project (Shenton, 2004). Detailed notes of the research process were recorded, including rich description of methods and analysis which lends dependability to this study. In future research, more information could be collected from the teachers regarding their backgrounds and motivations in order to further strengthen dependability.

Finally, confirmability refers to the researcher's concern for potential sources of bias. As a result, steps must be taken throughout the research process to ensure that data are derived from the participants' own experiences and remain uncolored by the researcher (Shenton, 2004). Confirmability relies on both triangulation (Shenton, 2004) and the ability of the researcher to understand her own potential biases and note the reason for decisions made throughout the research process (Miles \& Huberman, 1994). The primary researcher in this study has done her best to represent her actions and beliefs as honestly as possible, and given the triangulated research design, she believes that this study achieved confirmability. 


\section{Limitations}

As with any study, some limitations were inevitable. Student reading level was a major limitation to the study. Though the survey instrument was compiled from prior research aimed at middle school youth, many students in the sample struggled with reading the survey questions. For example, it became apparent that students could not answer the demographic question concerning families' financial situation, leading to the question to be removed from analysis. This may have been because these were new sixth-grade students who had not yet attained baseline middle school reading levels. Teachers also anecdotally reported inadequacies in elementary reading curricula within their school districts, which allowed weak readers to slip through grade level requirements and be promoted to the next grade level. When possible, research volunteers and attending teachers were assigned to assist struggling readers with survey comprehension. In some instances, struggling students were still overlooked either due to time constrains or their understandable unwillingness to request assistance. This led to incomplete or inaccurate surveys that may have impacted the resulting data (Price \& Murnan, 2004), particularly the control group which was much smaller than the experimental group.

The smaller sample size of the control had its own associated limitations (Price \& Murnan, 2004). Because SAS took place near the beginning of the school year, teachers were often rushed to complete field trip-related paperwork. SAS required many documents to be filled out before teachers could attend, and some teachers viewed the additional work of sending parental consent forms home to parents in the control group as an unnecessary burden. While entirely understandable on the part of the teachers, this caused a large portion of the original control group to be eliminated because missing parental consent forms. 
Small sample size could have also influenced the control group's survey responses, which showed lower scores than the experimental group (Price \& Murnan, 2004). Based on the pre-survey scores, the two samples appear dissimilar, which lowers the trustworthiness of the study's results (Price \& Murnan, 2004). The contrasting survey scores could have also been influenced by the non-random nature of participant selection. As Hughes et al. (2007) points out was also a limitation in their study, the teachers who attended SAS were self-selected and allowed to choose the students that attended SAS. Their interest in the opportunity to attend SAS may indicate a bias toward STEM and a preference for experiential learning. Their ability to select students to attend may have influenced the experimental population by favoring students with stronger academics or those who already had positive attitudes or interest in science. A final potential explanation of differing survey score results could be the students' knowledge of their camp attendance. The experimental group knew that they would be attending SAS, while the control group knew that they would not be attending. SAS attendance may have influenced experimental group students to interpret the survey more positively, while control group students could have interpreted it more negatively (Price \& Murnan, 2004).

Student interview results were also constrained by the high number of students who indicated positive interest in STEM before SAS. Teachers were first asked to select students who would be comfortable being interviewed by a stranger, and later asked to select students who did not show a preference for science, but they may have either knowingly or unknowingly chosen students with a positive view of science in an attempt to help the research study find positive results (Price \& Murnan, 2004). In some instances, the teacher assisting in research collection did not teach the students directly. They knew students well enough through reputation to choose one who would be comfortable talking, but they could only guess at their academic interests. 
Additionally, prior experience with STEM was not assessed with the survey sample and prior experience with outdoor activities was not assessed with either quantitative or qualitative samples. Students' unknown previous experience participating in these types of activities, either with their families or in school or club contexts, limits the degree of change that can be inferred from the SAS experience.

One of the most significant potential limitations is the unknown relationship between the SAS experience and the students' return to their classrooms. This study assumes that there was a transference of learning from SAS to the classroom, and that students who participated in SAS connected their learning at SAS to their school environments. However, as Brown (2010) points out in his work examining transference, this may not have happened. In the same way that students associate their classroom science with boredom, they may associate SAS with a fieldtrip type of experience that is engaging and amusing, but ultimately separate from their classrooms (Brown, 2010). This may lead to more ephemeral attitude changes toward STEM.

Even if transference is assumed to occur, it is unknown whether this effect will endure and impact students as they move on through the school year and progress to further grades. There is some anecdotal evidence collected during the interview of a teacher who participated in the prior SAS pilot study that suggests that students who participated in the pilot continued to maintain strong social bonds with each other and their accompanying teachers. However, one interview is not enough to verify this claim, and there is no data, anecdotal or otherwise, that would support the continuation of positive STEM attitudes and perceptions of relevancy at SAS beyond short-term changes. Based on Chawla's (1998) work it may be theorized that SAS could serve as a catalyst to maintain positive STEM values as students age. However, these effects are 
conjecture. Additional longitudinal research would need to take place to ascertain whether or not SAS has lasting effects on its participants. 


\section{Chapter Four: Results}

\section{Quantitative Results}

Quantitative results consisted of surveys for a treatment and control group of students. The guiding research question for this portion of the study was: "How does adventure STEM curriculum affect the STEM interest, STEM career interest, STEM career knowledge, STEM self-efficacy, STEM value and STEM identity of students participating in SAS?”

\section{Student Surveys}

Of the group of 393 sixth-grade students from eleven schools who attended the SAS, 344 students were surveyed, yielding a completion rate of $87.5 \%$. Of the 344 surveys administered, 98 were eliminated due to incomplete or inconsistent results or the absence of the student from either the pre- or post-survey, leaving a total of 246 completed surveys and a final overall response rate of $62.6 \%$.

Seventy-four sixth-students from six schools who did not attend SAS were surveyed to establish a control group. Of these surveys, 22 were eliminated due to incomplete or inconsistent results or the absence of the student from either the pre- or post-survey, which left a total of 53 completed surveys and a final response rate of $71.6 \%$. The racial and ethnic makeup of the control group was similar to that of the experimental group with the majority of students White or Caucasian (86.5\%). Other groups included Two or More Races at 3.8\%, Other at 1.9\%, and $7.7 \%$ of students chose not to disclose this information. The control also had a similar make-up of female $(51.9 \%)$ and male $(48.1 \%)$ students.

A paired t-test analysis of the test and control group was used to determine significant changes in science attitudes between the pre- and post- test scores. Based on data from the 246 
completed surveys in the experimental group, there were significant increases in two items from the science identity scale, one item from the science value scale, one item from the science selfefficacy scale, one item from the science career interest scale, and in the science career knowledge item (see Table 1). There was one significant decrease in one item on the science value scale.

There were no significant changes from pre-test to post-test found for the 53 paired surveys from the control group (see Table 2). However, pre-test scores of the control group were lower than those of the experimental group indicating a potential limitation within the data. An individual t-test was run to compare the two samples' pre-test scores. Results revealed a significant difference between the two groups in all but one construct.

For the science identity construct "My family thinks of me as a "science person.", there was an increase from pre-test $(M=3.02)$ to post-test $(M=3.24)$ of significance $(.004)$. Additionally, in the science identity construct "My teachers/instructors think of me as a "science person.", there was an increase from pre-test $(\mathrm{M}=3.11)$ to post-test $(\mathrm{M}=3.40)$ of significance $(.000)$.

For the science value construct "Knowing science is important.", there was a decrease from pre-test $(M=4.61)$ to post-test $(M=4.48)$ of significance (.038). For the science value construct "Thinking like a scientist will help me do well.", there was an increase from pre-test $(\mathrm{M}=3.85)$ to post-test $(\mathrm{M}=4.06)$ of significance $(.007)$.

For the science self-efficacy construct "I think I am very good at coming up with questions about science.", there was an increase from pre-test $(\mathrm{M}=3.14)$ to post-test $(\mathrm{M}=3.70)$ of significance (.000). 
For the science career interest construct "I would like to be a scientist when I leave school.", there was an increase from pre-test $(\mathrm{M}=2.93)$ to post-test $(\mathrm{M}=3.21)$ of significance $(.001)$.

There was also an increase from pre-test $(\mathrm{M}=3.08)$ to post-test $(\mathrm{M}=3.32)$ of significance (.000) in science career knowledge.

Cronbach's alpha statistic was run for both the pre- and post- survey results of the test group with post-test alpha values higher than pre-test. It is generally accepted that a Cronbach's alpha in the range of $.65-.80$ is adequate (Vaske, 2008) though more specifically alphas greater than or equal to .9 are excellent, $.8-.9$ is good, $.8-.7$ is acceptable, $.6-.7$ are questionable, and .5 - .6 are poor (Glen, 2014). Acceptable pre-test values were found for STEM interest (.78), STEM career interest (.745), and STEM identity (.752), and poor values for STEM self-efficacy (.59), and STEM value (.584). All post-test alpha values for STEM interest (.832), STEM career interest (.822), and STEM identity (.816) were good while STEM self-efficacy (.702), and STEM value (.791) were acceptable. 
Table One: Summary of Paired T-Test for Treatment Group

\begin{tabular}{|c|c|c|c|c|c|c|c|}
\hline Construct & Item & $\begin{array}{l}\text { Pre } \\
\text { Mean }\end{array}$ & $\begin{array}{l}\text { Post } \\
\text { Mean }\end{array}$ & $\begin{array}{l}\text { Mean } \\
\text { Change }\end{array}$ & $\begin{array}{l}\text { Standard } \\
\text { Deviation }\end{array}$ & $\mathrm{t}$ & $\begin{array}{l}\text { Significance } \\
\text { (2-tailed) }\end{array}$ \\
\hline \multirow[t]{3}{*}{$\begin{array}{l}\text { STEM Self- } \\
\text { Efficacy }\end{array}$} & $\begin{array}{l}\text { I think I am very good at coming up with } \\
\text { questions about science. }\end{array}$ & 3.41 & 3.70 & +.29 & 1.240 & -3.652 & .000 \\
\hline & I think I am very good at doing experiments. & 4.08 & 4.03 & -.05 & 1.256 & .660 & .510 \\
\hline & I can do the science activities I get in class. & 4.46 & 4.48 & +.02 & .932 & -.342 & .733 \\
\hline \multirow[t]{3}{*}{ STEM Interest } & Science lessons are fun. & 4.31 & 4.35 & +.04 & .985 & -.647 & .518 \\
\hline & I would like to learn more about science. & 4.28 & 4.17 & -.11 & 1.186 & 1.505 & .134 \\
\hline & $\begin{array}{l}\text { Science is one of the most interesting school } \\
\text { subjects. }\end{array}$ & 4.02 & 4.06 & +.04 & 1.089 & -.644 & .520 \\
\hline \multirow[t]{3}{*}{$\begin{array}{l}\text { STEM Career } \\
\text { Interest }\end{array}$} & $\begin{array}{l}\text { When I leave school, I would like to work with } \\
\text { people who make discoveries in science. }\end{array}$ & 3.47 & 3.53 & +.06 & 1.340 & -.714 & .476 \\
\hline & A job as a scientist would be interesting. & 3.93 & 3.90 & -.03 & 1.148 & .389 & .698 \\
\hline & $\begin{array}{l}\text { I would like to be a scientist when I leave } \\
\text { school. }\end{array}$ & 2.93 & 3.21 & +.28 & 1.300 & -3.433 & .001 \\
\hline $\begin{array}{l}\text { STEM Career } \\
\text { Knowledge }\end{array}$ & Name three potential STEM careers. & 3.08 & 3.32 & +.24 & 1.025 & -3.732 & .000 \\
\hline \multirow[t]{3}{*}{ STEM Identity } & I am a science person. & 3.68 & 3.70 & +.02 & 1.239 & -.206 & .837 \\
\hline & $\begin{array}{l}\text { My family thinks of me as a "science } \\
\text { person." }\end{array}$ & 3.02 & 3.24 & +.22 & 1.189 & -2.897 & .004 \\
\hline & $\begin{array}{l}\text { My teachers/instructors think of me as a } \\
\text { "science person." }\end{array}$ & 3.11 & 3.40 & +.29 & 1.096 & -4.129 & .000 \\
\hline \multirow[t]{3}{*}{ STEM Value } & Knowing science is important. & 4.61 & 4.48 & -.13 & .946 & 2.090 & .038 \\
\hline & $\begin{array}{l}\text { Knowing science helps me understand how the } \\
\text { world works. }\end{array}$ & 4.24 & 4.24 & 0 & 1.168 & -.109 & .913 \\
\hline & $\begin{array}{l}\text { Thinking like a scientist will help me do } \\
\text { well. }\end{array}$ & 3.85 & 4.06 & +.21 & 1.196 & -2.719 & .007 \\
\hline
\end{tabular}

Significance at $\alpha=.05, d f=245$

Response scale of 1-5, for all except STEM Career Knowledge with higher numbers corresponding to higher level of agreement Bolded text denotes significant items. 


\begin{tabular}{|c|c|c|c|c|c|c|c|}
\hline Construct & Item & $\begin{array}{l}\text { Pre } \\
\text { Mean }\end{array}$ & $\begin{array}{l}\text { Post } \\
\text { Mean }\end{array}$ & $\begin{array}{l}\text { Mean } \\
\text { Change }\end{array}$ & $\begin{array}{l}\text { Standard } \\
\text { Deviation }\end{array}$ & $\mathrm{t}$ & $\begin{array}{l}\text { Significance } \\
\text { (2-tailed) }\end{array}$ \\
\hline \multirow[t]{3}{*}{$\begin{array}{l}\text { STEM Self- } \\
\text { Efficacy }\end{array}$} & $\begin{array}{l}\text { I think I am very good at coming up with } \\
\text { questions about science. }\end{array}$ & 2.87 & 2.98 & +.11 & 1.491 & -.428 & .579 \\
\hline & I think I am very good at doing experiments. & 3.77 & 3.63 & -.14 & 1.329 & .731 & .468 \\
\hline & I can do the science activities I get in class. & 3.83 & 3.90 & +.07 & 1.296 & -4.280 & .671 \\
\hline \multirow[t]{3}{*}{ STEM Interest } & Science lessons are fun. & 3.71 & 3.75 & +.04 & 1.357 & -.204 & .839 \\
\hline & I would like to learn more about science. & 3.62 & 3.56 & -.06 & .826 & .503 & .617 \\
\hline & $\begin{array}{l}\text { Science is one of the most interesting school } \\
\text { subjects. }\end{array}$ & 3.31 & 3.15 & -.16 & 1.211 & .916 & .364 \\
\hline \multirow[t]{3}{*}{$\begin{array}{l}\text { STEM Career } \\
\text { Interest }\end{array}$} & $\begin{array}{l}\text { When I leave school, I would like to work with } \\
\text { people who make discoveries in science. }\end{array}$ & 2.83 & 2.98 & +.15 & 1.319 & -.841 & .404 \\
\hline & A job as a scientist would be interesting. & 3.46 & 3.35 & -.11 & 1.132 & .735 & .466 \\
\hline & $\begin{array}{l}\text { I would like to be a scientist when I leave } \\
\text { school. }\end{array}$ & 2.21 & 2.46 & +.25 & 1.493 & -1.207 & .233 \\
\hline $\begin{array}{l}\text { STEM Career } \\
\text { Knowledge }\end{array}$ & Name three potential STEM careers. & 3.08 & 2.83 & -.25 & .968 & 1.863 & .068 \\
\hline \multirow[t]{3}{*}{ STEM Identity } & I am a science person. & 2.92 & 2.79 & -.13 & 1.189 & .817 & .418 \\
\hline & My family thinks of me as a "science person." & 2.33 & 2.38 & +.05 & 1.162 & -3.580 & .722 \\
\hline & $\begin{array}{l}\text { My teachers/instructors thinks of me as a } \\
\text { "science person." }\end{array}$ & 2.67 & 2.56 & -.11 & 1.060 & .785 & .436 \\
\hline \multirow[t]{3}{*}{ STEM Value } & Knowing science is important. & 4.10 & 3.98 & -.12 & 1.338 & .622 & .537 \\
\hline & $\begin{array}{l}\text { Knowing science helps me understand how the } \\
\text { world works. }\end{array}$ & 3.52 & 3.67 & +.15 & 1.195 & -.154 & .357 \\
\hline & Thinking like a scientist will help me do well. & 3.29 & 3.31 & +.02 & 1.057 & -.131 & .896 \\
\hline
\end{tabular}

Table Two: Summary of Paired T-Test for Control Group

Significance at $\alpha=.05, d f=51$

Response scale of 1-5, for all except STEM Career Knowledge with higher numbers corresponding to higher level of agreement 


\section{Qualitative Results}

Qualitative results consisted of student and teacher interviews. The guiding research question for this portion of the study was: "How do students and teachers participating in SAS regard the relevancy of adventure STEM curriculum as contrasted with school curriculum?”

\section{Student Interviews and Themes}

Fourteen students from 11 schools were interviewed about their thoughts on SAS. Nine students identified as female and five students identified as male. Half (50\%) of these students reported having at least one parent working in a STEM field, and 79\% indicated that they had some degree of interest in STEM before coming to the SAS. The thematic categories that emerged from the interviews are defined and illustrated with representative quotes in Table 3 , and discussed in more detail below.

\section{Elementary School STEM Experience.}

The students' contrast of their SAS experience with their experience of elementary school science classes and school in general emerged as a major theme through the qualitative study.

When asked to describe their elementary school science classes, students reported that they spent the majority of their time reading from books, writing and taking notes, and memorizing material. Student Eight (boy) reported spending all of science class time reading and answering questions on worksheets:

"All we did was, like, a science book. We just read it and found the facts of the book. Like, they'd give us a piece of paper that was all questions and we'd have to answer it. Like a four-page thing we'd read." 
Though most students did not conduct experiments regularly, their most vivid memories of elementary school science involved experiments, and six students described specific experiments they remembered performing in science class. Student Five (girl) described a short activity as:

"Well, in fifth grade we made, we took toilet paper rolls and, like, without the toilet paper on them, we like cut them up however we wanted, and we had to make a ball go through without getting stuck but not too fast. And it was really fun. And ours didn't really work but it was cool."

Though not as prevalent, two students added that at their current schools, they felt it was more difficult to learn because of increased pressure to perform academically or get the correct answers in class. Student Three (girl) described the emphasis teachers put on doing activities correctly:

"Science [Adventure] school made it more fun to learn about and it made me think that science might be more fun than I thought it would be. Than a teacher yelling at us like "You're doing it wrong!"”

\section{Preference for Learning at Science Adventure School.}

Overwhelmingly, students preferred the experiential style of learning at SAS, with 13 (of 14) reporting it easier to learn than at their current school. Only one student felt that the ease of learning at SAS was similar to learning at school. Nine reported that subject material was easier to learn because they could see what they were learning and immediately put the knowledge into practice. Student Thirteen (boy) spoke about how the process of performing the activities of archery and rock climbing made the underlying scientific principles easier to understand: 
"I think it was a lot easier to learn at the Science Adventure School because, uh, you were constantly moving and you were actually doing that thing that they talk about, like they were talking about the physics of archery, you were actually doing archery, so you understood it a lot more. And with rock climbing, they were teaching you about body positions and why, like pulling up with your legs is better than your arms. It's easier to understand because you're actually doing it."

Ten also spoke about the finding enjoyment in the activities presented, which they felt aided their learning. Student Fourteen (girl) spoke about how SAS changed a previous association of science with boredom into a more enjoyable concept:

"[Science Adventure School] kind of puts a fun image in your head of what science means. Like instead of sitting in class and just looking at the definition of science and everything else like that, but down at Science Adventure School, they explained it, like, in a fun way."

\section{Changing STEM Attitudes.}

Overall, most students reported an increase in positive attitudes toward STEM, particularly in short-term outcomes including STEM knowledge, STEM self-efficacy, and STEM value.

Twelve students felt that they knew more about STEM and had a better knowledge of how the STEM principles they were introduced to at the SAS worked. Student Four (girl) directly related the adventure activities they completed to a better understanding of the underlying scientific principles: 
"I learned about, like, ziplining, like, there's the fastest part of the zip line at, like, the middle of the zipline because at the top you're getting to go faster and then at the end you're slowing down, so in the middle you're the fastest. And the rock climbing, you learned about balance."

Ten students also felt an increased sense of STEM self-efficacy with respect to the belief that they were better able to be successful doing STEM activities in the future. Student Five (girl) who reported that her favorite subject used to be writing but was now science wrote that: “I'm actually eager to learn more about [science] and before I wasn't eager and [Science Adventure School has] definitely changed my perspective on it." Additionally, all students believed that STEM was a valuable topic to know about, with all believing STEM was valuable in general and 6 students believing that STEM would be valuable to know about in professional areas. In discussing the general value of science, Student Twelve (girl) said:

"If you know science then it's easier for you to understand our world."

All students recognized that STEM was relevant to some area of their lives. Student Seven (girl) specifically applied the need to know science to take care of plants at home:

"I think [science is important] because if you don't know some things about science you might not know....so if you didn't know how plants work and you were trying to grow a plant, like you wouldn't know what to do. Cus like my family, we have, like, a few plants, like, pepper plants, and since I know about plants, like, I know to put it in dirt and water it every so often and if you didn’t know that, you wouldn’t know what to do. You might like put juice in it or something weird like that." 
Eleven students felt that STEM would be most relevant in general, while two students felt that STEM would be useful in their daily lives at school. Student Nine (girl) commented that science would be useful in some way for everyone because people would always encounter STEM in daily life:

"I think science is important to learn, because whatever you want to be, some things involve science and you have to know, if you're a nurse or something, you have to know which part is which so you don't mess up and stuff."

They were more divided on the construct of STEM identity and only four students indicated that they identified as a scientist. Furthermore, when asked how a member of the general public would describe a scientist, all students recognized the traditional societal view of a scientist. Student Nine (girl) said:

"I think [most people] would picture [scientists] in a lab coat and goggles and tables with huge computers and chemicals and stuff and mixing them and huge explosive things." They were not unanimous on whether or not their views of what a scientist looks like had changed. When asked if they would describe a scientist differently (after the SAS experience), five continued to hold a stereotypical view of a scientist, though a majority (nine) decided that anyone could be a scientist. The same student described how she did not see much of a difference between a scientist and herself:

"I'd picture them just like us. Like they're not always in a lab all the time. They have free time, so they can like go out, hang around with friends and stuff and they don't have to stay in lab coats, or the goggles or anything and they can just be themselves and stuff, just like us. They're not like robots.” 
Additionally, twelve students were interested in pursuing a STEM career in the future after their experience at SAS.

\section{Teacher Interview Themes}

Eight teachers from six different schools were interviewed about their thoughts on SAS. Six teachers identified as female and two teachers identified as male. Three teachers had zero to five years of teaching experience, and the other five had eleven or more years of teaching experience. Two teachers taught math, three taught science, one taught technology, and two taught non-STEM subjects. Teachers were asked about the teaching methods used in their classrooms, and they self-identified their preferred methods. Two teachers taught using more traditional methods, and three used experiential methods, and three used a blend of both. The thematic categories that emerged from the interviews are defined and illustrated with representative quotes in Table 4, and are discussed in more detail below. 
Table Three: Student Themes with Significant Codes

\begin{tabular}{|c|c|c|c|c|c|}
\hline Theme & Code Name & Child Code & Code Definition & $\begin{array}{c}\text { Percent of } \\
\text { students } \\
\text { mentioning } \\
\text { code idea }\end{array}$ & $\begin{array}{c}\text { Representative } \\
\text { Quote }\end{array}$ \\
\hline \multirow[t]{3}{*}{$\begin{array}{l}\text { Elementary } \\
\text { School } \\
\text { STEM } \\
\text { Experience }\end{array}$} & $\begin{array}{l}\text { Disconnect } \\
\text { Between } \\
\text { School and } \\
\text { SAS }\end{array}$ & & $\begin{array}{l}\text { Person notes that their } \\
\text { school is not like SAS or } \\
\text { SAS activities are not } \\
\text { possible at school }\end{array}$ & $64 \%$ & $\begin{array}{l}\text { SAS is mostly } \\
\text { hands-on and at the } \\
\text { school you can't do } \\
\text { a lot of hands on } \\
\text { because it's a } \\
\text { school and you're } \\
\text { not allowed } \\
\text { to....You can't } \\
\text { zipline through } \\
\text { the cafeteria? } \\
\text { Yeah. }\end{array}$ \\
\hline & $\begin{array}{l}\text { Experiments } \\
\text { in Class }\end{array}$ & & $\begin{array}{l}\text { Student refers to doing } \\
\text { experiments or a specific } \\
\text { experiment memory in } \\
\text { elementary school }\end{array}$ & $71 \%$ & $\begin{array}{l}\text { I figured out how to } \\
\text { make a pickle } \\
\text { glow. I did that as } \\
\text { one of my science } \\
\text { fairs. We hooked } \\
\text { up a bunch of } \\
\text { electricity to it and } \\
\text { then it made it } \\
\text { glow. }\end{array}$ \\
\hline & $\begin{array}{l}\text { Traditional } \\
\text { Teaching } \\
\text { Methods }\end{array}$ & & $\begin{array}{l}\text { Person describes a } \\
\text { traditional, non- } \\
\text { experiential teaching } \\
\text { method, including } \\
\text { reading from books, } \\
\text { doing worksheets, } \\
\text { lecturing, etc. }\end{array}$ & $86 \%$ & $\begin{array}{l}\text { You have to } \\
\text { remember all the } \\
\text { stuff in [the book], } \\
\text { and they'll quiz } \\
\text { you on it and stuff. }\end{array}$ \\
\hline \multirow[t]{2}{*}{$\begin{array}{l}\text { Preference } \\
\text { for Learning } \\
\text { at Science } \\
\text { Adventure } \\
\text { School }\end{array}$} & $\begin{array}{l}\text { Experiential } \\
\text { Learning }\end{array}$ & & $\begin{array}{l}\text { Person describes } \\
\text { "learning while doing" at } \\
\text { SAS, this can also be } \\
\text { described as hands-on, } \\
\text { real world, etc. }\end{array}$ & $100 \%$ & $\begin{array}{l}\text { At Adventure } \\
\text { School, we'd get to } \\
\text { go outside and } \\
\text { walk around and go } \\
\text { on ziplines and } \\
\text { figure out how it } \\
\text { works and } \\
\text { everything, and } \\
\text { archery and figure } \\
\text { out how that works } \\
\text { too. }\end{array}$ \\
\hline & $\begin{array}{l}\text { Science at } \\
\text { SAS is Fun }\end{array}$ & & $\begin{array}{l}\text { Student expresses that } \\
\text { learning at SAS was } \\
\text { enjoyable }\end{array}$ & $71 \%$ & $\begin{array}{l}\text { Down at Science } \\
\text { Adventure School, } \\
\text { they explained } \\
\text { [science], like, in a } \\
\text { fun way." }\end{array}$ \\
\hline $\begin{array}{l}\text { Changing } \\
\text { Science } \\
\text { Attitudes }\end{array}$ & $\begin{array}{l}\text { Change in } \\
\text { STEM } \\
\text { Opinion }\end{array}$ & $\begin{array}{l}\text { Science is } \\
\text { "bigger" }\end{array}$ & $\begin{array}{l}\text { Student expresses that } \\
\text { science includes more } \\
\text { component or aspects } \\
\text { than they previously } \\
\text { believed }\end{array}$ & $50 \%$ & $\begin{array}{l}\text { That there is a lot } \\
\text { more in science to } \\
\text { do than I thought } \\
\text { there would be. }\end{array}$ \\
\hline
\end{tabular}




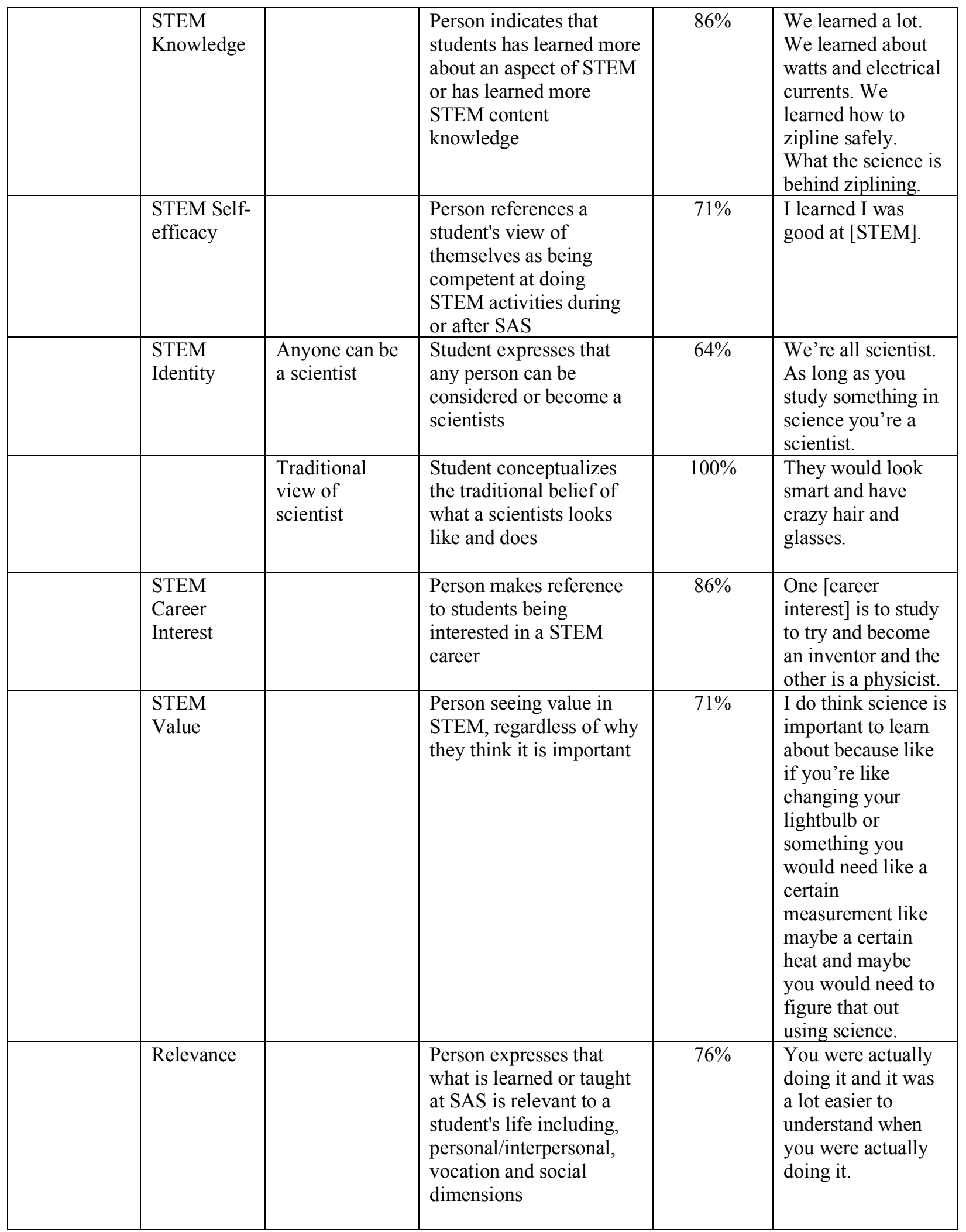

Bolded text denotes a comment from the researcher. 


\section{Science Adventure School Learning Environment.}

All teachers felt SAS was a positive learning environment for their students. Though they brought students for different reasons, all felt that the hands-on, experiential learning provided a beneficial vehicle for learning STEM. Teacher Two (female) expressed this as part of the reason she chose to bring her students to SAS:

"The main reason we wanted to bring them to the Science Adventure School is to give them the opportunity to learn the science behind things they do in everyday life...to be able to learn outside of the classroom with hands on experiences."

Four felt that the opportunities to challenge themselves were important to student growth. Teacher Five (male) in particular thought that the outdoor activities associated with daily life at SAS provided ample opportunity for students to feel challenged:

"I think that there was a lot of growth on the days that we had to hike a lot. There was not only physical struggle but also interpersonal struggle for some of my students that - as you know, there is a lot of hiking - throughout the facilities and throughout the base there. There were definitely moments of, 'We're gonna make it. You can do it. Come on.' But I think that there were little moments of that and big moments of that all throughout camp."

\section{Changing STEM Attitudes.}

Teachers had not yet been working with their current students for an extended period of time before coming to SAS, so all were hesitant to note changes in science attitude based purely on time at spent at the program. However, some teachers did make observations that could indicate change in STEM attitudes. 
Four teachers noticed an increase in STEM self-efficacy and comfort answering questions in the classroom. Teacher Eight (female) recounted a story from her class where one student who attended SAS returned more confident in her mathematics abilities:

"Even one of the students, she's really weak in math, she's gotten a couple of skills and she's gotten great at those and she wants to go and help, so her self-esteem, and I think it's something that they really have taken away from the [Science Adventure School]." Five also reported that their students seem to have a greater understanding of the concept of science as something bigger than their textbooks. Teacher Five (male) remembered noticing that his students were thinking of the concept of science more broadly:

"I think, broadly speaking, [students] might view [science], as not only something you can do in the classroom, but that is done by everyday people, outside of the classroom. So maybe if they just saw it as an academic, just sitting in chairs and reading books before, now they see it a little more broadly."

Six teachers noted that their students seemed highly interested in science after returning from the SAS. Teacher One (male) who organized a STEM club at his school even began to notice SAS students participating in their club:

"We do an afterschool STEM club that they can sign up for and several of the kids who participated in the science camp have also gone ahead and signed up for it. I don't know if that was because of it or coincidence or whatever, but I did notice that we were starting to see a lot of the same names pop back up again." 


\section{Changing Classroom Community.}

Teachers reported changes in classroom dynamics and behavior as a result of visiting SAS, to a much greater degree than was reported with respect to changes in science attitudes.

All teachers reported an increase in the students' sense of belonging to their schools. Teacher Three (female) who participated in the SAS pilot program two years earlier spoke about the group of students who attended the pilot and were now eighth graders:

"I mean they have stuck together. They still to this day have their own... I'm not really good with social media, but they have their own groups, like chat groups, and everybody in that group is Summit. It's actually really cool to watch them walk down the hall and hear some of the chants they started in sixth grade. And they're eighth-graders now, and they still do it. Just the comradery alone, is absolutely amazing."

She went on to add more about the group of sixth-graders who had just finished SAS:

"I think that this group will continue to also stick together and bond like the first group did, the pilot group."

Five teachers also felt that their interaction with students helped to deepen the teacherstudent relationship. Teacher Two (female) spoke about how SAS had also accelerated the rate of getting to know students:

"I will say that just that group in general especially compared to seventh- and eighthgrade for instance, I already feel connected to them at a much higher level than the seventh- and eighth-grade students. Them, the seventh- and eighth-grade students, I had last year. You typically grow a relationship like that over time, and it took a whole year to do that, but I feel like we were able to basically achieve that within a week pretty much and so I really feel like we have a good connection with those kids." 
Additionally, all teachers also noted that students who participated in SAS made stronger connections with each other which continued back at their schools. For example, Teacher Five (male) spoke about students in his class who had not been able to make friends before SAS:

"A handful of them that were able to make friends, like close friends that they have stayed friends with since then. And that was in September, so we're almost two months away from it now. And I definitely think that it helped kids come out of their shell and gain more confidence in their friend groups. And if they didn't really have a friend group, I think they found one there."

Four teachers reported higher social responsibility values in students, who became more cooperative as a learning community and were more willing to work with each other as a group. Teacher Two (female) reported that her students were helping each other learn new concepts together:

"[They're] helping each other out and trying to get everybody to the same level and make sure that everybody is understanding, and make sure that if somebody is struggling, you help them."

SAS also helped students develop social self-awareness and social skills with four teachers also noting higher rates of social self-efficacy. Teacher Seven (female) remembered that one of her students learned to appreciate and negotiate a trait that others in the group deemed annoying:

"We had one student that would - when the student would laugh it was high-pitched and loud and kind of like startling. And I think after a while, the student was just like "Well that's just how I am and I try to control it in certain situations, but that's me." So I do think there was some confidence there." 
Students also became more curious after SAS, with four teachers noting that their students were more willing to try new things. Teacher Seven also noted:

'Now I don't know if those changes have stuck, but I do know that when we immediately came back, they did see those changes as far as just a little more confident and willing to try things." 
Table Four: Teacher Themes with Significant Codes

\begin{tabular}{|c|c|c|c|c|c|}
\hline Theme & Code Name & Child Code & Code Definition & $\begin{array}{c}\text { Percent of } \\
\text { teachers } \\
\text { mentioning } \\
\text { code idea }\end{array}$ & $\begin{array}{l}\text { Representative } \\
\text { Quote }\end{array}$ \\
\hline \multirow[t]{2}{*}{$\begin{array}{l}\text { Science } \\
\text { Adventure } \\
\text { School } \\
\text { Learning } \\
\text { Environment }\end{array}$} & Relevance & & $\begin{array}{l}\text { Person expresses that } \\
\text { what is learned or taught } \\
\text { at SAS is relevant to a } \\
\text { student's life including, } \\
\text { personal/interpersonal, } \\
\text { vocation and social } \\
\text { dimensions }\end{array}$ & $88 \%$ & $\begin{array}{l}\text { We couldn't do } \\
\text { any of that without } \\
\text { science. So I think } \\
\text { that was also really } \\
\text { powerful for them } \\
\text { to see like "wow, } \\
\text { there's a whole lot } \\
\text { that goes into } \\
\text { this!", or "ok, it's } \\
\text { not as simple as I } \\
\text { thought", or "If I } \\
\text { want to do stuff } \\
\text { like this, then I } \\
\text { actually have to } \\
\text { know some } \\
\text { physics, or I'm } \\
\text { actually going to } \\
\text { have to know some } \\
\text { biology, or } \\
\text { whatever." }\end{array}$ \\
\hline & & Challenge & $\begin{array}{l}\text { Person expresses that a } \\
\text { student was challenged }\end{array}$ & $50 \%$ & $\begin{array}{l}\text { I think that there } \\
\text { was a lot of growth } \\
\text { on the days that we } \\
\text { had to hike a lot. } \\
\text { There was not only } \\
\text { physical struggle } \\
\text { but also } \\
\text { interpersonal } \\
\text { struggle. }\end{array}$ \\
\hline \multirow[t]{2}{*}{$\begin{array}{l}\text { Changing } \\
\text { Science } \\
\text { Attitudes }\end{array}$} & $\begin{array}{l}\text { Change in } \\
\text { STEM } \\
\text { Opinion }\end{array}$ & $\begin{array}{l}\text { Science is } \\
\text { "bigger" }\end{array}$ & $\begin{array}{l}\text { Person expresses that } \\
\text { science includes more } \\
\text { component or aspects } \\
\text { than was previously } \\
\text { believed }\end{array}$ & $63 \%$ & $\begin{array}{l}\text { I think, broadly } \\
\text { speaking, they } \\
\text { might view it, as } \\
\text { not only something } \\
\text { you can do in the } \\
\text { classroom, but that } \\
\text { is done by } \\
\text { everyday people, } \\
\text { outside of the } \\
\text { classroom. }\end{array}$ \\
\hline & $\begin{array}{l}\text { STEM Self- } \\
\text { efficacy }\end{array}$ & & $\begin{array}{l}\text { Person references a } \\
\text { student's view of } \\
\text { themselves as being } \\
\text { competent at doing } \\
\text { STEM activities during } \\
\text { or after SAS }\end{array}$ & $50 \%$ & $\begin{array}{l}\text { Even one of the } \\
\text { students, she's } \\
\text { really weak in } \\
\text { math, she's gotten } \\
\text { a couple of skills } \\
\text { and she's gotten } \\
\text { great at those and } \\
\text { she wants to go and } \\
\text { help, so her self- } \\
\text { esteem, and I think }\end{array}$ \\
\hline
\end{tabular}




\begin{tabular}{|c|c|c|c|c|c|}
\hline & & & & & $\begin{array}{l}\text { it's something that } \\
\text { they really have } \\
\text { taken away from } \\
\text { the [Science } \\
\text { Adventure School]. }\end{array}$ \\
\hline & $\begin{array}{l}\text { STEM } \\
\text { Interest }\end{array}$ & & $\begin{array}{l}\text { Person makes reference } \\
\text { to students' being } \\
\text { interested in STEM, } \\
\text { either generally, or in } \\
\text { reference to a specific } \\
\text { aspect of their lives such } \\
\text { as sports, classes, etc. }\end{array}$ & $75 \%$ & $\begin{array}{l}\text { I think [SAS has] } \\
\text { definitely helped } \\
\text { them try to open } \\
\text { their mind to new } \\
\text { ideas and also try } \\
\text { to just be more } \\
\text { curious in general, } \\
\text { honestly, which is } \\
\text { what science is all } \\
\text { about. And I think } \\
\text { that's the biggest } \\
\text { thing I've seen, } \\
\text { you know, more } \\
\text { curiosity, and } \\
\text { trying to explore } \\
\text { and ask questions } \\
\text { and interest in the } \\
\text { subject. }\end{array}$ \\
\hline \multirow[t]{5}{*}{$\begin{array}{l}\text { Changing } \\
\text { Classroom } \\
\text { Community }\end{array}$} & $\begin{array}{l}\text { Sense of } \\
\text { Belonging in } \\
\text { School } \\
\text { Community }\end{array}$ & & $\begin{array}{l}\text { Person references better } \\
\text { school community } \\
\text { including peer-to-peer } \\
\text { relations and teacher-to- } \\
\text { student relations }\end{array}$ & $100 \%$ & $\begin{array}{l}\text { I mean they have } \\
\text { stuck together. It's } \\
\text { actually really cool } \\
\text { to watch them walk } \\
\text { down the hall and } \\
\text { hear some of the } \\
\text { chants they started } \\
\text { in sixth-grade. }\end{array}$ \\
\hline & & $\begin{array}{l}\text { Peer } \\
\text { relationships }\end{array}$ & $\begin{array}{l}\text { Person references } \\
\text { relationships between } \\
\text { students }\end{array}$ & $100 \%$ & $\begin{array}{l}\text { A handful of them } \\
\text { that were able to } \\
\text { make friends, like } \\
\text { close friends that } \\
\text { they have stayed } \\
\text { friends with since } \\
\text { then. }\end{array}$ \\
\hline & & $\begin{array}{l}\text { Teacher } \\
\text { Relationships }\end{array}$ & $\begin{array}{l}\text { Person references } \\
\text { relationships between } \\
\text { students and teachers }\end{array}$ & $63 \%$ & $\begin{array}{l}\text { You typically grow } \\
\text { a relationship like } \\
\text { that over time, and } \\
\text { it took a whole } \\
\text { year to do that, but } \\
\text { I feel like we were } \\
\text { able to basically } \\
\text { achieve that within } \\
\text { a week. }\end{array}$ \\
\hline & $\begin{array}{l}\text { Social } \\
\text { Responsibility } \\
\text { Values }\end{array}$ & & $\begin{array}{l}\text { Person makes reference } \\
\text { to students considering } \\
\text { the needs of others more } \\
\text { or being helpful to peers } \\
\text { or teachers }\end{array}$ & $50 \%$ & $\begin{array}{l}\text { They're helping } \\
\text { other kids. }\end{array}$ \\
\hline & $\begin{array}{l}\text { Social Self- } \\
\text { Efficacy }\end{array}$ & & $\begin{array}{l}\text { Person references better } \\
\text { social skills including } \\
\text { improved friend-making } \\
\text { and friendship skills, }\end{array}$ & $50 \%$ & $\begin{array}{l}\text { I think that helped } \\
\text { them grow a lot } \\
\text { more in the sense } \\
\text { that they are }\end{array}$ \\
\hline
\end{tabular}




\begin{tabular}{|l|l|l|l|l|}
\hline & & $\begin{array}{l}\text { comfort expressing } \\
\text { opinions, and ability to } \\
\text { politely disagree with } \\
\text { others. }\end{array}$ & $\begin{array}{l}\text { gaining that social } \\
\text { awareness. Little } \\
\text { things like social } \\
\text { cues, when is it } \\
\text { appropriate to talk } \\
\text { in a group } \\
\text { discussion, when is } \\
\text { it appropriate to } \\
\text { listen. }\end{array}$ \\
\hline & $\begin{array}{l}\text { Willingness } \\
\text { to Try New } \\
\text { Things }\end{array}$ & $\begin{array}{l}\text { Person references } \\
\text { students as being more } \\
\text { willing to try new things. }\end{array}$ \\
& $\begin{array}{l}\text { I do know that } \\
\text { when we } \\
\text { immediately came } \\
\text { back, they did see } \\
\text { those changes as } \\
\text { far as just a little } \\
\text { more confident and } \\
\text { willing to try } \\
\text { things. }\end{array}$ \\
\hline
\end{tabular}




\section{Chapter Five: Discussion}

Findings from this study seek to build on previous research and close the gaps between adventure education and STEM education with the guiding research questions, 1) "How does adventure STEM curriculum affect the STEM interest, STEM career interest, STEM selfefficacy, STEM value and STEM identity of students participating in SAS?", and 2) "How do students and teachers participating in SAS regard the relevancy of adventure STEM curriculum as contrasted with in school curriculum?" Though results indicate that there is some support for increasing relevancy as a result of SAS, it is important to consider the relationship between survey and interview data and the concept of relevancy and its indicator STEM constructs, to gain a thorough understanding of potential implications for practice.

\section{Links to Prior Research}

Several of this study's qualitative findings echoed findings in prior literature. Interviewed students reported that they found their prior elementary school classes to be boring and uninteresting much like in the studies of Hossain and Robinson (2012) and Turner, et al. (2010). These same students also linked the idea of class as boring with reading from books, writing, and doing worksheets, similar to the dislike students showed to memorizing and writing reports as in Owens et al. (2008) and Osborne et al.'s (2003) work. Additionally, statistical evidence showed that students had a relatively high regard for the importance of STEM even before exposure to SAS. This was further corroborated in the interview analysis, echoing the study of Sjøberg and Schreiner (2005), which found that students tend to have a higher regard for STEM as a concept than they do for the subject as taught in schools. 


\section{STEM Self-Efficacy}

An increase in STEM self-efficacy is supported across all three sources of data (student survey, student and teacher interviews). SAS curriculum repeatedly placed students in activities that encouraged the hands-on exploration of science activities (Murphy, 2003), so they had multiple opportunities to develop STEM self-efficacy. Activities were not graded, which may have enhanced students' ability to feel successful (Riedinger, 2015). Students who might not have seen themselves as successful in traditional classroom science activities had the opportunity to experience success with the applied activities at SAS (Riedinger, 2015). Prior research found that many students perceive STEM as unwelcoming (Turner et al., 2010), so removing STEM from a formal classroom and placing it in a informal setting that emphasized social connections and student choice may have removed some of the barriers that intimidate some learners.

Students responses to showed one item in the STEM self-efficacy scale significantly increased -the perceptions students had about their own abilities to produce questions about science. This increase could relate to the exploration-based pedagogy employed by SAS that encourages questions. Based on student interviews, it appears that STEM classroom opportunities primarily revolved around reading from textbooks and completing worksheets in elementary schools, so students may not have been given curriculum that regularly allowed for the practice of generating their own questions before SAS. Additionally, Turner et al.'s (2010) work suggests that incorporating experiments, fun tasks, and a variety of activities increases engagement. Since SAS incorporates these sorts of activities, it may lead to greater engagement and thus a greater likelihood that students will ask questions. Though additional study of students' elementary school curriculum would be needed, this idea is further supported by 
teacher interviews, which indicated that students who participated in SAS began to ask more and better-quality questions in their classrooms.

The other two items on the self-efficacy scale addressed students' perceptions of performing well with experiments and the science activities they were given in class. Though not significant, the means of both pre- and post-tests were relatively high for both scores, perhaps indicating that students felt they already had the ability to perform relatively well at activities practiced within their classrooms. As many students in the interviews voiced positive memories associated with experiments in school, this may also be an area of their classroom curriculum which with they feel more comfortable with. Without knowing more about their elementary school curricula, it would be challenging to speculate regarding the difficulty of their previous experiences.

Student interviews suggest that students felt a general increase in their ability to engage in science, with several students stating that it was easier for them to do so after SAS. They further linked this to both a sense of enjoyment in the activity (Turner et al., 2010) and their experience of seeing the activities they were performing in conjunction with the relevant scientific principles, before putting the principles into practice through direct manipulation of objects (Julyan \& Duckworth, 2005), such as a bow and arrow. This response suggests that the experiential methodology in SAS engendered a greater sense of success due to the immediate application of the material (Riedinger, 2011). Students were also able to experience an immediate sense of STEM success at SAS. For instance, those who hit close to the center of the target at the archery activity or those who climbed high while rock climbing could feel they had exhibited mastery of the associated scientific principle. Feeling of mastery can lead to greater self-efficacy in related settings (Rittmayer \& Beier, 2009). Though there is likely some overlap 
in the feelings of success at an activity and success at science, students regularly reported feeling successful because of their ability to see science in practice (Cajete, 1999).

Teachers did not report the same level of increase in STEM self-efficacy among students as was expressed by the students themselves, but the teachers did note some changes. Four teachers felt that their students' STEM self-efficacy increased as a result of their SAS experience, in contrast to the ten students who reported the same observation. This is likely because SAS occurs at the beginning of the academic year, so teachers have less information about students prior to their attendance at SAS than they do later in the school year. Teachers also noted that students seemed to show more self-efficacy in their ability to ask and answer questions in class. As previously noted, teachers felt that their students were asking more questions and questions of better quality than before their trip to SAS, and that the students were generally more comfortable in all their classes, science included.

\section{STEM Interest}

STEM interest survey items showed no significant changes from pre- to post-survey, which contrasts somewhat with student and teacher interviews. A minority of six interviewed students did indicate a positive change in STEM interest, but most did not. However, as 11 of the 14 students indicated a prior interest in science before attending SAS, it is likely that most maintained their interest through the program, rather than experienced increased interest or a change from disinterest to interest. Six of the eight teachers indicated that they felt their students were showing more interest in class as a result of their attendance at SAS.

Though difficult to verify without further study, there are several potential reasons for discrepancies in STEM interest change. It could be that students perceive science at SAS and 
science in their schools differently, making it difficult to translate one to the other, as with Dewey's (1939) theory of continuity. Results from this research indicate that students found SAS to be an enjoyable experience (Ainley \& Ainley, 2011), while they generally found science in their schools to be less enjoyable (Osborne et al., 2003). Because students already have a preconceived negative connotation to learning science in their school settings, STEM interest may not translate well from SAS to the classroom.

It is also possible that students do not become more interested in science at all as a result of their SAS experience, or that they arrive with relatively high levels of STEM interest, which is not significantly impacted by the experience, as indicated by the pre- and post-survey. This latter hypothesis may be further supported by the selection process of bringing students to SAS. SAS allows teachers to select the students who will attend. As it was SAS's first full operating year, quotas were put in place for most schools, limiting schools to a small subset of students able to attend. It is possible that teachers selected students with a higher interest in science to attend, which would account for no significant change.

Teacher interviews could be interpreted in several ways. Teacher observation of students in their classrooms may be a more objective assessment of STEM interest than self-reported data from the students' surveys, because they may have a more accurate gauge of science interest in their classroom (Fredericks \& McColskey, 2012). Conversely, teachers could be equating science interest with another construct like STEM self-efficacy. When witnessing a student successfully performing STEM activities, they may perceive the student's achievement as interest. 
Ultimately, the contrast among sources of data for the STEM identity construct makes it difficult to reconcile. Additional research focused specifically on the construct of science interest would be needed to fully understand these results.

\section{STEM Career Interest}

An increase in STEM career interest is somewhat supported by the student surveys and student interviews. There was a significant positive increase in one of the three survey statements, "I would like to be a scientist when I leave school." Strengthening this finding, 12 of the 14 students interviewed indicated that they would be interested in pursuing a STEM career in the future.

This construct is likely to be closely linked to, and influenced by, other constructs (Riedinger, 2011, Hughes et al., 2013). If self-efficacy, interest, career knowledge, identity, and value rise, students are likely to be able to feel that they can pursue a career in STEM. Selfefficacy raises their ability to feel they will be successful at STEM activities (Eccles, 2007; Rittmayer \& Beier, 2009), interest relates to a desire to participate in STEM (Gilmartin et al., 2007; Eccles, 2007), identity helps them to feel like they are already a scientist or capable of being a scientist (Herrera \& Hurtado, 2011; Carlone \& Johnson, 2007), and STEM value increases the importance of STEM to them (Ainley \& Ainley, 2011; Sjøberg \& Schreiner, 2005). Hypothetically, it would follow that as these factors rise, so too would an interest in pursuing STEM as a career. As an example, when asked for their views on scientists, the majority of students' perceptions loosened from the stereotype of a man in a laboratory coat and glasses to someone that was described as a "regular person". A regular person is someone more like themselves, so in addition to increasing general STEM identity, the students' change in 
viewpoint may also make a career as a scientist seem more attainable (Hughes et al., 2013). As there was change across some constructs from the intervention, but not all, future research would be needed to fully understand construct linkages in an adventure STEM setting.

While not one of the survey constructs, many students reported an increased sense of enjoyment while undertaking STEM activities at SAS. As Hughes et al.'s (2013) and Ainley and Ainley's (2011) studies show, the idea that a career in STEM can be enjoyable may have made the potential of a career in STEM more appealing.

\section{STEM Career Knowledge}

Student surveys along with student and teacher interviews showed evidence of increasing STEM career knowledge. While at SAS, instructors showed or described multiple ways of conducting science and gave examples of current scientists and their specialties. This exposure to additional kinds of potential STEM careers likely influenced students' career knowledge (Hughes et al., 2013).

In interviews, students also repeatedly described coming to see science as "bigger" after their participation in SAS. Through the students' descriptions, it became apparent that describing their views of science as "bigger" meant that they were aware of more possibilities within the realm of STEM, a thought echoing Young and Glanfield's (1998) emphasis on linking science to broader social and cultural contexts. This included greater knowledge both of the variety of science disciplines and sub-disciplines and of potential career options. Several teachers also reported that their students seemed to see the concept of science as broader than before. This echoes Hughes et al.'s (2013) and Bell et al.'s (2003) findings that students came to a wider understanding of STEM careers after exposure to practical STEM experiences. Teachers also 
believed that their students no longer saw science as something confined to the classroom (Young \& Glanfield, 1998). When given fewer limits and more space to explore the concept of science, it appears that students are open to greater knowledge of science career options and the possibilities they contain.

\section{STEM Identity}

A change in STEM identity was supported by results from the student survey but was not supported by either student or teacher interviews. Though there was a significant increase in one of the student survey items, it was slight and close to the mean value for the Likert scale. Without triangulation from the qualitative data, is difficult to claim a substantial impact as a result of the intervention. These mixed results are not surprising as identity takes shape over a long period of time (Gee, 2000), while student involvement with SAS was only a few days. SAS may turn out to be the catalyst for future development of a STEM identity, but it would likely be difficult to see evidence of this change after a week's timespan (Ham, 2007).

Interestingly, the individual survey items that showed increases in STEM identity were "My family thinks of me as a science person" and "My teachers/instructors think of me as a science person", while there was no significant change in the statement, "I am a science person". The claiming of the first two statements and rejection of the last one may indicate that while students were not yet willing to claim the identity of a scientist for themselves, they were willing to interpret their identity as scientists relative to their social groups (Riedinger, 2015). It may also indicate that students are seeking validation from other trusted sources before claiming the identity themselves. Carlone and Johnson's (2007) study found that women studying in STEM fields sought the recognition of their home communities as a primary source of validation. 
Without focusing on the gender of the students, it would be difficult to fully support this possibility, but it does offer some explanation of survey results.

It is also not surprising that evidence of increased STEM identity did not appear in either teacher or student interviews. As teachers were only beginning to know their students, it is unlikely that something as deeply personal as student identity would be apparent to them (Wortham, 2004). The student survey results reveal that students had not had sufficient time to develop science identity or were unwilling to proclaim something as personal as identity, it is also not surprising that they would fail to articulate science identity to a researcher who was relatively unknown.

There are some differences in the results for STEM career identity and STEM identity, with the former being much more strongly supported by both student surveys and interviews. Career identity may be more easily shifted due to exposure to potential careers and practice with STEM-based activities (Barab \& Hay, 2001). Additionally, any potential career in STEM is many years in the future for these students. It may feel safer to claim a STEM career identity, because a career is still something malleable for a middle school student (Howard \& Walsh, 2011). It is also something that they have practiced articulating, given that adults commonly ask students to verbalize potential career interests. They are not yet expected to have decided upon a career path, so therefore may not feel that they are committing to something irrevocable by choosing an identity associated with a STEM career.

In contrast, claiming a STEM identity may feel more personal and more immediate as it is a present-day commitment. Students may be hesitant to claim a persona that frequently holds the negative associations of being a "nerd" or "science geek" (Riedinger, 2011, p. 295), particularly as they begin middle school, which is a transitional period for most students. 
While less supported than other constructs, the survey data does indicate that SAS may be a catalyzing experience for students. Prior studies have found linkages between positive environmental attitudes and childhood time spent in the outdoors (Chawla, 1998). It is possible that similar results may be true of science. Children who spent time participating in STEM activities may be more likely to feel more positively about claiming the identity of a scientist and more likely to parley their experience into a scientific career. More research would be needed, but the students' belief that they appear different ("a science person") to trusted adults may indicate a first step toward a more personal identity change.

\section{STEM Value}

Survey data for STEM value showed conflicting results, while student interviews showed a strong increase in STEM value. This construct is notable because across all survey construct areas, this construct demonstrated the only significant decrease. This item, "Knowing science is important", directly conflicts with the interview data in which all interviewed students reported believing that STEM was valuable to know about in general. Further, STEM value also showed an increase in the item "thinking like a scientist will help me do well", which also seems to show some contradiction with the decreased item.

Some explanation for the differing datasets may be found in the pool of interviewed students. While an effort was made to choose a diverse set of interview subjects, the majority of students who were interviewed indicated a prior interest in science before attending SAS. With a positive bias towards science, they may have been predisposed to see science as valuable in contrast to the larger pool of students who participated in the survey. Additionally, the two significant items (one positive and one negative) were quite different. In the item showing a 
decrease, students were asked to evaluate whether or not knowing science is important. In the item showing an increase, they were asked if science will help them do well. The former is a more global statement. Students may not make the connection between themselves and a general definition of science (Hughes et al., 2013). The latter statement is more specific, which may cause students to think of the skills learned through science lessons, rather than the subject in general, in relation to future success (Greene et al., 2004).

It may also be that the survey items for STEM value not hold together as a construct within this framework. The Cronbach alpha values for this construct are notable in that the pretest score was poor while the post-test score was at an acceptable level. The discrepancy between scores may because of increased familiarity the second time the survey was taken or because of the relatively small sample size.

Ultimately, it will take additional research to resolve discrepancies within the data. The additional support in the student interviews and significant increase in one survey item does suggest that the students' time at SAS may have some positive bearing on their view of STEM value.

\section{Additional Outcomes}

One of the strengths of qualitative methodology is the generation of data outside of the pre-selected constructs associated with the guiding research questions (Saldaña, 2016). In this study, emergent data added to the richness and complexity of the picture built from the students' SAS experience. The teacher interviews revealed increases in student interpersonal growth which is worth noting. 
Interviewing teachers provided another viewpoint and unique insight into student experience at SAS. Though teachers had only been with their classes for a limited period at the time of the interviews, they observed noticeable interpersonal changes in students. Most of the reported changes were related to social growth and social support. Students formed positive social bonds with their peers and teachers (Riedinger, 2015), developed better social selfawareness (Hattie et al., 1997; Powell et al., 2018), and were more willing to help peers in their classrooms (Hattie et al., 1997; Powell et al., 2018).

These results are not unexpected, as positive social outcomes are often associated with experiential and adventure-based programming (Hattie et al., 1997; Powell et al., 2018). Teachers identified at least two drivers of personal growth in students:1) being presented with challenge and 2) opportunities to practice independence. These, along with the experiences of living in tents, eating group meals, solving group challenges, and participating in group discussions together are common elements of adventure programming intentionally included to reach these outcomes.

Though not the focus of this study, the results' interpersonal aspects do have some potentially interesting implications for positive STEM attitudes and the relevancy of STEM curriculum to students. Classes who participated in SAS together may have a higher regard for STEM as a result of their shared experience, which could be reinforced upon their return to school (Riedinger, 2015). They may also feel more comfortable in their classrooms both with peers and with teachers, which could be related to higher levels of engagement and positive regard for school, as supported by previous findings that emphasize learning STEM cooperatively and socially (Ebenezer \& Zoller, 1993; Riedinger, 2015). These effects likely extend to all subjects to one degree or another, but as SAS was focused on STEM, they may be 
more prevalent in STEM subjects. While these effects are speculation, the social effect of adventure STEM and its implication to STEM relevancy and positive STEM attitudes merits further research.

\section{Implications for Relevancy}

Vocational relevancy in this study is seen through the lens of two frameworks: the Model of Three Dimensions of Relevancy (Stuckey et al., 2013a), and Ham's interpretive model of relevancy (2016). Stuckey et al.'s (2013a) model emphasizes that curriculum must be societally, individually, vocationally, intrinsically, and extrinsically relevant to students, while Ham's (2016) model of relevancy emphasizes that students must have a relationship to the material they are learning to care about it. Ultimately, both rely on the connection students are able to make with material while learning it to increase relevancy.

This study specifically looked at the domain of vocational relevancy, with STEM attitude constructs chosen as indicators of change in students' view of STEM as relevant to their classrooms. As students do not participate in organized work activities, vocational relevancy was operationalized as the students' experiences in their classrooms, with a student's school day functioning similarly to an adult's workday. The central premise of the study was that by increasing vocational relevancy of STEM subjects through SAS, students could come to see these subjects as more relevant when back in the vocational settings of their classroom (Stuckey et al., 2013a).

There is some evidence that vocational relevancy can be increased by attendance at SAS, shown by positive increases in the indicator constructs across student survey results, student interviews, and teacher interviews. STEM self-efficacy and STEM career knowledge increased 
across all data points including student surveys, student interviews, and teacher interviews. STEM career identity had positive gains in the student survey and student interviews, one item of the student survey showed an increase in STEM identity, and teacher interviews supported an increase in STEM interest. The findings for STEM value were more complex. Though this construct was present in student interviews, there were conflicting results from the student survey, with an increase in one item and a decrease in another. Overall, results cautiously indicate that SAS had a positive effect on relevancy, though additional research would be needed for confirmatory support.

Though this study operationalizes a student's "vocation" as the time spent in school, students did not see their SAS experience as relevant to their classrooms other than as a source of some general increased interest in STEM. This may relate to how students processed their experience at SAS. As Bell et al. (2003) point out, students can have difficulty reflecting on their experiences without help. While SAS does include reflective discussions in their curricula, these discussions do not implicitly cover the connection between SAS and students' classrooms as much they do specific concepts such as STEM identity. This study uses constructs to measure vocational relevancy, but students may not make the conscious connection between the two without being guided in their thought processes (Bell et al., 2003). Though they did not explicitly articulate relevancy in terms of their classrooms, students did see their experiences at SAS as generally relevant to their lives and specifically relevant to their future careers, with many indicating either an interest in pursuing a STEM career in the future, or at least a more positive regard for STEM subjects. SAS also appeared to have an affective impact as seen through students expressing enjoyment in STEM, which can also indicate an increase in relevancy (Ham, 2016). 
Interestingly, societal and individual domains of relevancy, which are part of Stuckey et al.'s (2013a) model but were not the focus of this study, were prevalent in teacher interviews. While teachers did see some connection between SAS and their students' relationship to STEM through an increase in interest and capability to ask questions, they were more likely to note social or individual changes in their students. As noted earlier in the discussion, teachers noticed that students felt more comfortable in their classrooms, interacting with peers and teachers, and were more likely to assist other students.

In conclusion, although students do not appear to make the explicit association between SAS and their classrooms in terms of vocational relevance, they do see STEM as more relevant to their future careers after SAS. Positive increases in survey and interview response data also suggest a degree of rise in vocational relevancy even though the concept is not articulated by students. Interviews with teachers indicate that SAS may have an effect of the societal and individual domains of relevancy. Though additional research is needed in this area, it does appear that the closer connection (Stuckey et al., 2013a; Ham 2016) to STEM material provided by SAS can translate to more vocationally relevant curricula.

\section{Recommendations for Future Research}

There are several potential ways this study could be improved in future iterations. SAS intends to grow, and provided this happens, a greater number of students could be recruited into the research sample, lessening the impact of participant bias and the effect of student reading levels. The existing instrument's language could also be simplified and undergo a survey validation process. 
Purposive sampling will continue to be an appropriate participant selection method for interviewing students. However, working more closely with teachers to choose students would reduce bias within the sample and provide a more balanced point of view. It would be preferable to have a balance between students who were interested in a STEM subject and those who were not.

Focusing more narrowly on one or two STEM constructs could also open a potential line of related research. In trying to keep the survey short for students, only three to four items for each construct were assessed. Though Cronbach's alpha analysis points to a validity within the survey instrument's constructs, focusing on a few constructs would allow for more associated items to be included. This could better show effects of SAS in relation to the chosen constructs.

This study suggests that there are some immediate influences associated with attendance at SAS and positive STEM attitudes. However, long-term influences of SAS are unknown. A future area of study could to be to follow up with students in the samples six months to a year later and reassess STEM attitudes, whether students engage continue to engage with STEM experiences, and potential plans related to college majors and future careers.

Finally, the relationship between gender and SAS experience would be an interesting new research area to explore. Analyzing survey data in relation to gender and asking questions related to STEM and gender in interviews could lead to results with implications for female students' STEM experiences.

\section{Implications for Practice}

The results of this study have implications for formal and informal science educators. Though limitations do not make these findings universally applicable, they still provide support 
for the importance of vocational relevancy in relation to curriculum and adventure STEM education as a method of increasing all domains of relevancy and positive STEM attitudes in youth.

Results indicate that SAS may be more relevant to students than their classroom curricula because students learn through activities that are associated with immediately being able to put learning into practice (Riedinger, 2015). This makes the learning tangible. Enjoyment also affects relevancy, as positive emotions influence connection to learning (Ham, 2016; Ainley \& Ainley, 2011), and students reported enjoyment while participating in SAS activities. While most teachers will lack the resources to undertake adventure activities in their classroom, they may be able to incorporate more hands-on activities related to tangible elements of students' lives to influence positive STEM attitudes.

This study also provides support for the idea that adventure STEM education can provide benefits similar to other informal STEM learning contexts. Multiple studies (Riedinger, 2015; Hughes et al., 2013; Barab \& Hay, 2001) show that informal science experiences can have a positive effect on youth. As adventure STEM education is a relative new phenomenon, there have been few studies highlighting the discipline's ability to generate similar positive effects. This study's findings add to the body of adventure STEM literature generally, and specifically lend support to the positive benefits of engaging youth in adventure STEM programming.

\section{Conclusion}

This study represented a preliminary effort to understand how participation in SAS affected the STEM attitudes of the sixth-grade students who attended adventure STEM camp in the autumn of 2019. The vocational relevancy of adventure STEM curricula was explored 
through the multiple perspectives provided by surveys and interviews with students and teachers. Findings lend support to the theory that adventure STEM education can provide meaningful educational experiences that help students to grow personally and socially, and to develop a greater appreciation for STEM subjects. Notably, the schools participating in SAS experienced a change in classroom social dynamics with reports of students being more inclined to ask questions, help their peers, and forge closer bonds with their teachers. These results show that the social context of SAS was an important piece of students' learning, and highlight the need for students to connect to each other as well as to their lessons. Equally important, teachers and students expressed the idea that students came to view science as something "bigger", beyond the context of their classrooms. When students start to see the connections between classroom and life, more possibilities open up for their consideration.

This study builds on prior research in adventure education and STEM education and begins to bridge the gaps between the two fields, with results of this study indicating that SAS provides many opportunities for youth to grow and explore STEM. However, there is much more to explore in this burgeoning field and additional study is needed to better understand the complex relationships among adventure STEM education, STEM attitudes, and curricula relevancy. One important avenue for future research would be the exploration of the longitudinal effects of SAS, which could lend greater support to adventure STEM programs. Results from this study indicate positive change as a result of the experience. However, without knowing if these effects last, it is difficult to fully gauge the impact of an adventure STEM experience like SAS. Future research should also explore adventure STEM impacts with a randomized selection of participants to gain a better understanding of the full implications of this approach to education. 
In conclusion, adventure STEM education represents a blossoming opportunity to foster connections with youth before their attitudes toward STEM turn from curiosity to disinterest. It is an approach that can not only teach students in ways that feel more relevant to their current and future lives, but can also foster powerful social relationships with teachers and peers that increase the depth of educational experiences. Adventure STEM education is a new field, but it shows great promise as an ameliorant in the struggle to make academic lesson interesting and meaningful to students. It deserves the time and attention of researchers to evaluate its efficacy and help to improve the discipline for its own sake and for the sake of students everywhere. 


\section{References}

ACT. (2017). STEM education in the U.S.: Where we are and what we can do [PDF]. Retrieved from https://www.act.org/content/dam/act/unsecured/documents/STEM/2017/STEM-Education-inthe-US-2017.pdf

Abels, S. (2015). Scaffolding inquiry-based science and chemistry education in inclusive classrooms. New Developments in Science Education Research, 77-96.

Ainley, M. , \& Ainley, J. (2011). Student engagement with science in early adolescece: The contribution of enjoyment to students' continuing interest in learning about sciences, Contemporary Educational Psychology, 36(1), 4-12

Ajzen, I. (1991). The theory of planned behavior. Organizational Behavior and Human Decision Processes, 50(2), 179-211.

Ajzen, I., \& Fishbein, M. (2000). Attitudes and the attitude-behavior relation: Reasoned and automatic processes. European Review of Social Psychology, 11(1), 1-33.

Alrashidi, O., Phan, H. P., \& Ngu, B. H. (2016). Academic engagement: an overview of its definitions, dimensions, and major conceptualisations. International Education Studies, 9(12), 41.

Anderson, E. L., \& Kim, D. (2006). Increasing the success of minority students in science and technology [PDF]. Retrieved from http://ww.cssia.com/pdf/20000066IncreasingtheSuccessofMinorityStudentsinScienceandTechnology.pdf

Appleton, J. J., Christenson, S. L., \& Furlong, M. J. (2008). Student engagement with school: Critical conceptual and methodological issues of the construct. Psychology in the Schools, 45(5), 369386.

Ballantyne, R. R., and D. L. Uzzell. "A checklist for the critical evaluation of informal environmental learning experiences." Environmental Education and Information 13, (1994): 111-111.

Bandura, A. (1986). The explanatory and predictive scope of self-efficacy theory. Journal of Social and Clinical Psychology, 4(3), 359-373.

Barab, S. A., \& Hay, K. E. (2001). Doing science at the elbows of experts: Issues related to the science apprenticeship camp. Journal of Research in Science Teaching, 38(1), 70-102.

Beard, C. M., \& Wilson, J. P. (2006). Experiential learning: A best practice handbook for educators and trainers. Kogan Page Publishers.

Bell, A. (2007). Designing and testing questionnaires for children. Journal of Research in Nursing, 12(5), 461-469. 
Bell, R. L., Blair, L. M., Crawford, B. A., \& Lederman, N. G. (2003). Just do it? Impact of a science apprenticeship program on high school students' understandings of the nature of science and scientific inquiry. Journal of Research in Science Teaching: The Official Journal of the National Association for Research in Science Teaching, 40(5), 487-509.

Bisson, C. (1996). The Outdoor Education Umbrella: A Metaphoric Model To Conceptualize Outdoor Experiential Learning Methods.

Bloomberg, L., \& Volpe, F. (2008). Completing your qualitative dissertation: A roadmap from beginning to end. Los Angeles, London: Sage Publications.

Blotnicky, K. A., Franz-Odendaal, T., French, F., \& Joy, P. (2018). A study of the correlation between STEM career knowledge, mathematics self-efficacy, career interests, and career activities on the likelihood of pursuing a STEM career among middle school students. International Journal of STEM Education, 5(1), 22.

Bowen, G. A. (2009). Document analysis as a qualitative research method. Qualitative Research Journal, 9(2), 27-40.

Breiner, J. M., Harkness, S. S., Johnson, C. C., \& Koehler, C. M. (2012). What is STEM? A discussion about conceptions of STEM in education and partnerships. School Science and Mathematics, 112(1), 3-11.

Brickman, S. J., \& Miller, R. B. (2001). The impact of sociocultural context on future goals and selfregulation. Research on Sociocultural Influences on Motivation and Learning, 1, 119.

Brown, M. (2009). Reconceptualising outdoor adventure education: Activity in search of an appropriate theory. Australian Journal of Outdoor Education, 13(2), 3-13.

Brown, M. (2010). Transfer: Outdoor adventure education's Achilles heel? Changing participation as a viable option. Journal of Outdoor and Environmental Education, 14(1), 13-22.

Bruner, J. (1996). The culture of education. Cambridge: Harvard University Press.

Bunting, C. J. (2006). Interdisciplinary teaching through outdoor education. Human Kinetics.

Cajete, G. A. (1999). Igniting the Sparkle: An Indigenous Science Education Model. Kivaki Press.

Campbell, D. T., \& Stanley, J. C. (1966). Experimental and quasi-experimental designs for research. Chicago: Rand McNally.

Carlone, H. B., \& Johnson, A. (2007). Understanding the science experiences of successful women of color: Science identity as an analytic lens. Journal of Research in Science Teaching, 44(8), 11871218. 
Cavert, G. (n.d.). Adventure education: A historical and theoretical perspective of challenge course education [PDF]. Retrieved from http://www.fundoing.com/uploads/1/2/4/4/12445824/ adventureedhistoricalperspective_cavert.pdf

Childs, P. E. (2006). Relevance, relevance, relevance. Physical Sciences Magazine, 5, 14.

Christensen, P., \& James, A. (Eds.). (2008). Research with children: Perspectives and practices. Routledge.

Christiadi, Deskins, J., \& Lego, B. (2014). Population trends in West Virginia through 2030 [PDF]. Retrieved from http://busecon.wvu.edu/bber/pdfs/BBER-2014-04.pdf

Clark, R., Kirschner, P. A., \& Sweller, J. (2012). Putting students on the path to learning: The case for fully guided instruction [PDF]. Retrieved from http://dspace.ou.nl/bitstream/1820/4716/1/ Putting\%20students\%20on\%20the\%20path\%20-\%20American\%20Educator\%20-\%20ClarkKirschner-Sweller.pdf

Cohen, J. (1998). Statistical power analysis for the behavioral sciences (2nd ed.). New York: Academic Press.

Cranston, M., \& Jessop, T. (2018) David Hume. In Encyclopaedia Britannica Online. Retrieved from https://www.britannica.com/biography/David-Hume

Cremin, L. (2018) Horace Mann. In Encyclopaedia Britannica Online. Retrieved from https://www.britannica.com/biography/Horace-Mann

Creswell, J. W., Plano Clark, V. L., Gutmann, M. L., \& Hanson, W. E. (2003). Advanced mixed methods research designs. In A. Tashakkori \& C. Teddlie (Eds.), Handbook of mixed methods in social and behavioral research (pp. 209-240). Thousand Oaks, CA: Sage.

Crumpton, H. E., \& Gregory, A. (2011). "I'm not learning”: The role of academic relevancy for lowachieving students. The Journal of Educational Research, 104(1), 42-53.

Csikszentmihalyi, M. (1997). Finding flow: The psychology of engagement with everyday life. Basic Books.

Chawla, L. (1998). Significant life experiences revisited: A review of research on sources of environmental sensitivity. The Journal of environmental education, 29(3), 11-21.

Daugherty, M. K. (2013). The prospect of an" A" in STEM education. Journal of STEM Education: Innovations and Research, 14(2), 10.

Department of Education and Science. (1988). Science at age 15:A review of the APU survey findings. Retrieved from https://searchworks.stanford.edu/view/223374 
Dewey, J. (1938). Experiential education. New York: Collier.

Dewey, J. (1958). Experience and nature. Mineola, NY: Dover Publications, Inc.

Dewey, J. (1973). Education as a social function. In S. D. Sieber \& D. D. Wilder (Eds.), The school in society (pp. 28-33). New York, NY: The Free Press.

Diekman, A. B., Brown, E. R., Johnston, A. M., \& Clark, E. K. (2010). Seeking congruity between goals and roles: A new look at why women opt out of science, technology, engineering, and mathematics careers. Psychological Science, 21(8), 1051-1057

Doering, A. (2006). Adventure learning: Transformative hybrid online education. Distance Education, 27(2), 197-215.

Doering, A., \& Veletsianos, G. (2008). Hybrid online education: Identifying integration models using adventure learning. Journal of Research on Technology in Education, 41(1), 23-41.

Dogan, U. (2015). Student engagement, academic self-efficacy, and academic motivation as predictors of academic performance. The Anthropologist, 20(3), 553-561.

Doody, O., \& Noonan, M. (2013). Preparing and conducting interviews to collect data. Nurse researcher, 20(5).

Ebenezer, J. V., \& Zoller, U. (1993). Grade 10 students' perceptions of and attitudes toward science teaching and school science. Journal of Research in Science Teaching, 30(2), 175-186.

Eccles, J. S. (2007). Where Are All the Women? Gender Differences in Participation in Physical Science and Engineering. In S. J. Ceci \& W. M. Williams (Eds.), Why aren't more women in science?: Top researchers debate the evidence (pp. 199-210). Washington, DC, US: American Psychological Association.

Eilks, I., Nielsen, J. A., \& Hofstein, A. (2014). Learning about the role and function of science in public debate as an essential component of scientific literacy. In Topics and trends in current science education (pp. 85-100). Springer, Dordrecht.

Ewert, A., \& Hollenhorst, S. (1989). Testing the adventure model: Empirical support for a model of risk recreation participation. Journal of Leisure Research, 21(2), 124-139.

Fishbein, M. (1966). The relationships between beliefs, attitudes and behavior. In Feldman, S. (Ed.) Cognitive consistency, motivational antecedents and behavioral consequents. New York, NY: Academic Press, Inc.

Forman, G. (2015). The project approach in Reggio Emilia. In Fosnot, C. (Ed.), Constructivism: Theory, perspectives, and practice ( $2^{\text {nd }}$ ed.). New York, NY: Teachers College Press. 
Fosnot, C., \& Perry, R. (2015). Constructivism: A psychological theory of learning. In Fosnot, C. (Ed.), Constructivism: Theory, perspectives, and practice ( $2^{\text {nd }}$ ed.). New York, NY: Teachers College Press.

Fredricks, J. A., Blumenfeld, P. C., \& Paris, A. H. (2004). School engagement: Potential of the concept, state of the evidence. Review of educational research, 74(1), 59-109.

Fredricks, J. A., \& McColskey, W. (2012). The measurement of student engagement: A comparative analysis of various methods and student self-report instruments. In Handbook of research on student engagement (pp. 763-782). Boston, MA: Springer.

Gawronski, B. (2007). Attitudes can be measured! But what is an attitude?. Social Cognition, 25(5), 573-581.

Gee, J. P. (2000). Chapter 3: Identity as an analytic lens for research in education. Review of Research in Education, 25(1), 99-125.

Gibson, H. L., \& Chase, C. (2002). Longitudinal impact of an inquiry-based science program on middle school students' attitudes toward science. Science Education, 86(5), 693-705.

Gilbert, J. K. (2006). On the nature of 'context' in chemical education. International Journal of Science Education, 28, 957-976.

Gilmartin, S., Denson, N., Li, E., Bryant, A., \& Aschbacher, P. (2007). Gender ratios in high school science departments: The effect of percent female faculty on multiple dimensions of students' science identities. Journal of Research in Science Teaching: The Official Journal of the National Association for Research in Science Teaching, 44(7), 980-1009.

Gilmer, T. C. (2007). An understanding of the improved grades, retention and graduation rates of STEM majors at the Academic Investment in Math and Science (AIMS) Program of Bowling Green State University (BGSU). Journal of STEM Education: Innovations and Research, 8(1/2), 11.

Glen, S. (2014). Cronbach's alpha: simple definition, use and interpretation. Retrieved from https://www.statisticshowto.com/cronbachs-alpha-spss/

Gonzalez, H. B., \& Kuenzi, J. J. (2012, August). Science, technology, engineering, and mathematics (STEM) education: A primer [PDF]. Retrieved from http://www.stemedcoalition.org/wpcontent/uploads/2010/05/STEM-Education-Primer.pdf

Goodlad, J. I. (1964). Understanding the self in the school setting. Childhood Education, 41(1), 9-14.

Greene, B. A., Miller, R. B., Crowson, M. H., Duke, B. L. and Akey, K. L. 2004. Predicting high school students' cognitive engagement and achievement: Contributions of classroom perceptions and motivation. Contemporary Educational Psychology, 29: 462-482. 
Greene, J. C., Caracelli, V. J., \& Graham, W. F. (1989). Toward a conceptual framework for mixedmethod evaluation designs. Educational Evaluation and Policy Analysis, 11(3), 255-274.

Guba, E. G. (1981). Criteria for assessing the trustworthiness of naturalistic inquiries. Educational Communication and Technology Journal, 29(2), 75.

Halpern, D. F., Benbow, C. P., Geary, D. C., Gur, R. C., Hyde, J. S., \& Gernsbacher, M. A. (2007). The science of sex differences in science and mathematics. Psychological Science in the Public Interest, 8(1), 1-51.

Ham, S. (2007, March). Can interpretation really make a difference? Answers to four questions from cognitive and behavioral psychology. In Proceedings, Interpreting World Heritage Conference, March (pp. 25-29).

Ham, S. (2016). Interpretation: Making a difference on purpose. Golden, CO: Fulcrum Publishing.

Hanna, G. (1991). Outdoor pursuits programming: Legal liability and risk management. Edmonton, Alberta: University of Alberta Press.

Hanushek, E. A., Peterson, P. E., \& Woessmann, L. (2012) Achievement growth: International and U.S. state trends in student performance [PDF]. Retrieved from https://files.eric.ed.gov/fulltext/ED534652.pdf

Harackiewicz, J. M., Rozek, C. S., Hulleman, C. S., \& Hyde, J. S. (2012). Helping parents to motivate adolescents in mathematics and science: An experimental test of a utility-value intervention. Psychological science, 23(8), 899-906.

Harrell, M. C., \& Bradley, M. A. (2009). Data collection methods. Semi-structured interviews and focus groups. Rand National Defense Research Inst., Santa Monica, CA.

Hattie, J., Marsh, H. W., Neill, J. T., \& Richards, G. E. (1997). Adventure education and Outward Bound: Out-of-class experiences that make a lasting difference. Review of Educational Research, 67(1), 43-87.

Herrera, F. A., \& Hurtado, S. (2011). Maintaining initial interests: Developing science, technology, engineering, and mathematics (STEM) career aspirations among underrepresented racial minority students [PDF]. Retrieved from https:/www.heri.ucla.edu/nih/downloads/ AERA\%202011\%20-\%20Herrera\%20and\%20Hurtado\%20-\%20Maintaining\% 20Initial\%20Interests.pdf

Herrera, F. A., Hurtado, S., Garcia, G. A., \& Gasiewski, J. (2012). A model for redefining STEM identity for talented STEM graduate students. In American Educational Research Association Annual Conference.

Hidi, S. (1990). Interest and its contribution as a mental resource for learning. Review of Educational Research, 60(4), 549-571. 
Hofstein, A., Eilks, I., \& Bybee, R. (2010). Societal issues and their importance for contemporary science education. Contemporary Science Education, 5-22.

Hofstein, A., \& Kesner, M. (2006). Industrial chemistry and school chemistry: Making chemistry studies more relevant. International Journal of Science Education, 28(9), 1017-1039.

Holland, W. H., Powell, R. B., Thomsen, J. M., \& Monz, C. A. (2018). A systematic review of the psychological, social, and educational outcomes associated with participation in wildland recreational activities. Journal of Outdoor Recreation, Education, and Leadership, 10(3).

Hooper-Greenhill, E. (1999). Museum learners as active postmodernists: Contextualizing constructivism. In Hooper-Greenhill, E. (Ed.), The educational role of the museum ( $2^{\text {nd }}$ ed.). London \& New York, NY: Routledge.

Hossain, M., \& Robinson, M. (2012). How to motivate US students to pursue STEM (science, technology, engineering and mathematics) careers [PDF]. Retrieved from https://files.eric.ed.gov/fulltext/ED533548.pdf

Hougham, R. J., Eitel, K. C. B., \& Miller, B. G. (2015). Technology-enriched STEM investigations of place: Using technology to extend the senses and build connections to and between places in science education. Journal of Geoscience Education, 63(2), 90-97.

Howard, K. A., \& Walsh, M. E. (2011). Children's conceptions of career choice and attainment: Model development. Journal of Career Development, 38(3), 256-271.

Hsieh, H. F., \& Shannon, S. E. (2005). Three approaches to qualitative content analysis. Qualitative Health Research, 15(9), 1277-1288.

Hsu, H., \& Lachenbruch, P. A. (2005). Paired t test. Encyclopedia of Biostatistics, 6.

Hughes, R. M., Nzekwe, B., \& Molyneaux, K. J. (2013). The single sex debate for girls in science: A comparison between two informal science programs on middle school students' STEM identity formation. Research in Science Education, 43(5), 1979-2007.

Huisman, M. (1999). Item nonresponse: Occurrence, causes, and imputation of missing answers to test items. Leiden: DSWO Press.

Jenkins, E. W., \& Nelson, N. W. (2005). Important but not for me: Students' attitudes towards secondary school science in England. Research in Science \& Technological Education, 23(1), 41-57.

Jenkins, E. W., \& Pell, G. (2006). The relevance of science education project (ROSE) in England: a summary of findings. Retrieved from http://www.leeds.ac.uk/educol/documents/152736.htm 
Johnson, R. B., Onwuegbuzie, A. J., \& Turner, L. A. (2007). Toward a definition of mixed methods research. Journal of Mixed Methods Research, 1(2), 112-133.

Julyan, C., \& Duckworth, E. (2015). A constructivist perspective on teaching and learning in science. In Fosnot, C. (Ed.), Constructivism: Theory, perspectives, and practice ( $2^{\text {nd }}$ ed.). New York, NY: Teachers College Press.

Kahl, S., \& Harms, N. (1981). Project synthesis: Purpose, organization and procedures. In N. Harms \& R. E. Yager (Eds.), What research says to the science teacher (Vol. 3). Washington, DC: NSTA.

Keller, J. M. (1983). Motivational design of instruction. Instructional Design Theories and Models: An Overview of Their Current Status, 1(1983), 383-434.

Klafki, W. (2000). The significance of classical theories of Bildung for a contemporary concept of Allgemeinbildung. In I. Westbury, S. Hopmann, \& K. Riquarts (Eds.), Teaching as a reflective practice: The German Didaktik tradition (pp. 85-108). Mahwah, NJ: Lawrence Erlbaum.

Knamiller, G. (1984). The struggle for relevance of science education in developing countries. Studies in Science Education, 11, 60-78.

Kolb, A. Y., \& Kolb, D. A. (2009). Experiential learning theory: A dynamic, holistic approach to management learning, education and development. In Armstrong, S. \& Fukami, C. (Eds.). The SAGE handbook of management learning, education and development. SAGE Publications, Inc.

Lamborn, S., Newmann, F., \& Wehlage, G. (1992). The significance and sources of student engagement. Student Engagement and Achievement in American Secondary Schools, 11-39.

Landreneau, K. J. (2009). Sampling Strategies [PDF]. Retrieved from http://www.natcol.org/research/files/samplingstrategies.pdf

Larsen J., Minner, D., Rowe, E., Edwards, T., Asbell-Clarke, J., Bardar, E., \& MacEachern, B. (2014, June). STEMLandia-The Nature's Apprentice Geocaching Adventure Opening the Door for STEM Learning Through Outside Games. In EdMedia: World Conference on Educational Media and Technology. Retrieved from https://www.learntechlib.org/primary/p/147785/

Lincoln, Y., \& Guba, E. (1985). Naturalistic inquiry. Thousand Oaks, CA: Sage.

Mackenzie, S. H., Son, J. S., \& Eitel, K. (2018). Using outdoor adventure to enhance intrinsic motivation and engagement in science and physical activity: an exploratory study. Journal of Outdoor Recreation and Tourism, 21, 76-86.

Maslow, A., \& Lewis, K. J. (1987). Maslow's hierarchy of needs. Salenger Incorporated, 14, 987. 
Maxcy, S. J. (2003). Pragmatic threads in mixed methods research in the social sciences: The search for multiple modes of inquiry and the end of the philosophy of formalism. Handbook of mixed methods in social and behavioral research, 51-89.

Mayer, R. E. (2004). Should there be a three-strikes rule against pure discovery learning?. American Psychologist, 59(1), 14.

McInerney, D. M., \& McInerney, V. (2000). A longitudinal qualitative study of school motivation and achievement [PDF]. Retrieved from https://files.eric.ed.gov/fulltext/ED441815.pdf

Means, T. B., Jonassen, D. H., \& Dwyer, F. M. (1997). Enhancing relevance: Embedded ARCS strategies vs. purpose. Educational Technology Research and Development, 45(1), 5-17.

Mellor, D., \& Moore, K. A. (2013). The use of Likert scales with children. Journal of Pediatric Psychology, 39(3), 369-379.

Merriam, S. B. (1998). Qualitative Research and Case Study Applications in Education. Revised and Expanded from" Case Study Research in Education.". San Francisco, CA: Jossey-Bass Publishers.

Miettinen, R. (2000). The concept of experiential learning and John Dewey's theory of reflective thought and action. International Journal of Lifelong Education, 19(1), 54-72.

Miles, J. C., \& Priest, S. (1990). Adventure education. State College, PA: Venture Publishing, Inc.

Miles, M. B., \& Huberman, A. M. (1994). Qualitative data analysis: An expanded sourcebook. Sage.

Miller, B. G., Doering, A., Roehrig, G., \& Shimek, R. (2012). Reports from the Field: Fostering Indigenous STEM Education: Mobilizing the Adventure Learning Framework through Snow Snakes. Journal of American Indian Education, 66-84.

Miller, R. A. (1976). Leader/agent's guide: Leadership life skills. Stillwater: Oklahoma State University.

Miller, R. B., \& Brickman, S. J. (2004). A model of future-oriented motivation and selfregulation. Educational Psychology Review, 16(1), 9-33.

Miner, J. L., \& Boldt, J. R. (2002). Outward bound USA: Crew not passengers. Seattle, WA: Mountaineers Books.

Montessori, M. (2013). The Montessori method. Transaction publishers.

Murphy, C. (2003). Literature review in primary science and ICT.

National Research Council. (2007). Committee on Prospering in the Global Economy of the 21st Century: An agenda for American science and technology, committee on science, engineering and public policy. 
Neill, A. S. (1960). Summerhill: A radical approach to child rearing. Oxford, England: Hart.

Newton, L. D., \& Newton, D. P. (1991). How relevant are primary science schemes of work? Innovations in Education \& Training International, 28, 43-54.

Noonan, R. (2017). STEM jobs: 2017 update [PDF]. Retrieved from https://www.commerce.gov/sites/commerce.gov/files/migrated/reports/stem-jobs-2017update.pdf

Osborne, J., Simon, S., \& Collins, S. (2003). Attitudes towards science: A review of the literature and its implications. International Journal of Science Education, 25(9), 1049-1079.

Onwuegbuzie, A. J., \& Collins, K. M. (2007). A typology of mixed methods sampling designs in social science research. The qualitative report, 12(2), 281-316.

Outward Bound. (2019). Outward Bound in the city: Urban expeditions. Retrieved from https://www.outwardbound.org/blog/outward-bound-city-urban-expeditions/

Owen, S., Dickson, D., Stanisstreet, M., \& Boyes, E. (2008). Teaching physics: Students' attitudes towards different learning activities. Research in Science \& Technological Education, 26(2), 113-128.

Payne, G. \& Payne, J. (2004). Key Concepts in Social Research. SAGE.

Pennycook, A. (1989). The concept of method, interested knowledge, and the politics of language teaching. TESOL quarterly, 23(4), 589-618.

Polkinghorne, D. E. (1989). Phenomenological research methods. In Existential-phenomenological perspectives in psychology (pp. 41-60). Springer, Boston, MA.

Polman, J. L., \& Miller, D. (2010). Changing stories: Trajectories of identification among African American youth in a science outreach apprenticeship. American Educational Research Journal, 47(4), 879-918.

Powell, R. B., Vezeau, S. L., Stern, M. J., Moore, D. D., \& Wright, B. A. (2018). Does interpretation influence elaboration and environmental behaviors?. Environmental Education Research, 24(6), $875-888$.

Price, J. H., \& Murnan, J. (2004). Research limitations and the necessity of reporting them. American Journal of Health Education, 35(2), 66.

Priest, S., \& Gass, M. (2017). Effective Leadership in Adventure Programming, 3E. Champaign, IL: Human Kinetics.

Ratcliffe, M. \& Grace, M. (2003). Science education for citizenship: Teaching socio-scientific 
issues. Maidenhead: Open University Press.

Ringholz, R. (2000). On belay: The life of legendary mountaineer Paul Petzoldt. Seattle, WA: Mountaineers Books.

Riedinger, K. A. (2011). Identity development of middle school students as learners of science at an informal science education camp [Unpublished Doctoral dissertation]. University of Maryland.

Riedinger, K. (2015). Identity Development of Youth during Participation at an Informal Science Education Camp. International Journal of Environmental and Science Education, 10(3), 453475 .

Rittmayer, A. D., \& Beier, M. E. (2008). Overview: Self-efficacy in STEM. SWE-AWE CASEE Overviews, 1-12.

Rittmayer, M. A., \& Beier, M. E. (2009). Self-efficacy in STEM. Applying research to practice (ARP) resources, 2-12.

Sadler, P. M., Sonnert, G., Hazari, Z., \& Tai, R. (2012). Stability and volatility of STEM career interest in high school: A gender study. Science education, 96(3), 411-427.

Sahin, A., Ayar, M. C., \& Adiguzel, T. (2014). STEM related after-school program activities and associated outcomes on student learning. Educational Sciences: Theory and Practice, 14(1), 309322.

Saldaña, J. (2016). The coding manual for qualitative researchers. Sage Publishing.

Sanders, M. (2009). Integrative STEM education: primer. The Technology Teacher, 68(4), 20-26.

Schwab, J. J. (1973). The practical 3: Translation into curriculum. The School Review, 81(4), 501-522.

Seaman, J. (2007). Taking things into account: Learning as kinaesthetically-mediated collaboration. Journal of Adventure Education and Outdoor Learning, 7(1), 3-20.

Seaman, J. (2008). Experience, reflect, critique: The end of the "learning cycles" era. Journal of Experiential Education, 31(1), 3-18.

Shenton, A. K. (2004). Strategies for ensuring trustworthiness in qualitative research projects. Education for information, 22(2), 63-75.

Shwartz, Y., Ben-Zvi, R., \& Hofstein, A. (2006). Chemical literacy: What does it mean to scientists and school teachers? Journal of Chemical Education, 83, 1557-1561.

Sjøberg, S., \& Schreiner, C. (2005). How do learners in different cultures relate to science and technology? Results and perspectives from the project ROSE (the Relevance of Science Education). In Asia-Pacific Forum on Science Learning and Teaching, 6(2), 1-17). 
Snow, J., \& Mann, M. (2013). Qualtrics survey software: handbook for research professionals. Qualtrics Labs, Inc.

Son, J. S., Mackenzie, S. H., Eitel, K., \& Luvaas, E. (2017). Engaging youth in physical activity and STEM subjects through outdoor adventure education. Journal of Outdoor and Environmental Education, 20(2), 32-44.

Stonehouse, P., Allison, P., \& Carr, D. (2011). Aristotle, Plato, and Socrates: Ancient Greek perspectives on experiential learning. Sourcebook of Experiential Education: Key Thinkers and Their Contributions, 18-25.

Stuckey, M., Hofstein, A., Mamlok-Naaman, R., \& Eilks, I. (2013). The meaning of 'relevance' in science education and its implications for the science curriculum. Studies in Science Education, 49(1), 1-34.

Stuckey, M., Sperling, J., Mamlok-Naaman, R., Hofstein, A., \& Eilks, I. (2013). The societal component in a model of relevance in science education. In ESERA conference, Nicosia.

Summit Bechtel Reserve. (n.d). The Summit Bechtel Reserve. Retrieved from https://www.summitbsa.org/

Taylor, S., \& Treacy, A. (2013). Just Dedoose it! Making mixed methods data analysis manageable. In annual meeting of the Northern Rocky Mountain Educational Research Association. Jackson Hole, $W Y$.

Terrell, S. R. (2012). Mixed-methods research methodologies. The Qualitative Report, 17(1), 254-280.

Thomas, G. (2009). How to do your research project: A guide for students. Sage.

Thorne, S. (1994). Secondary analysis in qualitative research: Issues and implications. Critical Issues in Qualitative Research Methods, 1, 263-279.

Trochim, W. M. (2006). Social Research Methods. Retrieved from https://www.socialresearchmethods.net/

Turner, S., Ireson, G., \& Twidle, J. (2010). Enthusiasm, relevance and creativity: could these teaching qualities stop us alienating pupils from science?. School Science Review. 91(337), 51-57.

United States Census. (2019). Quick Facts West Virginia. Retrieved from https://www.census.gov/quickfacts/WV

Van Manen, M. (2016). Phenomenology of practice: Meaning-giving methods in phenomenological research and writing. Routledge.

Vaske, J. J. (2008). Survey research and analysis: Applications in parks, recreation and human dimensions. State College, PA: Venture. 
Vaske, J. J., Beaman, J., \& Sponarski, C. C. (2017). Rethinking internal consistency in Cronbach's alpha. Leisure Sciences, 39(2), 163-173.

Veevers, N., \& Allison, P. (2011). Kurt Hahn. Springer Science \& Business Media.

Veletsianos, G., \& Kleanthous, I. (2009). A review of adventure learning. The International Review of Research in Open and Distributed Learning, 10(6), 84-105.

Vincent-Ruz, P., \& Schunn, C. D. (2018). The nature of science identity and its role as the driver of student choices. International Journal of STEM Education, 5(1), 48.

Von Glaserfeld, E. (2015). Introduction: Aspects of constructivism. In Fosnot, C. (Ed.), Constructivism: Theory, perspectives, and practice ( $2^{\text {nd }}$ ed.). New York, NY: Teachers College Press.

Walker, A., Leary, H., Hmelo-Silver, C., \& Ertmer, P. A. (2015). Essential readings in problem-based learning: exploring and extending the legacy of Howard S. Barrows. West Lafayette, IN: Purdue University Press.

Walsh, V., \& Golins, G. (1976). The exploration of the Outward Bound process.

Wang, X. (2013). Why students choose STEM majors: Motivation, high school learning, and postsecondary context of support. American Educational Research Journal, 50(5), 1081-1121.

Westbroek, H. B., Klaassen, K., Bulte, A. M. W., \& Pilot, A. (2010). Providing students with a sense of purposely adapting professional practice. International Journal of Science Education, 32, 603-627.

Wortham, S. (2004). The interdependence of social identification and learning. American Educational Research Journal, 41(3), 715-750.

Wurdinger, S. (1994). Examining the learning process used in adventure education. Journal of Adventure Education and Outdoor Leadership, 11(3), 25-27.

Young, M., \& Glanfield, K. (1998). Science in post-compulsory education: Towards a framework for a curriculum of the future. Studies in Science Education, 32, 1-20.

Zhang, L, \& Barnett, M. (2015). How high school students envision their STEM career pathways. Cultural Studies of Science Education, 10(3), 637-656

Zwick, T. T., \& Miller, K. W. (1996). A comparison of integrated outdoor education activities and traditional science learning with American Indian students. Journal of American Indian Education, 1-9. 


\section{Appendix A: Student Assent Form}

Principal Investigator

Department

Protocol Number

Study Title

Co-Investigator(s)

Sponsor (if any)
Dr. Dave Smaldone

Recreation, Parks \& Tourism

1906593622

WV Science Adventure School

Alice Morgan

N/A

\section{Contact Persons}

If you have any questions, concerns, or complaints about this research, you can contact Dr. Dave Smaldone at (304) 293-7404.

For information regarding your rights as a person in research or to talk about the research, call the Office of Research Integrity \& Compliance at (304) 293-7073.

\section{Introduction}

You, , have been asked to participate in this research study, which has been explained to you by Alice Morgan.

\section{Purpose of the Study}

The purpose of this project is to use outdoor education and adventure based activities to increase learning and growth for students in West Virginia related to science education and interpersonal development.

\section{Description of Procedures}

You will be attending the outdoor adventure experiences at the Summit Boy Scout Camp with your teacher and class. You will be asked to answer some questions before and again after participating. It will take about 20 minutes for you to answer the questions each time. You may see the questions before signing this page. You do not have to answer all of the questions.

\section{Discomforts}

None

\section{Benefits}

This study may not help you, but what we learn from the study may help make this outdoor adventure experience even better for other students.

\section{Confidentiality}

We promise that anything we learn about you in this study will be kept as secret as possible.

\section{Voluntary Participation}

You do not have to do this. No one will be mad at you if you refuse to do this or if you decide to stop. You have been allowed to ask questions about the research, and all of your questions were answered.

I willingly agree to be in this research. 


\section{Signatures}

Signature of Subject

Printed Name

The minor has had the opportunity to have questions addressed. The minor willingly agrees to be in the study.

Signature of Investigator or Co-Investigator

Printed Name

Date

Time 


\section{Appendix B: Parent Consent Form}

\begin{tabular}{ll}
\multicolumn{2}{c}{ Only Minimal Risk Parental or Guardian Consent (Without HIPAA) } \\
Principal Investigator & Dr. Dave Smaldone \\
Department & Recreation, Parks \& Tourism \\
Protocol Number & 1906593622 \\
Study Title & WV Science Adventure School \\
Co-Investigator(s) & Alice Morgan \\
Sponsor (if any) & N/A
\end{tabular}

\section{Contact Persons}

If you have any questions, concerns, or complaints about this research, you can contact Dr. Dave Smaldone at 304-293-7404.

For information regarding your child's rights as a research subject, to discuss problems, concerns, or suggestions related to the research, to obtain information or offer input about the research, contact the Office of Research Integrity and Compliance (304) 293-7073.

In addition if you would like to discuss problems, concerns, have suggestions related to research, or would like to offer input about the research, contact the Office of Research Integrity and Compliance at 304-293-7073.

\section{Introduction}

Your child, , has been asked to participate in this research study, which has been explained to you and your child by Alice Morgan. This study is being conducted by Dr. Dave Smaldone and Alice Morgan (M.S.) in the Recreation, Parks \& Tourism Program at West Virginia University.

This research is being conducted to better understand the benefits and learning of students who participate in the outdoor science and adventure activities.

\section{Purpose(s) of the Study}

The purpose of this project is to use outdoor science and adventure based activities to increase learning and growth for students in West Virginia related to science education and interpersonal development.

\section{Description of Procedures}

Your child will be asked to fill out a short questionnaire before participating, and again after participating. The questions are about science knowledge and interest and interpersonal development. The questionnaires ask the same questions to see if the outdoor and adventure activities impacted their knowledge and interests. It will take approximately 10 minutes to complete each questionnaire. Your child does not have to answer all the questions. Upon request, you will have the opportunity to see the questionnaire before signing this consent form. Your child may also be asked to interview with the researcher about their experiences at the camp, specifically their thoughts on science and their interpersonal development. Your child does not have to answer all the researcher's questions and can end the interview whenever they like. 
The study will be performed at your child's school. Approximately 504 students (total over 6 weeks) are expected to participate in this study.

\section{Risks and Discomforts}

There are no known or expected risks to your child from participating in this study, except potentially mild frustration associated with answering the questions.

\section{Alternatives}

Your child does not have to participate in this study.

\section{Benefits}

Your child may not receive any direct benefit from this study (filling out the questionnaires and interviews). The knowledge gained from this study will be used to improve the experience for other students in the future.

\section{Financial Considerations}

No payments will be made for participating in the study.

\section{Confidentiality}

Any information about your child that is obtained as a result of their participation in this research will be kept as confidential as legally possible.

In any publications that result from this research, neither your child's name nor any information from which your child might be identified will be published without your consent.

\section{Voluntary Participation}

Refusal to participate or withdrawal will not affect your child in any way, and will involve no penalty to you.

\section{Signatures}

Upon signing this consent, you may receive a copy upon request.

I willing consent to allow my child to participate in this research.

Signature of Parent or Guardian

\begin{tabular}{lll}
\hline Printed Name & Date & Time
\end{tabular}

Signature of Investigator or Co-Investigator 


\section{Appendix C: Teacher Assent Form}

$\begin{array}{ll}\text { Principal Investigator } & \text { Dr. Dave Smaldone } \\ \text { Department } & \text { Recreation, Parks \& Tourism } \\ \text { Protocol Number } & 1906593622 \\ \text { Study Title } & \text { WV Science Adventure School } \\ \text { Co-Investigator(s) } & \text { Alice Morgan } \\ \text { Sponsor (if any) } & \text { N/A }\end{array}$

\section{Contact Persons}

If you have any questions, concerns, or complaints about this research, you can contact Dr. Dave Smaldone at (304) 293-7404.

For information regarding your rights as a person in research or to talk about the research, call the Office of Research Integrity \& Compliance at (304) 293-7073. In addition, if you would like to discuss problems, concerns, have suggestions related to research, or would like to offer input about the research, contact the Office of Research Integrity and Compliance at 304-293-7073.

\section{Introduction}

You, , have been asked to participate in this research study, which has been explained to you by Alice Morgan. This study is being conducted by Dr. Dave Smaldone and Alice Morgan (M.S.) in the Recreation, Parks \& Tourism Program at West Virginia University.

This research is being conducted to better understand the benefits and learning of students who participate in the outdoor science and adventure activities.

\section{Purpose of the Study}

The purpose of this project is to use outdoor education and adventure based activities to increase learning and growth for students in West Virginia related to science education and interpersonal development.

\section{Description of Procedures}

You will be attending the outdoor adventure experiences at the Summit Boy Scout Camp with your class. You will be asked to answer some interviews questions about this experience. It will take about 20-30 minutes for you to answer the questions. Upon request, you may see the questions before signing this page. You do not have to answer all of the questions.

\section{Discomforts}

None

\section{Benefits}

You and your students may not receive any direct benefit from this study (interviews). The knowledge gained from this study will be used to improve the experience for other students in the future. 


\section{Confidentiality}

Any information about you that is obtained as a result of participation in this research will be kept as confidential as legally possible.

In any publications that result from this research, neither your name nor any information from which you might be identified will be published without your consent.

\section{Voluntary Participation}

Refusal to participate or withdrawal will not affect you in any way. You have been allowed to ask questions about the research, and all of your questions were answered.

I willingly agree to be in this research.

\section{Signatures}

Signature of Subject

Printed Name

Date

Time

The minor has had the opportunity to have questions addressed. The minor willingly agrees to be in the study.

Signature of Investigator or Co-Investigator

Printed Name

Date

Time 


\section{The WV Science Adventure Camper Survey}

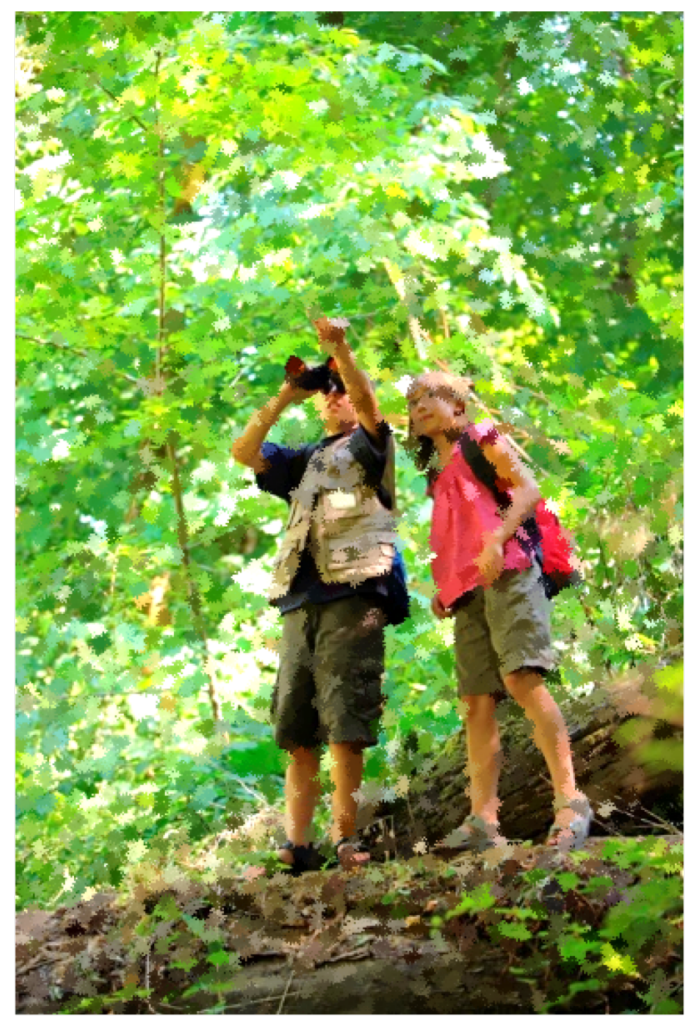

Survey conducted by:

Dr. Dave Smaldone

Recreation, Parks \& Tourism Program

Division of Forestry \& Natural Resources

West Virginia University

David.smaldone@mail.wvu.edu

\section{Survey Directions:}

Thank you for taking the time to complete this survey. The purpose of this survey is to understand your thoughts about participating in the WV Science Adventure Camp. This survey should only take about 15 minutes. Please read the instructions for each question and answer to the best of your ability. You can skip any question you want or stop at any time. 


\section{First, a few questions about you}

1. What school do you go to?

2. What is your teacher's name?

3. Are you a.... (Check one)

$\square$ Boy $\quad \square$ Girl $\quad \square$ other___ $\quad \square$ Prefer not to answer

4. What race are you? (Check one or more)

$\square$ White/Caucasian

$\square$ American/Native Indian

$\square$ Black/African American

$\square$ Pacific Islander

$\square$ Hispanic or Latino

$\square$ Other

Asian

Do not want to provide

5. What is your birthday? (Write in the complete date with month, day, and year)

6. What is the highest level of school your parents or guardians have achieved?

$\square$ Less than high school degree

$\square$ High school graduate (high school diploma or equivalent including GED)

$\square$ Some college but no degree

$\square$ Associate degree in college (2-year)

$\square$ Bachelor's degree in college (4-year)

$\square$ Master's degree

$\square$ Doctoral degree

$\square$ Prefer not to provide

7. Which of the following statements best describes your family's financial situation?

$\square$ We have a hard time buying the things we need

$\square$ We have just enough money for the things we need

$\square$ We have no problem buying the things we need, and we can also sometimes buy special things.

$\square$ We have enough money to buy almost anything we want.

$\square$ Prefer not to provide. 


\section{Next we'd like to know what you think about Science}

Please make an $X$ in the box that most closely shows what you believe about the statement on the left.

\begin{tabular}{|l|l|l|l|l|l|}
\hline & $\begin{array}{c}\text { Strongly } \\
\text { Disagree }\end{array}$ & $\begin{array}{c}\text { Somewhat } \\
\text { Disagree }\end{array}$ & $\begin{array}{c}\text { Neither agree } \\
\text { nor disagree }\end{array}$ & $\begin{array}{c}\text { Somewhat } \\
\text { Agree }\end{array}$ & $\begin{array}{c}\text { Strongly } \\
\text { Agree }\end{array}$ \\
\hline $\begin{array}{l}\text { a. I think I am very good at doing } \\
\text { experiments. }\end{array}$ & & & & & \\
\hline b. Science lessons are fun. & & & & \\
\hline $\begin{array}{l}\text { c. When I leave school, I would like } \\
\text { to work with people who make } \\
\text { discoveries in science. }\end{array}$ & & & & & \\
\hline $\begin{array}{l}\text { d. I am a science person. } \\
\text { e. Knowing science is important. }\end{array}$ & & & & & \\
\hline $\begin{array}{l}\text { f. I can do the science activities I get } \\
\text { in class. }\end{array}$ & & & & & \\
\hline $\begin{array}{l}\text { g. My family thinks of me as a } \\
\text { "science person." }\end{array}$ & & & & & \\
\hline $\begin{array}{l}\text { h. A job as a scientist would be } \\
\text { interesting. }\end{array}$ & & & & & \\
\hline
\end{tabular}

\section{Next we'd like to know more about what you think about Science}

Please make an X in the box that most closely shows what you believe about the statement on the left.

\begin{tabular}{|l|l|l|l|l|l|}
\hline & $\begin{array}{c}\text { Strongly } \\
\text { Disagree }\end{array}$ & $\begin{array}{c}\text { Somewhat } \\
\text { Disagree }\end{array}$ & $\begin{array}{c}\text { Neither agree } \\
\text { nor disagree }\end{array}$ & $\begin{array}{c}\text { Somewhat } \\
\text { Agree }\end{array}$ & $\begin{array}{c}\text { Strongly } \\
\text { Agree }\end{array}$ \\
\hline $\begin{array}{l}\text { i. I think I am very good at coming up } \\
\text { with questions about science. }\end{array}$ & & & & & \\
\hline $\begin{array}{l}\text { j. I would like to be a scientist when I } \\
\text { leave school. }\end{array}$ & & & & & \\
\hline $\begin{array}{l}\text { k. My teachers/instructors thinks of } \\
\text { me as a "science person." }\end{array}$ & & & & & \\
\hline $\begin{array}{l}\text { l. Knowing science helps me } \\
\text { understand how the world works. }\end{array}$ & & & & & \\
\hline $\begin{array}{l}\text { m. I would like to learn more about } \\
\text { science. }\end{array}$ & & & & & \\
\hline $\begin{array}{l}\text { n. Science is one of the most } \\
\text { interesting school subjects. }\end{array}$ & & & & & \\
\hline $\begin{array}{l}\text { o. Thinking like a scientist will help } \\
\text { me do well. }\end{array}$ & & & & & \\
\hline
\end{tabular}




\section{Next we'd like to know what you know about Science Jobs}

Think of some jobs you know of that require science to do them. Please name three jobs that use science.

1.

2.

3.

\section{This next section has questions about you}

Please make an $X$ in the box that most closely shows what you believe about the statement on the left.

\begin{tabular}{|l|l|l|l|l|l|}
\hline & $\begin{array}{c}\text { Strongly } \\
\text { Disagree }\end{array}$ & $\begin{array}{c}\text { Somewhat } \\
\text { Disagree }\end{array}$ & $\begin{array}{c}\text { Neither agree } \\
\text { nor disagree }\end{array}$ & $\begin{array}{c}\text { Somewhat } \\
\text { Agree }\end{array}$ & $\begin{array}{c}\text { Strongly } \\
\text { Agree }\end{array}$ \\
\hline $\begin{array}{l}\text { a. I have overcome setbacks to } \\
\text { conquer an important challenge. }\end{array}$ & & & & & \\
\hline b. I am a hard worker. & & & & \\
\hline $\begin{array}{l}\text { c. I am viewed as the leader when I } \\
\text { am playing with others. }\end{array}$ & & & & & \\
\hline $\begin{array}{l}\text { d. I feel like a part of my school. } \\
\text { e. Humans are part of nature, not } \\
\text { separate from it. }\end{array}$ & & & & & \\
\hline $\begin{array}{l}\text { f. Others want me in charge when a } \\
\text { group project needs to be done. }\end{array}$ & & & & & \\
\hline
\end{tabular}




\section{This next section has more questions about you}

Please make an $X$ in the box that most closely shows what you believe about the statement on the left.

\begin{tabular}{|l|l|l|l|l|l|}
\hline & $\begin{array}{c}\text { Strongly } \\
\text { Disagree }\end{array}$ & $\begin{array}{c}\text { Somewhat } \\
\text { Disagree }\end{array}$ & $\begin{array}{c}\text { Neither agree } \\
\text { nor disagree }\end{array}$ & $\begin{array}{c}\text { Somewhat } \\
\text { Agree }\end{array}$ & $\begin{array}{c}\text { Strongly } \\
\text { Agree }\end{array}$ \\
\hline g. Setbacks don't discourage me. & & & & & \\
\hline $\begin{array}{l}\text { h. I am good at leading a group to } \\
\text { get the job done. }\end{array}$ & & & & & \\
\hline $\begin{array}{l}\text { i. Other students here like me the } \\
\text { way I am. }\end{array}$ & & & & & \\
\hline $\begin{array}{l}\text { j. I feel it is important to take good } \\
\text { care of the environment. }\end{array}$ & & & & & \\
\hline $\begin{array}{l}\text { k. I have achieved a goal that took } \\
\text { time to reach. }\end{array}$ & & & & & \\
\hline $\begin{array}{l}\text { l. There's at least one teacher or } \\
\text { other adult in this school I can talk } \\
\text { to if I have a problem. }\end{array}$ & & & & & \\
\hline $\begin{array}{l}\text { m. I have the power to protect the } \\
\text { environment. }\end{array}$ & & & & & \\
\hline
\end{tabular}

\section{This next section has questions about working with others}

Please make an X in the box that most closely shows what you believe about the statement on the left.

\begin{tabular}{|l|l|l|l|l|l|}
\hline & Not at all & Slightly & Somewhat & Fairly well & Very well \\
\hline $\begin{array}{l}\text { a. How well can you } \\
\text { become friends with } \\
\text { other children? }\end{array}$ & & & & & \\
\hline $\begin{array}{l}\text { b. How well can you tell } \\
\text { other children that they } \\
\text { are doing something that } \\
\text { you don't like? }\end{array}$ & & & & & \\
\hline $\begin{array}{l}\text { c. How well can you } \\
\text { express your opinions } \\
\text { when other classmates } \\
\text { disagree with you? }\end{array}$ & & & & & \\
\hline $\begin{array}{l}\text { d. How well do you } \\
\text { succeed in staying friends } \\
\text { with other children? }\end{array}$ & & & & & \\
\hline
\end{tabular}

This next section has more questions about working with others 
Please make an X in the box that most closely shows what you believe about the statement on the left.

\begin{tabular}{|l|l|l|l|l|l|}
\hline & $\begin{array}{c}\text { Strongly } \\
\text { Disagree }\end{array}$ & $\begin{array}{c}\text { Somewhat } \\
\text { Disagree }\end{array}$ & $\begin{array}{c}\text { Neither agree } \\
\text { nor disagree }\end{array}$ & $\begin{array}{c}\text { Somewhat } \\
\text { Agree }\end{array}$ & $\begin{array}{c}\text { Strongly } \\
\text { Agree }\end{array}$ \\
\hline $\begin{array}{l}\text { e. I respect the opinions } \\
\text { of my teammates, even } \\
\text { when I disagree. }\end{array}$ & & & & \\
\hline $\begin{array}{l}\text { f. It is important to me to } \\
\text { consider the needs of } \\
\text { other people. }\end{array}$ & & & & & \\
\hline $\begin{array}{l}\text { g. I listen carefully to } \\
\text { other group members } \\
\text { when our team is making } \\
\text { a decision. }\end{array}$ & & & & & \\
\hline $\begin{array}{l}\text { h. It is important to me to } \\
\text { think about how my } \\
\text { actions affect people in } \\
\text { the future. }\end{array}$ & & & & & \\
\hline $\begin{array}{l}\text { i. I am very cooperative } \\
\text { when I work in groups. }\end{array}$ & & & & & \\
\hline $\begin{array}{l}\text { j. It is important to me to } \\
\text { make sure that all people } \\
\text { are treated fairly. }\end{array}$ & & & & & \\
\hline
\end{tabular}

\section{Thank you for answering these questions!}




\section{Appendix E: Student Interview Protocol}

1. What is your favorite subject in school? Why?

2. What is your least favorite subject in school? Why?

3. Have you ever studied science before? How would you define science?

4. What was science like in elementary school?

Prompt: What did you enjoy and what did you dislike about these classes?

Prompt: Do you think it was harder or easier to learn science at SAS than your school?

5. What do you think the similarities and differences are between science class at your school and the things you did at Science Adventure School?

6. Do you think differently about science now that you did before SAS

7. What do you think most people would picture when they think of a scientist or engineer? Prompt: Can you describe what that looks like?

8. How do you picture a scientist or engineer?

Prompt: Can you describe what that looks like?

9. Do your parents or caregivers work?

YES: What kinds of jobs do they have?

NO: Move to 9

10. What do you want to do when you grow up? Why?

11. Do you think science is important to learn about? Why?

12. What do you think you learned by participating in Science Adventure School? Prompt: Skills? Knowledge about self? Knowledge about subjects?

13. Can you tell me about what part of the Science Adventure School made the biggest impact on you? 


\section{Appendix F: Teacher Interview Protocol}

1. What subject do you teach?

2. How long have you been teaching? What grades have you taught?

3. Why did you decide to bring your class to the Science Adventure School?

4. What kind of teaching techniques do you use in your classroom?

5. Have you noticed any changes in your students since you have returned from the Science Adventure School?

Prompt: Can you give examples?

6. Have you noticed any changes in your students' views of science?

Prompt: Can you give examples?

7. Have you noticed any changes in your students' attitudes about themselves?

Prompt: Social skills? Persistence? Leadership? Teamwork?

Prompt: Can you give examples?

8. Have you noticed any changes in your classroom community?

Prompt: Can you give examples?

9. What activities do you think were the most impactful on students? Why?

10. Which activities were your favorites? Why? 
Appendix G: Additional Student Themes and Codes

\begin{tabular}{|c|c|c|c|c|c|}
\hline Theme & Code Name & Child Code & Code Definition & $\begin{array}{l}\text { Percent of } \\
\text { students } \\
\text { mentioning } \\
\text { code idea }\end{array}$ & $\begin{array}{c}\text { Representative } \\
\text { Quote }\end{array}$ \\
\hline $\begin{array}{l}\text { School } \\
\text { Experience } \\
\text { Compared to } \\
\text { SAS }\end{array}$ & $\begin{array}{l}\text { Limited Class } \\
\text { Time }\end{array}$ & & $\begin{array}{l}\text { Person refers to limited } \\
\text { time in classroom }\end{array}$ & $7 \%$ & $\begin{array}{l}\text { Since we don't have } \\
\text { very much time, } \\
\text { [teachers] probably } \\
\text { don't have time to } \\
\text { explain it. }\end{array}$ \\
\hline \multirow[t]{4}{*}{$\begin{array}{l}\text { Changing } \\
\text { Science } \\
\text { Attitudes }\end{array}$} & $\begin{array}{l}\text { Change in } \\
\text { STEM Opinion }\end{array}$ & No Change & $\begin{array}{l}\text { Student's opinion does } \\
\text { not change }\end{array}$ & $21 \%$ & $\begin{array}{l}\text { Um... I feel like I } \\
\text { know a little bit more } \\
\text { about it now, but } \\
\text { otherwise I feel like } \\
\text { it's kinda the same. }\end{array}$ \\
\hline & STEM Identity & $\begin{array}{l}\text { Self- } \\
\text { Identity }\end{array}$ & $\begin{array}{l}\text { Student self identifies as } \\
\text { a scientist or expresses } \\
\text { that they could be a } \\
\text { scientist }\end{array}$ & $22 \%$ & We're all scientists. \\
\hline & STEM Interest & & $\begin{array}{l}\text { Person makes reference } \\
\text { to students being } \\
\text { interested in STEM }\end{array}$ & $43 \%$ & $\begin{array}{l}\text { The science school } \\
\text { made [science] more } \\
\text { fun to learn about. }\end{array}$ \\
\hline & Relevance & $\begin{array}{l}\text { Vocational } \\
\text { Relevancy }\end{array}$ & $\begin{array}{l}\text { Person makes reference } \\
\text { to STEM knowledge } \\
\text { being relevant to the } \\
\text { classroom }\end{array}$ & $14 \%$ & $\begin{array}{l}\text { [Science class is] kind } \\
\text { of easier actually } \\
\text { because some of the } \\
\text { stuff we learned at } \\
\text { Science Adventure } \\
\text { School. }\end{array}$ \\
\hline \multirow[t]{3}{*}{$\begin{array}{l}\text { Positive } \\
\text { Youth } \\
\text { Development } \\
\text { Outcomes }\end{array}$} & $\begin{array}{l}\text { Social Self- } \\
\text { Efficacy }\end{array}$ & & $\begin{array}{l}\text { Person references better } \\
\text { social skills including } \\
\text { improved friend-making } \\
\text { and friendship skills, } \\
\text { comfort expressing } \\
\text { opinions, and ability to } \\
\text { politely disagree with } \\
\text { others }\end{array}$ & $14 \%$ & $\begin{array}{l}\text { You get to know } \\
\text { more friends and like } \\
\text { make new friends and } \\
\text { like learn about other } \\
\text { people that you never } \\
\text { knew before. }\end{array}$ \\
\hline & Persistence & & $\begin{array}{l}\text { Person references student } \\
\text { having more persistent } \\
\text { attitudes and specific } \\
\text { instances of persistent } \\
\text { behavior including } \\
\text { overcoming setbacks and } \\
\text { working to achieve } \\
\text { challenges }\end{array}$ & $21 \%$ & $\begin{array}{l}\text { Going to Science } \\
\text { Adventure Camp } \\
\text { totally showed me } \\
\text { that I'm capable of } \\
\text { doing a lot more } \\
\text { things that I thought I } \\
\text { was. }\end{array}$ \\
\hline & Teamwork & & $\begin{array}{l}\text { Person references } \\
\text { students working together } \\
\text { as teams including }\end{array}$ & $14 \%$ & $\begin{array}{l}\text { We definitely learned } \\
\text { how to work together. } \\
\text { Because on the very }\end{array}$ \\
\hline
\end{tabular}




\begin{tabular}{|c|c|c|c|c|}
\hline & & $\begin{array}{l}\text { cooperation, listening and } \\
\text { respecting opinions }\end{array}$ & & $\begin{array}{l}\text { first day, it was all } \\
\text { teamwork building. }\end{array}$ \\
\hline & $\begin{array}{l}\text { Sense of } \\
\text { Belong to } \\
\text { School } \\
\text { Membership }\end{array}$ & $\begin{array}{l}\text { Person references better } \\
\text { school community } \\
\text { including peer to peer } \\
\text { relations and teacher to } \\
\text { student relations }\end{array}$ & $29 \%$ & $\begin{array}{l}\text { Everyone was kind. } \\
\text { Especially our } \\
\text { teachers. }\end{array}$ \\
\hline & $\begin{array}{l}\text { Environmental } \\
\text { Attitudes }\end{array}$ & $\begin{array}{l}\text { Person makes reference } \\
\text { to more positive student } \\
\text { attitudes toward the } \\
\text { environment }\end{array}$ & $29 \%$ & $\begin{array}{l}\text { Cus now I think more } \\
\text { about the } \\
\text { environment and I } \\
\text { don't want to trash it, } \\
\text { and I tell other people } \\
\text { not to trash it, } \\
\text { because it's so } \\
\text { important. }\end{array}$ \\
\hline \multirow[t]{2}{*}{$\begin{array}{l}\text { Mechanisms } \\
\text { of Learning }\end{array}$} & Social & $\begin{array}{l}\text { Person references social, } \\
\text { peer-to- peer elements of } \\
\text { learning }\end{array}$ & $29 \%$ & $\begin{array}{l}\text { We could do [science } \\
\text { activities] with our } \\
\text { friends and we could, } \\
\text { like, talk. }\end{array}$ \\
\hline & $\begin{array}{l}\text { Positive Adult } \\
\text { Interaction }\end{array}$ & $\begin{array}{l}\text { Person describes positive } \\
\text { interaction between a } \\
\text { student and an adult } \\
\text { while learning, can be a } \\
\text { teacher or SAS instructor }\end{array}$ & $29 \%$ & $\begin{array}{l}\text { I thought like } \\
\text { everybody down } \\
\text { there would just like } \\
\text { spin away and the } \\
\text { counselors would just } \\
\text { go do that and go do } \\
\text { that, but like they } \\
\text { actually worked with } \\
\text { you and went through } \\
\text { it. }\end{array}$ \\
\hline \multirow[t]{5}{*}{$\begin{array}{l}\text { Science } \\
\text { Definition }\end{array}$} & $\begin{array}{l}\text { Learning } \\
\text { Something new }\end{array}$ & $\begin{array}{l}\text { Student describes science } \\
\text { as including learning } \\
\text { something new }\end{array}$ & $36 \%$ & $\begin{array}{l}\text { I would define } \\
\text { science as the practice } \\
\text { in which you study } \\
\text { something to the } \\
\text { point of learning } \\
\text { something new about } \\
\text { it. }\end{array}$ \\
\hline & $\begin{array}{l}\text { How things } \\
\text { work }\end{array}$ & $\begin{array}{l}\text { Student describes science } \\
\text { as including learning } \\
\text { about how something } \\
\text { works }\end{array}$ & $21 \%$ & $\begin{array}{l}\text { Science is how things } \\
\text { evolve or how they } \\
\text { work and why they } \\
\text { work and how it... } \\
\text { and what makes it } \\
\text { work. }\end{array}$ \\
\hline & $\begin{array}{l}\text { Answer a } \\
\text { question }\end{array}$ & $\begin{array}{l}\text { Student describes science } \\
\text { as including answering a } \\
\text { question }\end{array}$ & $29 \%$ & $\begin{array}{l}\text { You experiment and } \\
\text { you like get an } \\
\text { answer for a question } \\
\text { or something. }\end{array}$ \\
\hline & $\begin{array}{l}\text { Use scientific } \\
\text { tools }\end{array}$ & $\begin{array}{l}\text { Student describes science } \\
\text { as including using } \\
\text { scientific tools }\end{array}$ & $29 \%$ & $\begin{array}{l}\text { You can look through } \\
\text { microscopes. }\end{array}$ \\
\hline & No definition & $\begin{array}{l}\text { Student cannot give a } \\
\text { definition of science }\end{array}$ & $7 \%$ & $\begin{array}{l}\text { It's....[whispers] I } \\
\text { don't know. }\end{array}$ \\
\hline
\end{tabular}




\section{Appendix H: Additional Teacher Themes and Codes}

\begin{tabular}{|c|c|c|c|c|c|}
\hline Theme & Code Name & Child Code & Code Definition & $\begin{array}{l}\text { Percent of } \\
\text { teachers } \\
\text { mentioning } \\
\text { code idea }\end{array}$ & $\begin{array}{c}\text { Representative } \\
\text { Quote }\end{array}$ \\
\hline $\begin{array}{l}\text { School } \\
\text { Environment }\end{array}$ & $\begin{array}{l}\text { Limited Class } \\
\text { Time }\end{array}$ & & $\begin{array}{l}\text { Person refers to } \\
\text { limited time in } \\
\text { classroom }\end{array}$ & $38 \%$ & $\begin{array}{l}\text { And our class } \\
\text { periods are only } \\
45 \text { minutes long, } \\
\text { so [math class is] } \\
\text { kind of a rushed } \\
\text { scenario. }\end{array}$ \\
\hline \multirow[t]{5}{*}{$\begin{array}{l}\text { Changing } \\
\text { Science } \\
\text { Attitudes }\end{array}$} & STEM knowledge & & $\begin{array}{l}\text { Person indicates that } \\
\text { students have learned } \\
\text { more about an aspect } \\
\text { of STEM or has } \\
\text { learned more STEM } \\
\text { content knowledge }\end{array}$ & $25 \%$ & $\begin{array}{l}\text { They got to do the } \\
\text { science lesson and } \\
\text { then do the actual } \\
\text { activity and it } \\
\text { helped them to } \\
\text { understand the } \\
\text { science behind it }\end{array}$ \\
\hline & $\begin{array}{l}\text { Change in STEM } \\
\text { opinion }\end{array}$ & $\begin{array}{l}\text { Science is } \\
\text { "fun" }\end{array}$ & $\begin{array}{l}\text { Person expresses that } \\
\text { students see science } \\
\text { is more fun than } \\
\text { previously believed }\end{array}$ & $13 \%$ & $\begin{array}{l}\text { They learned to } \\
\text { just adapt, and } \\
\text { that learning can } \\
\text { be fun. It doesn't } \\
\text { have to be boring. }\end{array}$ \\
\hline & STEM Identity & & $\begin{array}{l}\text { Person references a } \\
\text { student's view of } \\
\text { themselves as a } \\
\text { scientist, including } \\
\text { their perceptions or } \\
\text { mentions of another } \\
\text { person (i.e. Parent or } \\
\text { teacher) viewing } \\
\text { them as a scientist }\end{array}$ & $13 \%$ & $\begin{array}{l}\text { And they have } \\
\text { found out that } \\
\text { they are just as } \\
\text { smart if not } \\
\text { smarter than the } \\
\text { boys and that they } \\
\text { can do the math } \\
\text { and the science } \\
\text { just as good. That } \\
\text { they are not } \\
\text { grossed out and } \\
\text { scared to do } \\
\text { experiments or to } \\
\text { wait around and } \\
\text { let the boys do all } \\
\text { the hands on. }\end{array}$ \\
\hline & STEM Value & $\begin{array}{l}\text { STEM Career } \\
\text { Value }\end{array}$ & $\begin{array}{l}\text { Person believes } \\
\text { student sees STEM as } \\
\text { important to people's } \\
\text { careers (though not } \\
\text { necessarily their own) }\end{array}$ & $13 \%$ & $\begin{array}{l}\text { [Students } \\
\text { realized] if [they] } \\
\text { want to do stuff } \\
\text { like this, then } \\
\text { [they] actually } \\
\text { have to know } \\
\text { some physics, or } \\
\text { [they're] actually } \\
\text { going to have to } \\
\text { know some } \\
\text { biology, or } \\
\text { whatever. }\end{array}$ \\
\hline & $\begin{array}{l}\text { Vocational } \\
\text { Relevance }\end{array}$ & & $\begin{array}{l}\text { Person makes } \\
\text { reference to STEM }\end{array}$ & $38 \%$ & $\begin{array}{l}\text { I think it really } \\
\text { did just build a lot }\end{array}$ \\
\hline
\end{tabular}




\begin{tabular}{|c|c|c|c|c|}
\hline & & $\begin{array}{l}\text { knowledge being } \\
\text { relevant to the } \\
\text { classroom, including } \\
\text { students being better } \\
\text { students because of } \\
\text { STEM knowledge }\end{array}$ & & $\begin{array}{l}\text { of skills that help } \\
\text { them in the school } \\
\text { day every single } \\
\text { day. }\end{array}$ \\
\hline \multirow[t]{2}{*}{$\begin{array}{l}\text { Positive } \\
\text { Youth } \\
\text { Development } \\
\text { Outcomes }\end{array}$} & Teamwork & $\begin{array}{l}\text { Person references } \\
\text { students working } \\
\text { together as teams } \\
\text { including } \\
\text { cooperation, listening } \\
\text { and respecting } \\
\text { opinions }\end{array}$ & $38 \%$ & $\begin{array}{l}\text { I think they're a } \\
\text { lot better about } \\
\text { working together } \\
\text { and things like } \\
\text { that. }\end{array}$ \\
\hline & Leadership & $\begin{array}{l}\text { Person references } \\
\text { students taking } \\
\text { leadership roles at } \\
\text { SAS or at school }\end{array}$ & $25 \%$ & $\begin{array}{l}\text { They seem to be } \\
\text { more, they take } \\
\text { more of a } \\
\text { leadership role } \\
\text { prior to, from } \\
\text { what [their } \\
\text { teachers have] } \\
\text { seen from them. }\end{array}$ \\
\hline \multirow[t]{2}{*}{$\begin{array}{l}\text { Mechanisms } \\
\text { of Learning }\end{array}$} & Independence & $\begin{array}{l}\text { Person describes } \\
\text { students learning } \\
\text { through being given } \\
\text { the opportunity to } \\
\text { make independent } \\
\text { choices }\end{array}$ & $25 \%$ & $\begin{array}{l}\text { I didn't get to see } \\
\text { too much of the } \\
\text { activities that they } \\
\text { got to do in their } \\
\text { free time... it's } \\
\text { kids being able to } \\
\text { be kids, go out } \\
\text { and try new } \\
\text { things and get } \\
\text { new hobbies and } \\
\text { things like that. } \\
\text { That was a great } \\
\text { experience for } \\
\text { them. }\end{array}$ \\
\hline & $\begin{array}{l}\text { Positive Adult } \\
\text { Models }\end{array}$ & $\begin{array}{l}\text { Person describes } \\
\text { positive interaction } \\
\text { between a student } \\
\text { and an adult while } \\
\text { learning, can be a } \\
\text { teacher or SAS } \\
\text { instructor }\end{array}$ & $13 \%$ & $\begin{array}{l}\text { They're listened } \\
\text { to and I think that } \\
\text { there were a few } \\
\text { students that that } \\
\text { really made a } \\
\text { difference, } \\
\text { because they had } \\
\text { these other people } \\
\text { that they didn't } \\
\text { know that were } \\
\text { really interested } \\
\text { in what they had } \\
\text { to say, and I think } \\
\text { that supported } \\
\text { their beliefs or at } \\
\text { least respect } \\
\text { them. }\end{array}$ \\
\hline
\end{tabular}

